\title{
Considering Tomorrow: Parse's Theory-Guided Research
}

\author{
Sandra Schmidt Bunkers \\ Loyola University Chicago
}

Follow this and additional works at: https://ecommons.luc.edu/luc_diss

Part of the Nursing Commons

\section{Recommended Citation}

Bunkers, Sandra Schmidt, "Considering Tomorrow: Parse's Theory-Guided Research" (1996).

Dissertations. 3582.

https://ecommons.luc.edu/luc_diss/3582

This Dissertation is brought to you for free and open access by the Theses and Dissertations at Loyola eCommons. It has been accepted for inclusion in Dissertations by an authorized administrator of Loyola eCommons. For more information, please contact ecommons@luc.edu. (c) (1) $\Theta \Theta$

This work is licensed under a Creative Commons Attribution-Noncommercial-No Derivative Works 3.0 License. Copyright ( 1996 Sandra Schmidt Bunkers 
LOYOLA UNIVERSITY CHICAGO

CONSIDERING TOMORROW:

PARSE'S THEORY-GUIDED RESEARCH

\author{
A DISSERTATION SUBMITTED TO \\ THE FACULTY OF THE GRADUATE SCHOOL \\ IN CANDIDACY FOR THE DEGREE OF \\ DOCTOR OF PHILOSOPHY \\ SCHOOL OF NURSING
}

BY

SANDRA SCHMIDT BUNKERS

CHICAGO, ILLINOIS

JANUARY 1996 
Copyright by Sandra Schmidt Bunkers, 1996

All rights reserved. 


\section{ACKNOWLEDGMENTS}

It is with gratitude that I acknowledge the people who have contributed to this study. Undertaking this research would not have been possible without the support and encouragement of my dissertation committee: Dr. Rosemarie Rizzo Parse, RN, PhD, FAAN, Chair; Dr. Diane Boyer, RN, PhD, CNM; and Dr. Esther Matassarin-Jacobs, RN, PhD, OCN.

I would like to recognize persons involved with Chicago Health Outreach whose daily nourishing of human life presents a unique model of creative human endeavor. I am mindful of the women, home-less, who with strength and courage shared their lived experiences with me.

I am grateful to my husband Tim, and daughters Diana and Paula, whose love and support were always there for me. A special thanks to $\mathrm{my}$ sister and brother-in-law, Diane and Dick Roster, who have in a special way shared my journey.

With regard, I would like to recognize Dr. Rosemarie Rizzo Parse for creating the possibility of conducting this type of nursing research. Her scholarly guidance has called me to a deeper understanding of human freedom and a desire to always look beyond the now to what is not-yet. 
Chapter

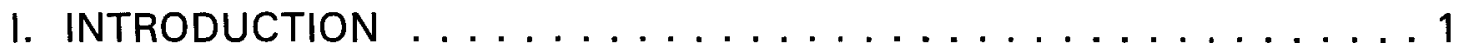

The Phenomenon of Interest: Considering Tomorrow . . . . . . . . 2 Women Who are Home-less as the Population for the Study . . . . 5 Purpose of Study . . . . . . . . . . . . . . 7

Significance of the Study . . . . . . . . . . . . . 7

Research Question .................. . 8

Nursing Perspective: Parse's Human Becoming Theory . . . . . . . 8

Summary . . . . . . . . . . . . . . . . . . . 17

II. REVIEW OF RELEVANT LITERATURE . . . . . . . . . . . 18

Review of Literature on Hope . . . . . . . . . . . . . . . 19

General Theoretical Literature . . . . . . . . . . . . . . . . . . 19

Nursing Theoretical Literature-Totality Paradigm . . . . . . . . . . 39

Nursing Theoretical Literature-Simultaneity Paradigm . . . . . . . 42

General Research Studies . . . . . . . . . . . . . . . . . . 42

Nursing Research Studies-Totality Paradigm . . . . . . . . . . . 44

Nursing Research Studies-Simultaneity Paradigm . . . . . . . . 55

Review of Literature on Imagination . . . . . . . . . . 60

General Theoretical Literature . . . . . . . . . . . . . . . . 61

Nursing Theoretical Literature-Totality Paradigm . . . . . . . . . 78

Nursing Theoretical Literature-Simultaneity Paradigm . . . . . . . 79

General Research Studies . . . . . . . . . . . . . . . . . 80

Nursing Research Studies-Totality Paradigm . . . . . . . . . . 85

Nursing Research Studies-Simultaneity Paradigm . . . . . . 88

Conclusion of Literature on Hope and Imagination . . . . . . . . . 91

Theoretical Synthesis of Concept: Considering Tomorrow . . . 94

Review of Literature on Women Home-less . . . . . . . . . . . . 95

General Theoretical Literature . . . . . . . . . . . . . . . . . . 95

Nursing Theoretical Literature-Totality Paradigm . . . . . . . . . 98

Nursing Theoretical Literature-Simultaneity Paradigm . . . . . . 100 General Research Studies . . . . . . . . . . . . . . . . . . 101

Nursing Research Studies-Totality Paradigm . . . . . . . . . . . 102

Nursing Research Studies-Simultaneity Paradigm . . . . . . . 105 
III. METHODOLOGY . . . . . . . . . . . . . . . . . . 109

Background of the Method . . . . . . . . . . . . . . . . 109

Description of the Method . . . . . . . . . . . . . 112

Processes of the Method . . . . . . . . . . . . . . . . . 114

Participant Selection . . . . . . . . . . . . . . . . 114

Protection of Human Subjects . . . . . . . . . . . 115

Dialogical Engagement . . . . . . . . . . . . 116

Extraction-Synthesis . . . . . . . . . . . . . 116

Heuristic Interpretation . . . . . . . . . . . . 117

Rigor and Credibility . . . . . . . . . . . . . . 118

Summary . . . . . . . . . . . . . . . . . . . . . 122

IV. PRESENTATION OF FINDINGS . . . . . . . . . . . . . 124

Propositional Statements of Participants . . . . . . . . . . 136

The Lived Experience of Considering Tomorrow . . . . . . . . . . . 138

Core Concepts . . . . . . . . . . . . . . . . . . . 138

Structure of the Lived Experience . . . . . . . . . . . . . 138

Heuristic Interpretation . . . . . . . . . . . . . 138

V. DISCUSSION OF FINDINGS . . . . . . . . . . . . . . . . . . 144

Contemplating Desired Endeavors . . . . . . . . . . . . . . . 145

Longing For What is Cherished . . . . . . . . . . . . . . 151

Intimate Alliances With Isolating Distance . . . . . . . . . . . 156

Resilient Endurance Amidst Disturbing Unsureness . . . . . . . . 161

Considering Tomorrow, Health, and Quality of Life . . . . . . 167

VI. CONCLUSIONS, RECOMMENDATIONS, REFLECTIONS . . . . . . 175

Conclusions . . . . . . . . . . . . . . . . . 176

Recommendations . . . . . . . . . . . . . . . . 177

Reflections ...................... 181

Appendix

A. LOYOLA UNIVERSITY INSTITUTIONAL REVIEW BOARD . . . . . . 184

B. CHICAgo HEALth OUTREACH REQUEST . . . . . . . . . . . 186

C. CHICAGO HEALTH OUTREACH LETTER OF APPROVAL . . . . . 188 
D. PARTICIPANT EXPLANATION CONSIDERING TOMORROW .... 190

E. CONSENT FORM CONSIDERING TOMORROW . . . . . . . . . . . . 192 REFERENCES . . . . . . . . . . . . . . . . . . . . . 194

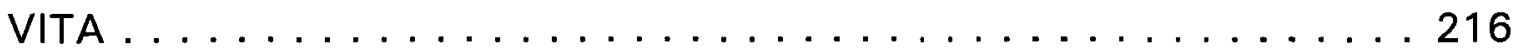




\section{LIST OF TABLES}

Table

1. Concept Evident in Propositions of Participants:

Contemplating Desired Endeavors . . . . . . . . . . . . . 139

2. Concept Evident in Propositions of Participants:

Longing For What is Cherished . . . . . . . . . . . . . . . . 140

3. Concept Evident in Propositions of Participants:

Intimate Alliances With Isolating Distance . . . . . . . . . . . 141

4. Concept Evident in Propositions of Participants:

Resilient Endurance Amidst Disturbing Unsureness . . . . . . . 142

5. Progressive Abstraction of Core Concepts of

Considering Tomorrow with Heuristic Interpretation . . . . . . 143 


\section{CHAPTER I}

\section{INTRODUCTION}

The purpose of this study was to investigate the meaning of considering tomorrow for women who are home-less. Humans live day-today existence in a creative tension between the now and the not-yet, thus, considering tomorrow portends the possibility of life becoming other than what it is. Considering tomorrow exists even in the most difficult of situations. Frankl (1984) found this to be true in experiencing the captivity and hardships of life in a concentration camp. He writes, "It is a peculiarity of humanity that we can only live by looking to the future. And this is our salvation in the most difficult moments of our existence although we sometimes must force our minds to the task" (Frankl, 1984, p. 81).

Noted existential philosopher Gabriel Marcel (1962) suggests that out of various types of captivity and illness arises a pushing forward to overcome what seems like a closing off of life. This pushing forward involves envisioning a future.

Current nursing literature does not address the human health phenomenon of considering tomorrow. Thus, this author explored the related concepts of hope and imagination in the nursing, philosophy, and psychology literature. And, literature related to women who are home-less has been surveyed in nursing, sociology and psychology. 
The researcher's perspective, Parse's nursing theory of human becoming $(1981,1992,1995 \mathrm{a})$, is the theoretical framework through which the literature has been synthesized to create a formulation of the concept of considering tomorrow. The human becoming theory is a theory of nursing rooted in the human sciences and articulates principles and concepts through which an understanding of the lived experience of considering tomorrow can be reached.

\section{The Phenomenon of Interest: Considering Tomorrow}

Considering tomorrow is a universally lived health experience and can be understood at ascending levels of abstraction as "envisioning the notyet", and at a higher level as, "imagining the possibles." It involves imagination which includes hope for and anticipation of possibilities for the future (Fromm, 1968; Kierkegaard, 1980; Marcel, 1962, 1965; Parse, 1981, 1992, 1995a).

In deriving the concept of considering tomorrow, this author first developed conceptualizations of hope and imagination based on the theory of human becoming and the reviews of literature. Literature was reviewed that supported the traditional view of hope and imagination (totality paradigm viewing hope as an attribute and imagination a mental faculty which individuals possess) and literature was surveyed supporting the human becoming perspective of hope and imagination (simultaneity paradigm viewing hope as a paradoxical life process and imagining a unitary lived 
experience). Ultimately, in agreement with both world views, hope and imagination denote a movement toward what is not-yet (Kierkegaard 1980; Lynch, 1965, 1985; Marcel, 1962, 1965; Parse, 1981, 1992, 1990b; Stotland, 1969).

Hope, in accordance with the researchers perspective of the human becoming theory, can be described as a paradoxical life process involving both the situation and those in the situation. Hope occurs not only when one has reason to despair and is an act of liberation; it is a mysterious creative patient posture in communion toward what is not-yet (Marcel, $1962,1965)$. With a synthesis of understandings from selected literature and the human becoming theory, this author posits the following definition of hope: Hope is a pushing-resisting in the comfort-discomfort of the treasured, as persistent visions of possibles are disclosed-not disclosed, cocreating new ways of moving with the familiar-unfamiliar in communionaloneness (Bunkers, 1995). Hope expands the self and is interconnected with human becoming.

Imagination, in accordance with the human becoming perspective, can be viewed as a unitary lived experience. The theory of human becoming is a process-orientated theory (Parse, 1992). Thus, in being consistent with the theory, in further discussion imagination will be referred to as imagining.

Imagining, as a unitary lived experience, involves an openness to possibilities and occurs as imaging, imagining-that, or imagining-how (Casey, 
1976). From a synthesis of the understandings of imagining from selected literature and the theory of human becoming, this author posits the following definition of the concept: Imagining is shifting views of the familiarunfamiliar while disclosing-not disclosing cherished beliefs in propelling envisioned opportunities and limitations all at once, while cocreating new ways of speaking-being silent, moving-being still while being with and apart from others, objects, ideas, and events (Bunkers, 1995). Imagining is inherent to human becoming.

Hope and imagining are concepts that merge in the human health phenomenon of considering tomorrow. From this merging of the understandings of hope and imagining, this author developed the following theoretical conceptualization of considering tomorrow: Considering tomorrow is envisioning the not-yet amidst the disclosing-not disclosing of the familiar-unfamiliar, as comfort-discomfort propels cherished opportunities and limitations all at once, cocreating new ways of speaking-being silent, moving-being still while being with and apart from others, objects, ideas, and events (Bunkers, 1995). Since this is a conceptualization developed exclusively from the literature, the following research on this health phenomenon was necessary to uncover a structure of the lived experience of considering tomorrow. 


\section{Women Who Are Home-less as the Population for the Study}

The term home-less has many conflicting meanings in the literature.

For some authors home-less implies a certain set of characteristics common to certain types of individuals. These characteristics tend to categorize, standardize, and conclude assumptions about individuals. For other authors the term home-less implies a social process of alienation and marginality (Bard, 1990). To avoid using the word home-less to describe, label, and categorize a certain type of person, this author chooses to hyphenate the word and thus convey the meaning of home-less to be a unitary lived experience involving the human-universe-health process.

Current literature suggests that being home-less for women is a type of lived experience involving focusing on survival and moving toward a future. Even if a woman chooses to leave a home and live on the streets or in a shelter, it is a time of intense, purposeful pushing toward tomorrow (Bard, 1990; Francis, 1992; Hagan, 1987; Heise, 1993; Maurin, Russell, \& Memmott, 1989; Rasmussen, 1995).

Bard (1990) in her book, Shadow Women, notes that "whether it be uptown, downtown, crosstown, retreats, tourist town, tracktown, or the beach, home-less women are using innovative methods of surviving in the urban and suburban milieu without ready detection" (p.45). Rasmussen (1995) writes about her work with persons who are home-less. She notes how the home-less talk about moving beyond the now moment. "The 
moving beyond is witnessed in the dreams of what might be, in the struggles to go on one more day..."(p. 107). Rasmussen (1995) quotes a person who is home-less as saying, "Life is not possible on the streets, just survival; you have to watch out for yourself" (p. 106). The following scenario depicts this notion:

The woman stood in the doorway of the home-less shelter in Chicago. The necessity that brought her to see the midwife was the need for AIDS testing, having discovered that her boyfriend was bi-sexual. Her statement to this author was, "I want to be tested as often as necessary for AIDS. I'm not very big and if I know right away that I have it, I can get treatment. Then I will have a better chance of surviving" (Rersonal communication of a woman, home-less, 1994). That statement was the beginning of a conversation in which many episodes in her life were discussed.

The woman was eager to share experiences which she termed as "very difficult" for her. There was the experience of once having a job, buying a gold necklace and having it ripped off her neck as she rode the subway. She described her struggle with anorexia and bulimia. She recounted a time, while living on the street, when she was beaten with a pipe and injured seriously. Accounts of involvement in an abusive relationship with a man, while sharing a place to live with him, were described in detail. Now this woman was seeking assistance because of possible exposure to a life-threatening disease. Through all of this difficulty, 
this woman was hoping for survival; she was considering tomorrow.

Toward the end of the conversation the woman posed the question, "People don't understand what survival is for us street people. Do you know what I mean?" (Personal communication, a woman home-less, Chicago, 1994).

The woman's question is a relevant question not only for this researcher, but for all of nursing. One's survival is germane to health and quality of life. Her question also denotes a desire to have her lived experience understood; and it indicates a pushing toward tomorrow.

\section{Purpose of the Study}

The purpose of this study was to advance nursing science by gaining an understanding of the lived experience of considering tomorrow from persons living the phenomenon.

\section{Significance of the Study}

Understanding the lived experience of considering tomorrow is of paramount importance to nursing. First of all, understanding this lived experience through the lens of Parse's theory of human becoming advances nursing science. It enhances the theoretical base of the human becoming theory providing nurses with new insights concerning how individuals move on in the face of profound and unique life experiences.

Secondly, new understandings concerning how individuals move on through considering tomorrow can "lead to an openness that can change the ways nurses interrelate with persons in practice" (Mitchell \& Heidt, 1994, 
p. 119). In view of the fact that nurses connect with individuals and groups during some of the most difficult moments in life, as well as during some of the most joyous moments in life, both understanding and openness are critical in facilitating "nurse participation in human health, healing, and quality of life" (Mitchell \& Heidt, 1994, p. 119) during such times.

And, finally, gaining insight into the lived experience of considering tomorrow will help to explicate unique ways of becoming, thus uncovering unique and diverse ways of living health. The fact that there are multiple ways of living health is a crucial consideration for nurses if they value the person's own perspective.

\section{Research Question}

The research question was: what is the structure of the lived experience of considering tomorrow?

\section{Nursing Perspective: Parse's Human Becoming Theory}

Parse's nursing theory of human becoming is the theoretical framework for this inquiry. The theory of human becoming, arising from the simultaneity paradigm in nursing, is a theory originating in the human sciences. Human science focuses on a person's participative experience with a situation (Parse, $1981 ; 1987)$. The term human science originated with the German philosopher Wilhelm Dilthy (1833-1911). Dilthy described life as interconnected with others and with history (Mitchell \& Cody, 1992). Dilthy proposed that human beings were the preeminent source of 
knowledge and that the subject matter of the human sciences should be lived experiences with a focus on meaning, values, and relationships (Dilthy, 1976).

Consistent with the philosophical underpinnings of the human sciences, Parse's theory was developed through a synthesis of principles and concepts from Rogers' science of unitary human beings with major tenets of existential-phenomenological thought including intentionality, human subjectivity, coconstitution, coexistence and situated freedom (Parse, 1981). "Humans are viewed as open beings cocreating becoming with the universe, recognized by patterns, and freely choosing within situations" (Parse, 1992, p. 36). Health is described as a process of becoming with the world and a personal commitment to a lived value system (Parse, 1987, 1990a). "Health for the creative author is a process of unfolding. Humans assume responsibility for health, which is cocreated in the humanenvironment interrelationship" (Parse, 1990a, p. 137). Parse posits that through creative imagining in living moment to moment individuals can change the meaning of lived situations, thus changing the pattern of their lives. If an individual imagines (supposes) a situation, a way of life, or a way of living a particular situation differently, the person is already on the way to a new way of living in the present moment (Parse, 1987, 1990a).

How one is considering tomorrow is important when considering quality of life. In accordance with the human becoming theory, individuals 
freely choose within situations. These choices, cocreated in the humanuniverse-health process, are imbedded with the meaning given to situations which construct quality of life in the now and will-be (Parse, 1981, 1994b). "Quality of life is not what those outside the life looking in think it is, but rather it is what the person there living the life says it is" (Parse, 1994b, p. 17). And, from the human becoming perspective, quality of life is the overall focus of nursing (Parse, 1992). Considering tomorrow coshapes one's quality of life in that hope and imagining move one into the not-yet through the creative envisioning of plans, hopes, and dreams.

The theory of human becoming proposes that the individual cocreates self (Parse, 1981, 1987). Existential philosopher Paul Tillich (1980) also embraces this idea when he writes:

A person creates what one is. Nothing is given to a person to determine one's creativity. The essence of being--the "should-be", "the ought-tobe"--is not something which one finds; one makes it. A person is what one makes of oneself.

And the courage to be as oneself is the courage to make oneself what one wants to be. (p. 150)

Parse's and Tillich's words support the notion that considering tomorrow is part of a process of cocreating oneself in the moment. 
Three major themes emerge from the philosophical assumptions of the human becoming theory: meaning, rhythmicity, and cotranscendence (Parse, 1981, 1987, 1992, 1995a). These themes are explicated in the following three principles of the theory:

PRINCIPLE 1: "STRUCTURING MEANING MULTIDIMENSIONALLY IS COCREATING REALITY THROUGH THE LANGUAGING OF VALUING AND IMAGING" (Parse, 1981, p. 69, 1992, p. 37). This principle means human beings cocreate meaning with the universe. It emphasizes how individuals structure their own reality through the meaning they give to an experience. Cody (1994) suggests "meaning is both personal and shared, both representation and event, and all these without boundaries" (p. 50). Imaging, in this structuring of reality, refers to one's knowing at both an explicit (critical reflecting) and tacit (prearticulate and acritical) level (Parse, $1981,1992)$. "Imaging reality, that is, making concrete the meaning of multidimensional experiences, then incarnates the simultaneity of the explicit-implicit knowing..." (Parse, 1981, p. 44). Valuing involves choosing and living cherished beliefs which give meaning to multidimensional experiences. Languaging is expressing through ways of speaking-being silent and moving-being still and is reflective of human interconnectedness, and of the way one represents personal reality (Parse, 1981, 1992, 1994b). Thus, imaging, valuing, and languaging emerge with diversity within 
individuals, and considering tomorrow is lived through these unitary processes.

Considering tomorrow can be manifested through conversing with others or can happen in one's silent reflecting in a situation. It involves envisioning hopes, dreams, and new possibilities through reflection and prereflection as cherished beliefs are examined and confirmed and not confirmed. Parse (1994b) suggests that the meaning of reality continuously changes for individuals as they grow more diverse. Considering tomorrow can thus be viewed as contemplating new experiences while different images give rise to possibilities that incarnate changing value priorities (Parse, 1992). In gaining understanding of this health phenomenon, nurses can come to a clearer awareness of how individuals structure meaning during pleasant and trying times. When such lived experiences occur there is joy and sorrow simultaneously experienced all-at-once.

PRINCIPLE 2: "COCREATING RHYTHMICAL PATTERNS OF RELATING IS LIVING THE PARADOXICAL UNITY OF REVEALING-CONCEALING, ENABLING-LIMITING WHILE CONNECTING-SEPARATING" (Parse, 1981, p. 69,1992, p. 37). This principle relates to how the human-universe-health process emerges through cocreated paradoxical rhythms. Paradox refers to opposites, but in the human becoming theory the paradoxical patterns of relating are viewed as two sides of the same rhythm, with both sides of the rhythm present at once, one in the foreground the other background (Smith, 
1990a). Mitchell (1993) defines living paradox as described by the human becoming theory as "a rhythmical shifting of views, the awareness of which arises through experiencing the contradiction of opposites in the day to day relating of value priorities while journeying to the not-yet" (p. 51).

Experiencing such contradiction in opposites opens one to unlimited choices which can be lived through imagining the "journey to the not-yet." Choices arise through the process of imagining alternatives. Choice implies an infinite number of possibilities (Parse, 1981, 1992).

An individual's unique way of living these paradoxical patterns of relating cocreates with the universe the way of considering tomorrow. A paradox present in the situation is that there are both limitations and opportunities present in considering tomorrow. For example, when individuals consider moving in one direction toward particular choices they are simultaneously moving away from other possibilities (Parse, 1981), thus living the paradox of enabling-limiting. When an individual shares certain ideas, fears or concerns with another, there are other ideas and feelings not being shared. This is living the paradox of revealing-concealing. Parse suggests that there are always unknowns with all persons since one can never disclose all that one is (Parse, 1981).

Another rhythmical pattern of relating with others when considering tomorrow is connecting-separating. It is a rhythm of "connecting with one phenomenon and simultaneously separating from others" (Parse, 1981, 
p. 54). Connecting-separating is an intersubjective relationship where people coming together are "simultaneously unifying and separating as their togetherness evolves" (Parse, 1981, p. 54). Considering tomorrow can thus be viewed as involving all of these paradoxes of lived experiences in the process of struggling to decide what is next. Within paradox there is always a struggling to decide, often manifested through an individual's attempts to connect with others and at the same time seek aloneness and separateness (Mitchell, 1993). Or, the struggle can surface in postponing making decisions involving a direction or choice for one's life. Also, the individual may share certain feelings and ideas about the situation, but will not share other concerns. Every choice facilitates and hinders the individual in some way, showing the paradoxical nature of the situation and of considering tomorrow.

PRINCIPLE 3: "COTRANSCENDING WITH THE POSSIBLES IS POWERING UNIQUE WAYS OF ORIGINATING IN THE PROCESS OF TRANSFORMING" (Parse, 1981, p. 69, 1992, p. 38). This principle describes moving beyond through powering, originating, and transforming, involving living hopes and dreams through creating new ways of viewing what is familiar. Powering is seen as the pushing-resisting rhythm in human processes, and is an energizing force which moves one beyond the moment. Originating is creating new and unique ways of living with people and 
projects. Transforming involves the shifting of views as new light is shed on what is known (Parse, 1994a).

Hodnicki, Horner, and Simmons (1993) use the metaphorical poem entitled, "The Sea Of Life" to symbolize transforming through the revealingconcealing of valuing. "The living sea is used as the symbolic medium for expressing the universal human experience of change, a natural ongoing process" (p. 26). Readers are invited by the metaphor to imagine how life itself is like the rhythmical wave pattern of the sea. The processes of changing and transforming, integral to Parse's theory of human becoming, occur simultaneously in "imagining the possibles" (Parse, 1981, 1992).

Powering, originating, and transforming imply a movement beyond what is to what is not-yet. Thus, considering tomorrow is linked to powering and is a movement involving a contemplation of possibilities arising out of imagining and hoping. All of an individual's imagined possibilities are interwoven in the processes of choosing a path in life.

Choosing a path arises out of a person's explicit and tacit knowing (Parse, 1990a). The human becoming theory posits that each person knows "the way" or knows their path somewhere within self (Parse, 1990a). Parse writes (1990a):

Each person lives a way, his or her own way, which is both alike and different from the "ways" of others. It is like that of others in that it is a personal 
way of being; each individual has a personal way of

being. It is different from others in that it is

one's own. (139)

Choosing one's own way involves examining and perhaps changing

value commitments. Ways of changing value commitments, thus changing health, include creative imagining, affirming self, and spontaneous glimpsing of the paradoxical (Parse, 1990a).

In creative imagining one pictures, sees, hears, and feels what a situation might be like; in affirming self one discovers personal patterns of preference and makes choices according to these preferences; in spontaneous glimpsing of the paradoxical one recognizes incongruities in a situation, sees the humor in the incongruity and laughs, thus moving beyond the moment changing the meaning of a situation (Parse, 1990a). Through creative imagining, affirming self, and glimpsing of the paradoxical an individual engages in the processes of considering tomorrow and coming to know one's own way.

Considering tomorrow is contemplating what might be while living moment to moment in the now. It is not a human experience that can be managed, avoided, coped with, or manipulated. It is essential to one's becoming. Even how an individual views an experience depends on the meaning the person ascribes to the situation. Both difficult and effortless experiences hold unique meanings and possibilities for individuals, and 
meaning and possibility incarnate personal choice (Parse, 1987, 1992).

Existential philosopher Kierkegaard suggests, "the self must be broken in order to become itself" (Kierkegaard, 1980, p. 65). He further posits that a human being is a synthesis of the limited and unlimited and exists in movement through which the self becomes itself in the medium of imagination where possibility becomes actuality (Kierkegaard, 1980). Kierkegaard's philosophical axioms support the principles of the human becoming theory. For "the essence of Parse's theory is embedded in meanings, patterns in relationships, and in hopes and dreams" (Parse, 1992, p. 37).

\section{Summary}

The theoretical concepts of the human becoming theory including the unitary nature of the human-universe-health process, health as a process of becoming, individually defined quality of life, structuring meaning multidimensionally, cocreating rhythmical patterns of relating, and cotranscending with the possibles compose the theoretical perspective through which this research will be conducted. Considering tomorrow is a universal human-universe-health phenomenon and is understood through the meaning individuals give to it. It involves constructing meaning multidimensionally, envisioning new ways of being with and apart from others, choosing possibilities, and cocreating the not-yet. Considering tomorrow is fundamental to human becoming. 


\section{CHAPTER II}

\section{REVIEW OF RELEVANT LITERATURE}

Since the health phenomenon of considering tomorrow was not found in any known literature, the related concepts of hope and imagination were reviewed in nursing, philosophy and psychology. The literature on women who are home-less was also reviewed. Thus, the review of literature is presented in the following three parts: literature on hope; literature on imagination; and literature on women home-less.

Due to the very distinct differences in ontology and epistemology of the totality and simultaneity paradigms in nursing, the nursing literature review for this paper is arranged in relationship to the two differing world views.

The totality paradigm in nursing considers humans to be bio-psychosocio-spiritual organisms whose environment can be manipulated to achieve balance (Parse, 1987). Health is viewed as a dynamic state and a process of physical, psychological, social, and spiritual well-being with the nurse being the authority and prime decision-maker concerning matters of health (Parse, 1987).

In contrast, the simultaneity paradigm views humans as more than and different from the sum of their parts and as open beings free to choose in mutual rhythmical process with the environment. Health is viewed as a 
process of emerging. The prime decision maker concerning matters of health is the person and not the nurse (Parse, 1987).

\section{Review of Literature on Hope}

The Greeks told the story of the minotaur, the bull-headed flesh-eating man who lived in the center of the labyrinth.

He was a threatening beast, and yet his name was Asterion-Star.

I often think of this paradox as I sit with someone with tears in her eyes, searching for some way to deal with a death, a divorce, or a depression.

It is a beast, this thing that stirs in the core of her being, but it is also the star of her innermost nature.

We have to care for this suffering with extreme reverence

so that, in our fear and anger at the beast, we do not overlook the star. (Moore, 1992, p. 21)

Review of literature on hope was conducted in nursing, philosophy, and psychology. First, general and then nursing theoretical literature will be presented, followed by general research studies on hope and nursing research studies.

Two distinct conceptualizations of hope were formulated from the literature review: hope as an attribute; and hope as a paradoxical life process. These two conceptualizations will provide the thematic framework for the literature review.

\section{General Theoretical Literature}

Hope as an attribute is discussed by several theorists (Bloch, 1986; Erikson, 1964; Godfrey, 1987; Holy Bible, 1985; Kant, 1951, 1982; Lynch, 1965; Metz, 1966; Moltman, 1967; Stotland, 1969). The definition of 
attribute used for this paper is the following: An attribute is "a quality or characteristic of a person, thing, or group" (The Random House Dictionary of The English Language, 1987, p. 13).

Philosopher Ernest Bloch (1986), an atheist and Marxist, depicts hope as an attribute which makes people broad instead of confining them. He conceptualizes hope within the framework of history, social justice, and the community. Bloch approaches his analysis of hope from a communal perspective instead of from an individualistic perspective. He writes, "thinking means venturing beyond" (Bloch, 1986, p. 3). By this statement Bloch depicts hope as a cognitive/affective attribute present in individuals as they work within a community of people. He states, "The work of this emotion requires people to throw themselves actively into what is becoming, to which they themselves belong" (Bloch, 1986, p. 3).

Bloch develops the concept of learned hope as that which is active and comes to grips with world process in mutual involvement. According to Bloch's Marxist stance, total hope is for "humanum"-to overcome alienation. Bloch suggests that hope be viewed as a social objective located in history, rather than as an individual objective located outside of history (Bloch, 1986).

Philosopher Immanuel Kant (1982) takes both a communal and an individualistic stance in his analysis of hope. For Kant ultimate hope points to perpetual peace. The peace of which he speaks is societal peace and is 
the absence of war (Godfrey, 1987). Kant equates ultimate hope with ultimate good. Kant's answer to the question, "What may I hope" (Kant, 1982 , p. 243) is "I may hope for happiness proportionate to virtue, inasmuch as this is the highest good." Hope for happiness is sound hope; it is sound because its possibility is implied by what the moral law obliges. Kant writes, "Just as moral principles are necessary according to reason in its practical use, so it is equally necessary according to reason in its theoretical use to assume that everybody has cause to hope for happiness to the extent that he has made himself worthy of it in his behavior, and the system of morality is inseparably joined with that of happiness, but only in the idea of pure reason" (Kant, 1982, p. 245). Kant asserts that the goal of humanity (hope) is a social goal, the promotion of the highest as a social good. But, within this promotion of the highest as a social good, operates the attribute of individual hope as an ethical stance of morality (Godfrey, 1987).

The idea of hope being an attribute that activates toward a goal is supported by Stotland (1969) who suggests that hope includes the active expectation of attaining a goal. Stotland, however, views hope from a more individualistic stance than either Bloch or Kant. He suggests a person hopes in correlation to the perceived importance of the goal and the probability of attaining the goal (Stotland, 1969). Lynch (1965) further supports this probabilistic nature of hope when he defines hope as a sense of the possible. 
He states, "Hope therefore involves three basic ideas that could not be simpler: what I hope for I do not yet have or see; it may be difficult; but I can have it-it is possible" (Lynch, 1965, p. 32).

From a western Judeo-Christian theological perspective Metz (1966) also identifies hope as a characteristic attitude which focuses on the future. "What stirs modern individuals is not involvement in the world above, but involvement in the future. This is still capable of drawing a person out of self and stretching one's effort, no matter how de-mystified and a-religious one may be" (Metz, 1966, p. 281). He further suggests that the eschatological city of God is itself in the process of becoming. "By moving toward it in hope we build it. We are the builders and not just the interpreters of the future, while God's is the strength that awakens it" (Metz 1966, p. 286).

Moltman (1967) expands this Judeo-Christian perspective on hope by pointing out that Christian faith pushes toward the future. And, that theologically, the attribute of hope is the inseparable companion of faith (Moltman, 1967). Moltman states, "In the contradiction between the word of promise and the experiential reality of suffering and death, faith takes its stand on hope" (Moltman, 1967, p. 19). The bounds that mark the end of all human hopes are broken through in the belief in the rising of the crucified Christ and faith expands into hope. This hope becomes a 'passion for the 
possible' because it is a passion for what has been made possible in the Christian belief of the resurrection (Moltman, 1967).

In biblical literature both the Old and the New Testament emphasize themes of hope. In Jeremiah 29:11 it is written, "For I know the plans I have for you', declares the Lord, 'plans to prosper you and not harm you, plans to give you a future and a hope. Then you will call upon me and come and pray to me, and I will listen to you. You will seek me and find me when you seek me with all your heart. I will be found by you', declares the Lord, 'and I will bring you back from captivity'" (Holy Bible, 1985, p. 1171).

In the New Testament the apostle Paul continues this theme of hope when in 2 Corinthians 1:10-11 he points to God's past action of granting physical deliverance from death and danger, and concludes, "But this happened that we might not rely on ourselves but on God who raises the dead. He has delivered us from such a deadly peril, and he will deliver us. On him we have set our hope that he will continue to deliver us" (Holy Bible, 1985, p. 1763). At another point Paul discusses the gifts of the spirit and identifies faith, hope, and love as the most enduring (Holy Bible, 1985).

Hope has been identified as an attribute acquired early in life. Developmental theorist Erik Erikson (1964) posits that hope is an outcome of the first stage of human development which deals with basic trust versus mistrust. He suggests that the foundation for hope is established in infancy and is based on early experiences of trust and security with a maternal figure 
involving attachment-separation issues. As trust is developed hope is procured (Erikson, 1964).

Godfrey (1987) follows Erikson's developmental analysis of hope suggesting that hope involves a plurality of desiring that extends over time; "what is hope of one age is something else later" (Godfrey, 1987, p. 21). He indicates that as a human strength, hope changes focus with maturity. Godfrey identifies two types of hope evolving in human development: ultimate hope and fundamental hope. Ultimate hope is preferential hope that is a disposition with a target or aim. Thus, what one's ultimate hope is may change with maturity and circumstance. Fundamental hope has no particular focus, but is rather an attitude or orientation toward the future. It is "an openness of spirit with respect to the future" (Godfrey, 1987, p. 66). Thus, fundamental hope deals with one's overall life orientation.

In contrast to viewing hope as an attribute, other authors view hope as a paradoxical life process (Frankl, 1984; Fromm, 1968; Jones, 1985; Marcel, 1962, 1965; Morris, 1992; Oliver, 1974; Pascal, 1966; Steindl-Rast, 1984; Tillich, 1963, 1980; Wu, 1972). The term paradox refers to "1. a statement or proposition that seems self-contradictory or absurd but in reality expresses a possible truth 2 . an opinion or statement contrary to commonly accepted opinion" (The Random House Dictionary of The English Language, 1987, p. 1406). 
Philosopher Erich Fromm (1968) begins his classical work The

Revolution of Hope by writing: "Hope is paradoxical. It is neither passive waiting nor is it unrealistic forcing of circumstances that cannot occur. It is like the crouched tiger, which will jump only when the moment for jumping has come" (Fromm, 1968, p. 9).

This metaphorical description illuminates Fromm's major thesis concerning hope: it is "a state of being--an inner readiness,--that of intense but not-yet activeness" (Fromm, 1968, p. 12). Fromm, as other theorists, links the inner readiness of hope closely to faith. He writes that "faith is a vision of the present in a state of pregnancy; it is certainty about the reality of a possibility. The paradox of faith is: It is certainty of the uncertain" (Fromm, 1968, p. 13).

Frankl (1984) focuses on the paradoxical nature of hope by centering on the human capacity to creatively turn life's negative aspects into something positive or constructive. In Man's Search for Meaning (1984), Frankl identifies what he sees as the central theme of human existence: "to live is to suffer, to survive is to find meaning in the suffering" (Frankl, 1984, p. 9). For Frankl finding meaning holds the possibility of generating hope and optimism in the face of no-hope and tragedy. Such hope and optimism in view of human potential allow for: (a) turning suffering into a human achievement and accomplishment; (b) deriving from guilt the opportunity to 
change oneself for the better; and (c) deriving from life's transitoriness an incentive to take responsible action (Frankl, 1984).

The perception of meaning in one's life, according to Frankl, "boils down to becoming aware of a possibility against the background of reality, or, to express it in plain words, to becoming aware of what can be done about a given situation" (Frankl, 1984, p. 145). The way in which a person views suffering gives an opportunity, even under the most difficult circumstances, to add a deeper meaning to life. Hope here is linked to attaining the moral development a difficult situation may afford an individual (Frankl, 1984).

In underscoring this positive potential of hope, Frankl describes his personal experiences as a prisoner in the Auschwitz concentration camp. He notes that fellow prisoners who lost faith in the future--their own future-were doomed. With the loss of belief in the future, they lost their spiritual hold; they let themselves decline and became subject to physical and mental decay. Thus, Frankl viewed hope as a healer and a paradoxical life process from which meaning, value and more hope arises out of the depths of nohope and anguish (Frankl, 1984).

Hope as paradoxical life process is further elaborated on by philosopher Kuang-Ming Wu. He writes, "misery is created by man's conscious practice against and within his existing situation. It is this lifeprotest that makes misery a stigmata, and it is this stigmata that gives rise 
to hope" (Wu, 1972, p. 132). Wu cites three essential characteristics of hope as a life process: (a) hope as immortal; (b) hope as life's responsibility; and (c) hope as life's necessity (Wu, 1972).

Hope as immortal means that even in protesting the value of hope-questioning its value--one betrays one's secret hope for something better. "Hope is the supporting power even of the negations of hope, it is a pervasive power in things hopeless as well as things hopeful. It follows, then, that hope, as the persistent "project", is universal. Contrary to our usual impression, hope is everywhere" (Wu, 1972, p. 133).

Hope as life's responsibility suggests that potentiality is the essence of all things. And, if all things are possible, then individuals are responsible for actualizing them in a safe, moral way (Wu, 1972). Wu (1972) writes the following concerning hope as life's responsibility:

In other words, things either come out of our visions or die in them. Things are born of our dreams that plan and accomplish. Things die in our visions that are mere fantasies. Whether the dreams become productive hope or defeatist opiates depends on what we do with those visions when we are confronted with the disastrous here and now. (p. 146)

Hope as life's necessity emphasizes that hope is an essential element in every human act. Wu states, "for every step of our life is literally impossible without some imaginative projection into what is meant to 
happen" (Wu, 1972, p. 133). He develops this idea of hope as life's necessity further by suggesting that hope creates "the horizon of life" by contextualizing meaning, developing a perspective on purpose, and by envisioning the good to come through which life's activities and dreams make sense (Wu, 1972). Thus, Wu developed the following definition of hope: "Hope is the creative pull between the now and the future, originating from the contrast of the actual with the ideal. Hope is our life-nisus to a better tomorrow, spurred on by the disillusionments of today" (Wu, 1972, p. 134).

Oliver (1974) concurs with this idea of hope as life responsibility and life-nisus. He writes:

A genuine hope is one which leads us to face life responsibly. The experience of hope is not just a collection of ideas about the future, though its form will include futuristic symbols. It is a way of being in the world by which the meaning of life is affirmed in the face of the apparent meaninglessness of death. (p. 85)

Several theorists use metaphor to expand on hope as life-nisus or life process (Fromm; 1968, Morris, 1992; Pascal, 1966; Paulus, 1972; SaintExupery, 1971; Steindl-Rast, 1984). These metaphors illuminate the vast nature of the courage to be activated by hope (Tillich, 1980). 
The metaphor of "heart" is used in an analysis of hope as paradoxical life process through illuminating its apparent reasonable and unreasonable nature. The reasonable nature of hope focuses on goals that are yearned for and appear to be achievable (Fromm, 1968; Lynch, 1965). The unreasonable nature of hope concerns itself with hoping when there appears to be no reason to hope (Morris, 1992). Morris (1992) points out, however, that reason has its limits. Reason is based on first principles and first principles are based on the knowledge of the heart, not on reason. The type of hope which transcends reason is connected with an inner knowing which philosopher Blaze Pascal (1966) associates with "first principles".

Concerning human knowing and first principles Pascal (1966) writes:

We know the truth not only through our reason but also through our heart. It is through the latter that we know first principles, and reason, which has nothing to do with it, tries in vain to refute them.

The skeptics have no other object than that, and they work at it to no purpose. We know that we are not dreaming, but, however unable we may be to prove it rationally, our inability proves nothing but the weakness of our reason, and not the uncertainty of all our knowledge, as skeptics maintain. For knowledge of first principles, like space, time, motion, number, 
is as solid as any derived through reason, and it is such knowledge, coming from the heart and instinct, that reason has to depend and base all its arguments. (p. 58)

Pascal believed perception by the heart was more complex, multiform, and deeper than the single modality of the external senses (Morris, 1992). The knowledge of first principles is the base for the knowledge "of the heart."

The use of the metaphor "heart" in discussing inner knowledge and hope is a complex one. One must look to the word "heart" itself to understand this complexity. At the center of the word heart is ear and also the word hear and tear are present. It is one's inner ear that hears the whispers of intuitions, dreams, desires, passions, remembrances, and imaginings. It is such as these that compose the hope of inner knowing (Jones, 1985). The inner ear is the center, the heart of it all. As Antoine de Saint-Exupery (1971, p. 23) wrote in the story of The Little Prince: "It is only with the heart that one can see rightly; what is essential is.invisible to the eye."

Often the hearing of the inner ear is made more explicit to the individual through the experience of tears; and, as authors have noted, it is in this place of tears where hope predominantly originates (Frankl, 1984; Marcel, 1962, 1965; Jones, 1985). 
Alan Jones in the book entitled Soulmaking, (1985) discusses the desert tradition of using tears as agents of hope, resurrection and transformation. He writes:

Tears flow when the real source of our life is uncovered, when the mask of pretense is dropped, when our strategies of selfdeception are abandoned. Trials and humiliations are necessary only insofar as they are the means by which our true life is uncovered. To come to this place where one is truly alive, one must hit rock-bottom. There must be a breakthrough to the place of deepest helplessness. Then, a beginning can be made. (p. 83)

This theme of deepest helplessness in the "gift of tears" also emerges in relationship to hope in the writings of Brother David Steindl-Rast (1984), a Benedictine monk, whose attempts to unite Eastern and Western spirituality suggest that hope happens when the bottom drops out of one's pessimism. "We have no where to fall but into the ultimate reality of God's motherly caring. That is why St. Paul tells us that 'turbulence leads to patience; and patience to experience; and experience to hope'" (Steindl-Rast, 1984, p. 136). Hope is both reasonable and unreasonable; it transcends reason. Hope is the bridge between the world of empirical reality and the world of mystery and transformation (Jones, 1985; Marcel, 1962, 1965; Steindl-Rast, 1984). 
Since hope serves as this bridge between empirical reality and inner knowing and transformation, to understand hope one needs to look closely at the concept of transformation. Transformation is "a major change in form, nature, or function" (Webster's Ninth New Collegiate Dictionary, 1990, p. 1253). Synonymous with transformation are the words metamorphosis and transmutation. Metamorphosis suggests "an abrupt or startling change induced as if by a supernatural power; transmute implies transforming into a higher element or thing" (Webster's Ninth New Collegiate Dictionary, 1990, p. 1253).

Hope as a transformative process as well as a paradoxical life process is facilitated by short story writer Tina Paulus (1972) and four noted Christian philosophers; Soren Kierkegaard (1980, 1992, 1993), Gabriel Marcel (1962, 1965), Brother Steindle-Rast (1984), and Paul Tillich (1963). Paulus uses metaphor to describe the transformative power of hope and Kierkegaard, Marcel, Steindle-Rast, and Tillich view hope as a paradoxical life process that occurs in relationship through communion-aloneness.

The transformative nature of hope is depicted by Paulus in a story entitled, Hope For the Flowers (1972) where she uses the metaphor of a cocoon to depict the essence of hope. The story begins with two fuzzy caterpillars, Stripe and Yellow, searching for a way to get up higher in life. Stripe takes the path of climbing up a pillar of caterpillars knocking others down as he climbs. He disregards all other caterpillars, caring only that he 
get to the top of the pile. Yellow, refuses to take this option to get up higher and instead meets up with a wise, older caterpillar that tells her that if she would spin a cocoon and be very still and wait, she would become a butterfly and be able to fly.

...Yellow thought, How could she risk the only life she knew when it seemed so unlikely she could ever be a glorious winged creature?...Yellow decided to risk for a butterfly. For courage she hung right beside the other cocoon and began to spin her own. Imagine, I didn't even know I could do this. That's some encouragement that I am on the right track. If I have inside me the stuff to make cocoons-maybe the stuff of butterflies is there too. (Paulus, 1972, pp. 75-84)

In the darkness and stillness of the cocoon Yellow was transformed into a butterfly. She let go of life the way it was because she imagined she could be a butterfly. It was a silent, but active process (Paulus, 1972).

Paulus (1972) suggests that in the darkness and stillness of hope transformation occurs. Such stillness is also identified as hope by Brother Steindl-Rast (1984). He asserts that hope is a patient waiting, it is a stillness that allows one to hear the inner voice of guidance. "It is only in that stillness that we can clearly hear what our task is" (Steindl-Rast, 1984, p. 136). The stillness of hope is described as the stillness of integrity (Stendle-Rast, 1984). Tillich (1963) supports the importance of stillness and 
solitude in the process of living hope. He states, "In moments of solitude something is done to us. The center of our being, the innermost self that is the ground of our aloneness, is elevated to the divine center and taken into it. Therein we rest without losing ourselves" (Tillich, 1963, p. 24). Tillich exhorts that solitude puts us in touch with our utmost self which is our source of hope, strength, and creativity in times of trial (Tillich, 1963).

Kierkegaard in his classic The Sickness Unto Death (1980) views hope as arising out of one's imagination. He writes:

In order for a person to become aware of self and of God, imagination must raise one higher than the miasma of probability, it must tear one out of this and teach her/him to hope and to fear--or to fear and to hope--by rendering possible that which surpasses a sufficient amount of any experience. (p. 41)

Kierkegaard identifies hope as the process of transcending oneself. He states, "The formula that describes the state of the self when despair is completely rooted out is this: in relating itself to itself and in willing to be itself, the self rests transparently in the power that established it" (Kierkegaard, 1980, p. 14). Thus, both hope and faith are intricately linked by Kierkegaard to the life process of becoming a unique self in relationship to God (Mehl, 1992). This becoming a unique self in relationship to God, the ultimate hope for individuals according to Kierkegaard, involves the task of 
understanding oneself in existence (Kierkegaard, 1992). "Live in such a way that you are conscious of being an individual" (Kierkegaard, 1993, p. 113). Thus, hope, according to Kierkegaard, can be viewed as the process of expanding the relational ties that constitute a self.

Hope as a paradoxical life process is supported in the writings of existential philosopher Gabriel Marcel $(1962,1965)$. Marcel identifies that the conditions that make hope possible are the very same conditions as those which make it possible to despair. In fact, death is considered as the springboard of an absolute hope (Marcel, 1965). "A world where death was missing would be a world where hope only existed in the larval stage" (Marcel, 1965, p. 93).

Marcel suggests that hope is a life essence. "The soul itself seems to me the intermediate term between life and hope" (Marcel, 1965, p. 95). Marcel, like Kierkegaard, Steindl-Rast, and Tillich associates hope with faith. He writes, "The common root of hope and prophecy is faith" (Marcel, 1965, p. 94).

In his classic work, Homo Viator: The Metaphysics of Hope (1962), Marcel describes hope from a very low order of tension to its highest tension or point of saturation. An example of a low order of hope is, "I hope my sister will arrive in time for lunch tomorrow and not at 5 p.m." This form of hope is close to the point of indifference, for it is not very important if the 
sister arrives at lunchtime or 5 p.m. There is nothing, as Marcel would say, "to take to heart" (Marcel, 1962).

On the contrary, at the highest or greatest tension of hope, the individual longs for some deliverance which would bring the trial to an end. This "I hope" in all its strength is directed toward liberation. It is a longing to come out of a darkness in which one has been plunged. Marcel sees hope situated within the framework of the trial, it is a being's response to the trial. In this trial in its most devastating developments, there is much to "take to heart". The paradoxical nature of hope is again experienced at this moment. For when little is at stake, hope is at its lowest tension; when much is to be lost, hope is at its greatest tension (Marcel, 1962).

This greatest form of hope--hope for liberation and salvation--is experienced in communion. It is this communion with the situation and with others in the situation which gives rise to the creative process leading to the transformative powers of hope. Marcel (1962) describes it clearly:

Might we not say that hope always implies the superlogical connection between a return (nostos) and something completely new (Kainon ti)? Following from this it is to be wondered whether preservation or restoration, on the one hand, and revolution or renewal on the other, are not the two movements, the two abstractly dissociated aspects of one and the same unity, which dwells in hope and is beyond the reach of all our 
faculties of reasoning or conceptual formulation. This aspiration can be approximately expressed in the simple but contradictory words: as before but differently and better than before. Here we undoubtedly come again upon the theme of liberation, for it is never a simple return to the status quo, a simple return to our being, it is that and much more, and even the contrary of that: an undreamed-of promotion, a transfiguration. (p. 67) Marcel's major thesis concerning hope is this: "I hope in thee for us" (Marcel, 1962, p. 60). As noted, Marcel believes that in the experience of hope one develops a connection or relationship with the circumstance and with the others in the circumstance. This relationship involves a communion. Communion in this context by definition means, "an act or instance of sharing; intimate fellowship or rapport" (Webster's Ninth New Collegiate Dictionary, 1990, p. 247). Marcel uses the metaphor of a river to describe the mysterious communal qualities of hope. "Hope, like water, has a way of making things fluid" (Marcel, 1965, p. 77). When the communal flow of hope is blocked, like water it flows under or around the obstacle in its invisible journey to be. Marcel (1965) concludes:

Hope is a prophetic power. It has no bearing on what should be; it just says "This will be". Reflecting on hope is perhaps our most direct means of apprehending the meaning of the 
word 'transcendence', for hope is a spring, it is the leaping of a gulf. (p. 79)

Hope, according to Marcel, is a creative process that is patient and yet nonaccepting of the trial given. "Hope means first accepting the trial as an integral part of the self, but while so doing it considers it as destined to be absorbed and transmuted by the inner working of a certain creative process" (Marcel, 1962, p. 39). Marcel terms this creative process as a "no-action" or "no-technique" since it is characteristic of hope to be unable to make direct use of any technique or to call it to her aid. "Hope is the weapon, or (more exactly) it is the very opposite of a weapon and in that, mysteriously enough, its power lies" (Marcel, 1962, p. 76).

Marcel concludes his writings on Homo Viator: A Metaphysics of

Hope (1962) by defining hope as the following:

We might say that hope is essentially the availability of a soul which has entered intimately enough into the experience of communion to accomplish in the teeth of will and knowledge the transcendent act--the act establishing the vital regeneration of which this experience affords both the pledge and the first fruits. (p. 67)

In conclusion, from this definition and from the writings of these authors in the general literature, it can be seen that hope is a paradoxical life 
process involving both the situation and those in the situation. It is lifegiving when life is threatened.

Nursing Theoretical Literature-Totality Paradigm

Hope as an attribute has been identified in the nursing literature as having both a state and a trait component (McGee, 1984). As a trait variable McGee suggests an individual has a predisposition toward a hopeful or pessimistic approach to life. The state component of hope, on the other hand, involves perception, such as the perceived probability of goal achievement, perceived internal and external resources, importance of the goal, and influence of the level of hopefulness exhibited at a given time (MCGee, 1984).

Farran, Herth and Popovich (1995) view hope as having four central attributes: (a) an experiential process; (b) a spiritual or transcendent process; (c) a rational thought process; and (d) a relational process. They define hope as the following:

Hope constitutes an essential experience of the human condition. It functions as a way of feeling, a way of thinking, a way of behaving, and a way of relating to oneself and one's world. Hope has the ability to be fluid in its expectations, and in the event that the desired object or outcome does not occur, hope can still be present. (Farran, Herth, \& Popovich, 1995, p.6) 
Stephenson (1991) views hope as a basic human response that is essential to life. Hope is defined as "an anticipation that involves the interaction of thinking, acting, feeling and relating, and is directed toward a future fulfillment that is personally meaningful" (Stephenson, 1991, p. 1459). Thompson (1994) and Gewe (1994) support the essence of this definition of hope and further suggest that hope is a powerful motivator to take action.

Thompson (1994) defines hope as "a mental state indicated by future expectation and goal specific action" (p. 12). Thompson views hope as a spiritual need, one in which nurses can help meet through quality nursing care (Thompson, 1994).

Scanlon (1989) supports this notion of hope being an attribute that nurses can foster in patients through helping them to create a vision when darkness surrounds them. She writes: "To create a vision is to shine light in dark corners, to help another find a new perspective, and to facilitate strength in broken places" (Scanlon, 1989, p. 491). Scanlon suggests that offering another the opportunity for an authentic human relationship creates the possibility for hope. Hope is actualized in relationship (Scanlon, 1989).

Hockley (1993) furthers the premise of hope being activated and supported through authentic relationships suggesting that if someone shows care for another, hope can be generated in that person. 
A sense of personal control has been identified as closely connected to the attribute of hope by Wurzbach (1992). Wurzbach sees personal control as contributing to an optimal level of certainty-uncertainty in an individual, which in turn encourages a positive attitude of hope (Wurzbach, 1992).

Ellyn Bushkin (1993), a nurse dying of metastatic cancer, wrote before her death that when faced with such "insurmountable odds" one "must believe in things not seen and understand that all that is seen is not necessarily what it seems" (p. 869). She saw hope providing the energy necessary to travel the life journey of chronic illness and suffering. Hope, to Bushkin, consisted of the attributes of confidence, assurance, reliance, expectations, optimism, faith, belief, and quality. She believed that the quality of life of one suffering is improved by the light of hope (Bushkin, 1993). For Bushkin hope was essential for the process of survival. Bushkin defined survival as "to survive is to learn to live" (Bushkin, 1993, p. 869). In conclusion, the nursing theoretical literature from a totality view depicts hope as the following: an expectation and goal orientation toward what is personally meaningful in the future; closely connected with a Christian belief in divinity and afterlife; an attribute developing at an early stage of human growth and development; a basic human response to life; a spiritual need which is met through authentic human relationships; having a correlation with a positive sense of personal control over the events in one's 
life; and as an energy helping one focus on living and on the future. Hope as an attribute, according to this literature, can be assessed, measured, and promoted by nurses. Such a view of hope is consistent with the totality paradigm in nursing.

Nursing Theoretical Literature-Simultaneity Paradigm

Hope, in the simultaneity paradigm in nursing, is viewed as a paradoxical life process as explicated by nursing research studies. With this depiction of hope suggested, it is difficult to concur with those authors who state that hope can be quantitatively assessed, measured, and promoted by nurses. Hope appears to be more of a life process that nurses participate in with others. Thus, hope as a participatory life process may be better understood through the lens of the simultaneity paradigm in nursing. In reviewing the theoretical nursing literature on hope in this paradigm, no specific theoretical writings other than those arising from the research studies reviewed later in this chapter were found by this author to be representative of the simultaneity view. This is an area that needs future scholarly development in nursing.

\section{General Research Studies}

Two significant research studies conducted outside of nursing in the fields of sociology and psychology are Klenow's 1991 study and Brackney \&. Westman's 1992 study. Klenow (1991) conducted an exploratory study on hope by reading and analyzing ten written case descriptions of kidney 
transplant patients, hemodialysis patients, patients who were dying, popular press accounts of physician views and patient's experiences; and a variety of other accounts.

From this review Klenow (1991) derived a topology of five major sources of hope. These sources include: (a) religion; (b) medical science; (c) fallibilism; (d) self-discipline; and (e) false hope (Klenow, 1991). Klenow suggests that this identified topology may serve as a theoretical resource to advance research on hope during life-threatening illness. However, even though Klenow identifies certain situations and activities which appear to foster hope, his research does not describe the essence of hope itself.

Brackney \& Westmann (1992) conducted a correlational study on hope, psychosocial development, and locus of control with 29 male and 79 female undergraduate and graduate students. It appears that the most important finding of the research was the unexpected finding that the Miller Hope Scale and the self-report measure of hope were not significantly correlated.

The authors suggest that hope is more complex than what a single instrument can measure or that the instruments do not adequately tap the multidimensionality of the concept of hope (Brackney \& Westman, 1992). These findings do lead to legitimate questions concerning measuring hope as a quantity. 
Nursing Research Studies-Totality Paradigm

Hope as an attribute which can be measured quantitatively has been the focus of a of number nurse researchers (Dufault \& Martocchio, 1985; Farran \& McCann, 1989; Herth 1991, 1992; Miller \& Powers, 1988; Nowotony, 1989; Raleigh 1980, 1992). Several of these researchers focused on development of tools to empirically measure the attribute of hope Isee for example Herth, 1991, 1992; Miller \& Powers, 1988; Nowotony, 1989). Since this present study focuses on understanding the lived experience of considering tomorrow, tool development for measuring hope as a characteristic that can be quantified is viewed peripheral to this health phenomenon, thus the research on tool development will not be discussed here. Quantitatively measuring and explaining relationships concerning the personal characteristics of hope is one way of generating knowledge. But this information does not enhance understanding the essence of how persons day-to-day live the process of hope-no-hope.

Eight other totality paradigm studies on hope are reviewed here. Raleigh (1980, 1992) studied the attribute of hope in physically ill adults and adults with chronic illness. The correlation was found to not be statistically significant at the p. $>.05$ level. The important finding in the demographic data of this study was that individuals cited interaction with others as a helpful means of coping with their illness (Raleigh, 1980). In 1992 Raleigh sought to identify the sources supporting hope in patients with chronic 
illness. The insight gained from this study was that the most commonly reported sources supporting hopefulness were family, friends, and religious beliefs (Raleigh, 1992).

Other research in nursing seeking to describe hope as an attribute focuses on defining hope by its relationship to other variables (Carson \& Soeken, \& Grimm, 1988; Carson, Soeken, Shanty, \& Terry, 1990; Herth, 1989; Mickley \& Soeken, 1993; O'Malley \& Menke, 1988; Stoner \& Keampfer, 1985). O'Malley \& Menke (1988) conducted a correlational study concerning the relationship of perceived stress from an acute myocardial infarction and perception of hope with seven persons and found no statistically significant findings. The researchers theorized that denial may be the reason for the study results (O, Malley \& Menke, 1988). This reviewer questions the legitimacy of such theorization considering the small sample size $(N=7)$. Such theorization from the findings violates statistical rules of the totality paradigm.

Herth (1989) conducted a descriptive correlational study with 120 adults (over 21 years of age) undergoing chemotherapy. Herth investigated the relationship between hope and coping and a signific ant positive relationship was found between hope scores and coping response. In addition, strength of religious belief and performance of family role responsibilities were significantly related to hope. 
The importance of religiousness and spirituality in relation to hope was studied by Mickley \& Soeken (1993). These researchers conducted a comparative study with 25 Hispanic-American women and 25 AngloAmerican women with breast cancer to compare the women on selected religious variables and a measure of hope. The only significant difference found between the two groups was that Hispanic women scored higher in intrinsic religiousness (Mickley \& Soeken, 1993). The authors suggest from the findings that nurses need to incorporate religious beliefs into health-care practices as a method of mobilizing hope in cancer patients (Mickley \& Soeken, 1993).

Carson, Soeken, \& Grimm (1988), with a correlational design, studied the relationship between hope and spiritual well-being in a convenience sample of 197 healthy young people between the ages of 19 and 45 years of age. Hope was found to be statistically significantly related to both religious and existential dimensions of well-being on the Spiritual Well-Being Scale at the $>p$. 001 level. The authors suggest nursing needs to provide spiritual care focusing on spiritual needs to develop hope in patients (Carson, Soeken, \& Grimm, 1988).

Carson, Soeken, Shanty, \& Terry (1990) also studied hope and existential and spiritual well-being in a group of 65 adult male patients living with AIDS ranging in age from 22-70 years old. The correlation between hope and Existential Well-Being was significantly stronger than that between 
hope and Religious Well-Being. From this observation the authors noted that men with AIDS achieve their hope and spiritual well-being not so much from religious well-being as from primarily existential well-being (Carson, Soeken, Shanty, \& Terry, 1990).

This empirical-based research on spirituality and existential well-being and their relationship to hope lends insight into the intangible processes involved in the processes of hoping, even though this research seeks to isolate those processes as attributes which can be measured. The meaning of an individual's religious beliefs and spirituality and these beliefs' interconnection with hope needs further exploration through a phenomenological research approach focusing on the lived experience of hope and spirituality.

Stoner \& Keampfer (1985), using a cross-sectional survey design, studied 55 cancer patients to determine the relationship between recalled life expectancy information and hope. Individuals having no recollection of receiving information regarding their prognosis were more hopeful (Stoner \& Keampfer, 1985). The authors suggest the findings support further investigation of life expectancy as a factor influencing hope in cancer patients; with a potential for the development of therapeutic nursing interventions to promote hope (Stoner \& Keampfer, 1985).

Developing nursing intervention strategies to inspire hope has been a research focus for nurse researchers (Dufault \& Marocchio, 1985; Herth, 
1990, 1993; Yancey, Greger, \& Coburn, 1994). These authors also focused more on hope as a life process rather than an attribute.

Dufault \& Martocchio (1985) developed a model of hope to guide nursing interventions based on clinical data collected over a 2-year period on 35 elderly (65 years or older) cancer patients. Dufault \& Martocchio conceptualized hope as having two spheres with common dimensions. The spheres are generalized and particularized hope. Generalized hope is a sense of future beneficial developments. It is broad and is not linked to any particular object of hope. Particularized hope is concerned with a valued outcome and has an object of hope. The common dimensions within these two spheres of hope include the affective, cognitive, behavioral, affiliative, temporal, and contextual dimensions (Dufault \& Martocchio, 1985). Dufault \& Martocchio defined hope as, "a multidimensional dynamic life force characterized by a confident yet uncertain expectation of achieving a future good which, to the hoping person, is realistically possible and personally significant" (Dufault \& Martocchio, 1985, p. 380). This life process conceptualization of hope adds to the nursing literature and contributes to a more comprehensive understanding of hope. However, the authors contradict themselves when they define hope as "a multidimensional life force," but then go on to isolate into particular parts this dynamic life force. Yancey, Greger, and Coburn (1994) in an exploratory pre-and posttest design studied the affect of an adult cancer camp experience on levels 
of hope, perceptions of social support, coping strategies, and mood states of 32 first time attenders at the camp. No significant differences between precamp and postcamp scores were found. A serendipitous finding of the study, however, was that some campers who previously had refused to attend monthly cancer support group meetings began attending them postcamp. These people acknowledged the beneficial aspects of the support and friendship they experienced from other patients with cancer. Although this study did not contribute specific information concerning hope, the serendipitous finding suggests the importance of interpersonal relatedness for people experiencing cancer and serious illness, as has been found in other studies (Miller, 1989; Raleigh, 1980, 1992).

In a longitudinal study on the meaning of hope, the influence of specific background characteristics on hope, and identified strategies that are used to foster hope in family caregivers of terminally ill people, Herth (1993) identified hope as a life process. Herth defined hope from the findings as "a dynamic inner power that enables transcendence of the present situation and fosters a positive new awareness of being" (Herth, 1993, p. 538).

Data from this study with 25 adult care-givers (ages 21-83) were reduced into six hope-fostering categories and three hope-hindering categories. The hope-fostering categories included: (a) sustaining relationships which were ongoing and supportive; (b) cognitive reframing 
using thought processes to reappraise, restructure, and transform threatening perceptions into a more positive frame; (c) time refocusing which involved changing one's perception of space and span of time and focusing more on living one day at a time and less on the future; (d) attainable expectations which included a sense of 'being with' the person who was dying and less on 'doing for' as death approached; (e) spiritual beliefs which included belief in a power greater than self or a natural order to the universe; and (f) uplifting energy which encompasses both a physical and psychological dimension involving learning to balance available energy by participating in strategies such as posting positive notes, listening to music, and reliving favorite activities (Herth, 1993).

Hope-hindering categories for these caregivers included: (a) feeling isolated from significant others; (b) concurrent losses occurring simultaneously with their caregiving leading to a feeling of overwhelming grief; and (c) poorly controlled symptom management of the terminally ill family member, particularly unrelenting pain, continuous vomiting, and increased agitation (Herth, 1993).

This study suggests the interdependent nature of the hoping process and also gives credence to Marcel's $(1962,1965)$ philosophical principle that when "there is much to take to heart" hope is at its greatest tension. Again the importance of interpersonal connectedness in the hoping process is brought out in the findings. 
The importance of such interpersonal connectedness in the process of hoping was found by Herth (1990) in another descriptive study exploring the meaning of hope and identified strategies used to foster hope in a convenience sample of 30 terminally-ill adults using a semi-structured interview and the Herth Hope Index. The definition of hope synthesized from the findings was, "Hope is an inner power that facilitates the transcendence of the present situation and movement toward new awareness and enrichment of being" (Herth, 1990, p. 1256).

There were several qualitative nursing studies found in the literature focusing on hope as a life process that needs support and maintenance from nursing intervention (Ersek, 1992; Fryback, 1993; Hall, 1990; Hinds, 1988; Miller, 1989; Owen, 1989). Miller (1989) conducted a descriptive study of 60 persons ( 38 to 83 years of age) who had been critically ill. The purpose of the study was to determine what mechanisms they used to maintain or increase hope. Data were reduced into nine hope-inspiring categories: (a) cognitive strategies, which included using thought processes to buffer threatening perceptions; (b) a mental attitude of determinism which included having a conviction in a positive outcome; (c) a philosophy of life that included feeling life has meaning and growth results from crisis; (d) spiritual strategies involving beliefs and practices enabling transcendence of suffering; (e) relationships with caregivers that gave a constructive view of the patient, confidence in therapy, and expectations that the patient could 
manage difficulty; (f) family bonds which sustained relationships with loved ones; (g) a sense of being in control; (h) goal accomplishment with desired activities and outcomes to attain; (i) and miscellaneous strategies such as distraction and humor which thwarted feelings of despair (Miller, 1989).

Threats to hope identified by the respondents included: (a) physical evidence of setbacks; (b) feeling no one cares; and, (c) negative self-talk (Miller, 1989). This qualitative study identified that the most frequently identified sources of hope were family, significant others and religion and faith (Miller, 1989). The findings are informative, but are written at differing levels of discourse which distracts the reader and limits the scientific usefulness of the themes.

Owen (1989) used a qualitative methodology, specifically a grounded theory approach, to develop an understanding of the meaning of hope for patients with cancer. Owen interviewed six oncology clinical nurse specialists (ages 32 to 45 ) about their clinical experiences with patients with cancer that were hopeful. From thematic analysis of the data a conceptual model for hope in persons with cancer was developed. The overall unifying component of the model was the concept of energy (Owen, 1989).

Owen's research and subsequent construction of a model of hope for patients with cancer gives rise to two concerns. The first concern is related to the fact that the model was constructed from data given by the nurses and not the people who did have cancer. Descriptions of the lived 
experience must come from those living it if the data is to be noteworthy. The second concern is that a theoretical framework is not explicitly articulated for the model, although symbolic interactionism is the basis for the grounded theory methodology.

Another grounded theory qualitative study to explore the processes of hoping in adults undergoing bone marrow transplantation was conducted by Ersek (1992). Ersek interviewed 10 men and 10 women between ages 20 to 58 using purposive sampling of those who had experienced this lived situation. The conceptual model for hope that Ersek described was termed "The dialectic of maintaining hope" (Ersek, 1992, p. 887). This dialectic of maintaining hope contained two core categories that are contradictory processes: Dealing With It and Keeping It In Its Place. Dealing with it is a process of working through the threat. Keeping it in its place is the process of managing the impact of the disease and its treatment by controlling one's response to the disease and therapy (Ersek, 1992).

The dialectic of maintaining hope is a conceptual construction which brings to light the paradoxical life process of hoping. A further contribution to nursing literature could be made by analyzing this model through the lens of nursing theory.

Hall (1990) addresses the difficulty of maintaining hope for those diagnosed as terminally ill in a study conducted with 11 men who were in stage 2 (asymptomatic) HIV disease. Hall herself had also received a 
diagnosis of metastatic cancer 7 years before conducting this study. She drew from this subjective view concerning hope as well as from the data from interviews with her informants. The inducted definition of hope from Hall's (1990) study is this:

The underlying dilemma of hope for the diagnosed terminally ill person is how to establish an inextricable interconnection between the present and the future, and a strong feeling of optimism often in the face of dire predictions. Specifically, possessing hope involved:

1. Having a future life in spite of the diagnosis.

2. Having a renewed zest for life.

3. Finding a reason for living, usually one that was not evident before.

4. Finding a treatment in the professional or alternative care system that one believes will contribute to survival. (p. 183) Health for people with a terminal diagnosis was studied by Fryback (1993) using a naturalistic design and Newman's theory of health as a conceptual framework. The participants were 10 men and five women who had cancer or AIDS (ranging in age from $20-76$ years). The findings of this study as they relate to hope are that the informants identified hope as being an essential component of health. Hope helped them face the challenges of their lives. "One way that they maintained their struggle with their diseases 
and continued to enjoy their lives was through their hope for the future" (Fryback, 1993, p. 150). Thus, the researcher concludes that a way for nursing to promote the health of terminally ill patients is through developing interventions promoting hope (Fryback, 1993).

Adolescent hopefulness in illness and health was studied by Hinds (1988). Grounded theory methodology was used to generate and verify a definition of adolescent hopefulness. Three separate adolescent populations were sampled and data was collected over a two-year period by the same investigator using interviews, observations, and health records. A total of 117 adolescents were involved in the three studies. The final inducted definition of adolescent hopefulness became, "the degree to which an adolescent possesses a comforting or life-sustaining reality-based belief that a positive future exists for self and others" (Hinds, 1988, p. 85).

Nursing Research Studies-Simultaneity Paradigm

Five studies on hope were found within the simultaneity paradigm (Brunsman, 1987; Parse, 1990b; Smith, 1990b; Stanley, 1978, Thornburg, 1993). Of these five studies, three were conducted using Parse's theory of human becoming and research methodology, one was a phenomenological study using Parse's theory of human becoming as the theoretical perspective and the Giorgi modification of the phenomenological method of research, and one used van Kaam's existential-phenomenological approach. All five studies supported the conceptualization of hope as a paradoxical life process. 
Young healthy adults and their experiences of hope were studied by Stanley (1978) who through an existential-phenomenological approach (van Kaam's modified method) identified a structural definition of hope. The general structural definition for the lived experience of hope for 100 young healthy adults was presented as the following (Stanley, 1978):

The lived experience of hope is a confident expectation of a significant future outcome, accompanied by comfortable and uncomfortable feelings, characterized by a quality of transcendence and interpersonal relatedness and in which action to effect the outcome is initiated. (p. 165) Stanley's human science research on hope contributes to the understanding of the concept of hope, but does not add to the specific knowledge base of nursing science. Future human science research utilizing a nursing theory will contribute to understanding hope within the framework of nursing science as did the following four studies.

Brunsman (1987) studied the structure of the lived experience of hope in families with a chronically ill child using the Giorgi modification of the phenomenological method of research and Parse's theory of human becoming. The participants included two families ( 4 persons) and each family member was asked to describe individually a situation unique to her/him in which they had experienced a feeling of hope. The structure of hope uncovered in this study was "hope is the process of creating anew" 
(Brunsman, 1987, p. 115). This structure of the lived experience of hope reveals it to be a process that becomes known through an anticipation of the future. Hope is linked to concepts within Parse's theory of human becoming: imaging, enabling-limiting, and originating. No causal relationships exist among these concepts, but there is a interconnectedness among the concepts (Brunsman, 1987).

Parse (1990b) studied the lived experience of hope as a universal health phenomenon with 10 persons using Parse's theory of human becoming and research methodology. Parse (1990b) found the structure of the lived experience of hope in this study to be the following: "Hope is anticipating possibilities through envisioning the not-yet in harmoniously living the comfort-discomfort of everydayness while unfolding a different perspective of an expanding view" (p. 15).

At an even higher level of abstraction (structural integration), where the structure of the lived experience is connected with the theory of human becoming, hope is "the persistent picturing of possibles while incarnating opportunities-limitations all at once, which unfolds in viewing the familiar in a new light" (Parse, 1990b, p. 16). Conceptual interpretation moves the structure of hope to the level of theory and "hope is imaging the enablinglimiting of transforming" (Parse, 1990b, p. 16). These findings support the paradoxical life process of hope and suggest hope is intrinsic to the meaning of "imaging the will-be" (Parse, 1990b, p. 17). 
Smith (1990b) studied the lived experience of hope in families of critically ill persons using Parse's theory of human becoming and research methodology. Fifteen families of individuals hospitalized in a critical care unit were recruited and 23 individuals participated. This study was the first in which Parse's research methodology was used with groups of individuals, so dialogical engagement with the researcher was limited to 1 to 3 family members in order to obtain depth in the discussion (Smith, 1990b, audiotape).

The structure of the lived experience of hope for families of critically ill persons was "resolute intending while abiding in faith as unburdening and burdening unfolds in dwelling with the turbulence and nurturing relating surfaces a confident view of the not-yet" (Smith, 1990b, audiotape). At the conceptual integration level hope was connected to the theory as "hope is imaging the enabling-limiting of transforming" (Smith, 1990b, audiotape).

Thornburg (1993), using the human becoming theory as a nursing perspective and Parse's research methodology, examined the meaning of hope in parents of infants who had died from Sudden Infant Death Syndrome. Dialogical engagement began with the researcher asking eight parents of infants who had died to discuss the meaning that hope had for them.

Thornburg (1993) found the structure of the lived experience of hope in this study to be "moving on despite barriers in the comfort-discomfort of 
being with and apart from others while anticipating the possibilities amidst treasured moments" (p. 57). At the heuristic interpretation level of theory, hope was identified as powering connecting-separating through imaging. "Powering emerged as a concept unique to this study on hope, and hope was found to exist simultaneously with no-hope" (Thornburg, 1993, p. 66). In summary, these five research studies within the simultaneity paradigm in nursing contribute to a comprehensive understanding of the multidimensionality of the paradoxical lived experience of hope. Four of the studies used Parse's theory of human becoming as the nursing perspective and the findings contribute to the expansion of that nursing theory and knowledge unique to nursing.

This concludes the literature review on hope. From the theoretical perspectives reviewed, this author posits the following definition of hope synthesized from understandings gained from the literature and from Parse's theory of human becoming: Hope is a pushing-resisting in the comfortdiscomfort of the treasured, as persistent visions of possibles are disclosednot disclosed, cocreating new ways of moving with the familiar-unfamiliar in communion-aloneness.

This definition links hope to the theoretical structures of Parse's theory of human becoming in the following ways: pushing-resisting in comfort-discomfort of the treasured is powering the enabling-limiting of valuing; as persistent visions of possibles are disclosed-not disclosed, 
cocreating new ways is imaging the revealing-concealing of originating; and moving with the familiar-unfamiliar in communion-aloneness is languaging the transforming of connecting-separating. Therefore, at the conceptual level of the human becoming theory hope is powering the enabling-limiting of valuing as imaging the revealing-concealing of originating evolves through languaging the transforming of connecting-separating. This definition of hope links all nine core concepts of Parse's theory to hope. Implications of this linkage to the research on considering tomorrow will be elaborated on in the conclusion section of the literature review.

\section{Review of Literature on Imagination}

Imagine how it feels to always belong-belong in a diversified community, for it is the diversity

in nature that gives the web of life its strength and cohesion.

Imagine a time where everyone welcomes diversity in people because they know that is what gives community

it richness, its strength, its cohesion.

Imagine being able to relax into our connectednessinto a web of mutually supportive relations with each other and with nature....

The very fact that one can imagine these things makes them real, makes them possible.

(Adair, 1984, p. 284)

Review of the literature on imagination was conducted in nursing, philosophy, and psychology. Additional important readings were selected from references retrieved in the literature. First, general theoretical literature on imagination will be surveyed. Then, nursing theoretical literature in the totality and simultaneity paradigms will be discussed followed by general 
research studies and nursing research studies in the two prevailing paradigms.

Based within a historical perspective, three distinct conceptualizations of imagination were devised from the literature review: imagination as a human faculty; imagination as a healing modality (shamanism and imagery); and imagination (imagining) as a unitary lived experience. These three conceptualizations grounded in a historical perspective will provide the thematic framework for the literature review.

\section{General Theoretical Literature}

Webster's Ninth New Collegiate Dictionary (1990) defines imagination as a mental faculty including:

(a) the act or power of forming a mental image of something not present to the senses or never before wholly perceived in reality; (b) creative ability; (c) ability to confront and deal with a problem (resourcefulness); (d) the thinking of an active mind; and (e) a creation of the mind (an idealized or poetic creation). (p. 600)

From this definition imagination can be understood as a key capacity in developing human potential.

Philosopher Edward Casey (1976) in his book entitled, Imagining: A Phenomenological Study, outlines his view of the historical development of beliefs concerning imagination. He suggests that there exists in the history 
of Western philosophy three representative positions concerning imagination: (a) the school of thought placing imagination in a position of subordination to other mental faculties; (b) the school of thought placing imagination as a middle-range mental faculty located between perception and intellect; and (c) the school of thought placing imagination in a superior position to other mental faculties, naming it the primary creative capacity of the human mind. This review of literature will identify one philosopher in each of the above schools of thought for a brief overview on this proposed historical view of the philosophical thinking surrounding imagination.

Plato, who first fully articulated philosophical theory concerning the imagination in the West, placed imagination in the lowest rank of mental faculties. For Plato, imagining was mere supposing, a phantom or pseudoknowing (Casey, 1976). As Plato makes clear in The Republic (1991), imagination's primary product, the image, was an imitation of an imitation which needed to be regarded with suspicion. Plato described images as shadows, "And by images, I mean, in the first place, shadows, and in the second place, reflections in water and in solid, smooth and polished bodies and the like: Do you understand?" (Plato, 1991, p. 250). Plato (1991) goes on to identify four faculties in the human soul which he ranks in the following hierarchical order:

Let there be four faculties in the soul-reason answering to the highest, understanding to the second, faith (or conviction) to 
the third, and perception of shadow to the last-and let there be a scale of them, and let us suppose that the several faculties have clearness in the same degree that their objects have truth. (p. 253)

Thus, for Plato, imagination which produced images, was a perception of a shadow and a lower form of generating hypotheses. In a higher form of reason, the soul ascended above hypotheses to the idea of good.

The philosophical school which placed imagination as a mediary faculty between perception and memory included the greatest philosopher of the eighteenth century, Immanuel Kant. Kant explained imagination's mediatory role by distinguishing between two kinds of imagining: a reproductive type connected with memory and perceptual apprehension, and a productive type, which is based on conceptual thinking. Thus, imagination stands precisely between sensibility and understanding, the two major human faculties which together outline Kant's topography of mind (Casey, 1976).

Kant (1951) in the Critique of Judgement writes concerning the beautiful and the sublime and suggests the following concerning imagination:

For the feeling of the sublime brings with it as its characteristic feature a movement of the mind bound up with the judging of the object, while in the case of the beautiful taste presupposes and maintains the mind in restful contemplation. (p. 85) 
The third school of thought, which situates imagination as a primary creative capacity of the human mind, is supported in the writings of the existential phenomenologist Martin Heidegger. In his classical work, Being and Time (1962), Heidegger posits that imagination is itself the basis of our Being. He writes the following concerning imaginative projection:

Because it is primordially constituted by care, any Dasein is already ahead of itself. As being, it has already projected itself upon definite possibilities of its existence; and in such existential projections it has, in a pre-ontological manner, also projected something like existence and Being. (363)

Casey (1976) critiques these three historical philosophical views of the imagination by suggesting there is another way of viewing the role that imagination plays in the lives of humans which is less hierarchical. He suggests an alternative view of imagination which he entitles, "the multiplicity of the mental" (Casey, 1976, p. 19). He suggests that within this multiplicity there is no strict hierarchical structure of mental faculties-"only a proliferation of unforeclosable possibilities" (Casey, 1976, p. 19). Casey (1976) suggests the following concerning imagination: "Imagining occurs more frequently and more influential than we care to admit to ourselves or to others...Imagining remains inseparable from the life of mind as a whole, essential to its welfare, indeed to its identity and very existence" (p. 4). Casey (1976) suggests imagination must be evaluated on its own 
terms and from this suggestion he has generated phenomenological research on imagination which will be discussed later in this literature review.

Another historical perspective on imagination is proposed by Kearney (1987) who posits three genealogical paradigms of imagination, and then makes recommendations for a fourth paradigm of imagination moving beyond postmodern times. The three genealogical paradigms are the following: (a) the premodern image (from Plato to the Renaissance) which was conceived as a mirror reflecting reality; (b) the modern image (from German Idealists and the Romantics to the Existentialists) which was seen as a lamp projecting reality from a light source within imagination itself; and (c) the postmodern image which is a multiple looking glass reflecting endless imitations and no longer serving to reflect some pre-existing origin.

Kearney (1987) suggests the following about imagination and the postmodern era:

The very distinction between the real and the imaginary which prevailed in Western philosophy from Plato to Sartre has been virtually abolished; or as the 'postmodern' thinker would be more inclined to say, it has become 'undecidable.' Image and reality have dissolved into a play of mutual parody--to the point where we can no longer say which is which. (p. 40) Kearney suggests that imagination, as a mental faculty, needs to be reconceptualized from a humanist, self-centering imagination to a "human" 
imagination. Thus, Kearney presents a fourth historical paradigm of an ethical imagination to replace the postmodern deconstructed humanistic imagination. This paradigm of the ethical imagination would confer the ethical reality of the human right to exist as an other, the right to be recognized as a person whose very otherness refuses to be reduced to a mimicry of sameness (Kearney, 1987). Kearney is proposing a new interpretation of imagination capable of responding to the challenge of postmodernism. Such an ethical imagination would be a critical, poetic, and hermeneutical imagination (Kearney, 1987).

A critical imagination, Kearney (1987) suggests, is an imagination capable of discriminating between authentic and unauthentic aspects of post-modern culture. Such an imagination would expose the anthropocentric model of the human as sole origin of meaning and open the possibility for a more ethical relationship to the other; it would refuse to see a person as a mere copy or copier which denies a person any creative role in history; and, it would criticize the unauthentic potential of deconstruction itself, that is, its capacity to remystify the model of imitation having demystified that of origin.

A poetic imagination is an "inventive" imagination. This poetic imagination must be prepared to commit itself to the invention of a new social project: Kearney (1987) suggests: 
a project which rejects both the humanist model of willful mastery (the ideology of voluntarism) and the ontotheological model of submissive obedience (the ideology of acquiescence), and what is more, a project also capable of challenging the nihilism which increasingly informs our postmodern society of commodification (the ideology of endless imitations). (p. 44)

Kearney (1987) further suggests that a critical-poetic imagination is also a hermeneutical imagination capable of imagining what things might be like after postmodernism, and what things were like before it. A hermeneutical imagination responds to history through recognizing narratives of the past and calls for a reinterpretation of the notion of "the self." A critical-poetic-hermeneutical imagination, Kearney (1987) suggests:

bids us to tell and retell the story of ourselves....out of fidelity to the other. It is above all the other who demands that I remain responsible to myself. For if there is no longer a self to abide by its promises or covenants, there is no ethical relation to the other possible. (p. 55)

Thus, Kearney provides a futuristic paradigm of a critical-poetichermeneutical imagination and through this suggestion establishes the possibility of such an imagination historically in the present.

Within this historical evolution of world views concerning imagination, authors have addressed issues surrounding imagination as a mental faculty 
(Casey, 1974; Fischer, 1985; Heidegger, 1962; Huizinga, 1950; Kiros, 1994; Knowles, 1985; Lynch, 1965, 1985; MacKenzie, 1983; Moore, 1994; Murray, 1986; Schalow, 1992). One of the main concerns addressed in the literature on imagination as a mental faculty is the difference between fantasy and imagination.

Knowles (1985) addresses this concern by first pointing out the differences in fantasy and imagination. Fantasy, he sees as such acts as daydreaming, dreaming, and wishful thinking. At the extreme of fantasy are delusions and hallucinations. An essential constituent of fantasy is the forgetting of or absenting oneself from the life context. It is out of fear that fantasy emerges and this fear is a fear of one's vulnerability and one's fear of confronting things in life the way they are. If fear is strong enough a person may fail to respond to the possibilities of growth (Knowles, 1985). Fantasy, thus, is a process of disregarding one's life context, and becoming immobilized with the fear of seeing things as they are.

In contrast to fantasy, imagination includes a form of perceiving, but it also includes a willingness and a move toward action. Knowles (1985) describes imagination as openness, willingness, and movement encompassing an imaginative mode (the act of imagining) and an imaginative life style (movement).

The openness of imagination is an opening of perception where one looks at other ways of being or doing. Willingness involves the willingness 
to become engaged in the task, the overcoming of resistance and ambivalence. Movement occurs in imagining the solution; for in imagining it one is already moving to carry it out. Knowles (1985) writes:

In fact, we might say that imagination is a particular way of moving in the world. In contrast to the plodding movement of depression or the frantic movement of hysteria, imagination is a way of moving in harmony with the rhythm of the world and others. (p.61)

Fischer (1985) concurs with the position that the imagination is very different from fantasy, and involves openness, willingness, and movement. She suggests that imagination is a fundamental way of knowing and is central to human transformation. This movement toward transformation occurs due to several facets of the life of the imagination: (a) imagination is the center of conversion; (b) imagination opens one to compassion; (c) imagination is the source of hope and human possibility; and (d) imagination grounds a contemplative vision of life.

Imagination as the center of conversion is illustrated by Fischer (1985) through examples of the power of parables and life stories. Parables are the language of the imagination. The parables of Jesus illustrate the power of the parable to transform individuals through participation in the truth it conveys. "We do not fully know an image, ritual, or story from the outside. Rather, we must enter into it to grasp its truth" (Fischer, 1985, p. 31). It is 
this quality of participation, Fischer suggests, that makes biography and autobiography a powerful force for conversion. "Life story is embodied truth, the language of the imagination" (Fischer, 1985, p. 32).

Imagination's role of opening one to compassion is accomplished by embracing the situations and feelings of other persons and taking their pain into our own person and history. Thus, in opening to compassion, one enters imaginatively into other people's lives (Fischer, 1985).

The imagination nurtures hope and human possibility through being open to the new. It envisions new possibilities. "The imagination takes images from the past and shapes them into new constellations. It calls out the possibilities embedded within the actual" (Fischer, 1985, p. 36).

Imagination as a grounding for the contemplative life is accomplished through opening an individual to the depth of life. Imagination fosters attention on the real and helps one see the wonder in all things. "Contemplation keeps alive a sacramental vision of life, the faith that the particulars of existence can be vessels of grace" (Fischer, 1985, p. 38).

The role imagination and contemplation have in the sacramental vision of life is further explored by Moore in, SoulMates (1994) where he suggests that the very nature of "soul" is the imagination. Moore (1994) identifies soul as that quality of life which inspires depth, intimacy and deep-seated relationships. In one's intimate relationships, Moore suggests, the most "within" dimensions of oneself and the other are engaged (Moore, 1994). 
This intimate engagement of the depth of a person, Moore attributes to the imagination, which provides direction and "a quality of life through a kind of poetics, a language of image and symbol" (Moore, 1994, xiv). Moore (1994) writes: "It is my conviction that slight shifts in imagination have more impact on living than major efforts at change. Deep changes in life follow movements in imagination" (Moore, 1994, p. viii).

Lynch (1965) suggests that the first task of the imagination is to find a way through lies and fantasy into fact and authentic existence. The second task it has is to create perspective for the facts it has found. The imagination will always suppose that there is a fact and a possibility that is not yet known. Thus, imagination grounded in openness, willingness, and movement, provides for an authentic, intimate existence. This authentic existence is accomplished through the imagination by uniting the three great moments of time; the present, the past, and the future (Lynch, 1985). "It should be expected that whenever the present of human beings reaches the stage where it finds good company in itself, it will look for further support in the possession of a past and a future. The imagination will go back to its past and forward to a future to build a larger and larger image of itself" (Lynch, 1985, p. 70).

The possibility of authentic self-construction is one of a human being's intrinsic properties. This self-construction must be as free as possible from judgment so that, through creativity and imagination, human beings can 
reveal otologically the possibility of freedom (Kiros, 1994). According to Kiros (1994), human beings are value-creating possibilities. "As possibilities, humans can create values that reflect their authentic desires, desires that power the self to tenaciously and courageously seek freedom as selfrealization" (Kiros, 1994, p. 100).

Creating values which reflect authentic desires requires authentic thinking. Such authentic thinking is accomplished through imagining and developing norms that are self-constructed and have the capacity to give one a stable, self-controlling, responsible, and original existence (Kiros, 1994). Such an original existence creates personal identity (Mackenzie, 1983). Mackenzie (1983) posits that personal identity is more than bodily identity or brain identity, but consists of stages of the same person. In other words, personal identity is bound up in an authentic, "continued existence." This "continued existence" is brought together by the imagination in its ability to disclose the individual by projecting meaning through time; past, present, and future. With the creative capacity of the imagination, time facilitates the disclosure of being (Heidegger, 1962; Schalow, 1992).

Heidegger (1962) points out that authentic existence is not possible every day of one's life. He speaks of "the they" existence being that in which one imagines one's life as it has been imagined by one's elders, forefathers and foremothers, founding fathers and founding mothers and so on. Heidegger believes that to move from this style to a critical owning and 
shaping of one's own life, is to move toward a more authentic mode of existence. In other words, the unauthentic mode of life is that upon which one builds and with which one functions. In time, with sufficient amount of experience, one may move to question the cultural mores and norms. This is done, however, within the understanding and parameters of what one has learned (Murray, 1986). Concerning this critique of one's life and way of being, Murray (1986) suggests the following:

This is another way of pointing up the famous hermeneutical circle of which phenomenologists speak, wherein one employs what one has been given to critique what one has been given. We grow toward authenticity by using and even transcending what has been given to us so that we may from within rethink what has been given us and perhaps even better it. (p. 69) Heidegger also views as important the anticipation and the imagining of one's own death as a way of becoming free of "the they" and becoming one's own self. He writes (1962):

Anticipation, however, unlike unauthentic Being-towards-death, does not evade the fact that death is not to be outstripped; instead, anticipation frees itself for accepting this. When, by anticipation, one becomes free for one's own death, one is liberated from one's own lostness in those possibilities which may accidentally thrust themselves upon one; and one is 
liberated in such a way that for the first time one can authentically understand and choose among the factical possibilities lying ahead of that possibility which is not to be outstripped. (p. 308)

In this statement, Heidegger makes clear his belief that in anticipating and accepting the fact of one's own death, an individual opens oneself to a variety of possibilities for living authentically. This living of the authentic self is expressed through disclosure (disclosedness) of Dasein (Being) (Heidegger, 1962). Such disclosedness involves imagination, understanding, and language.

Language and its relationship to imagination and understanding is emphasized in the writings of Edward Murray (1986) in his work entitled, Imaginative Thinking and Human Existence. Murray (1986) states:

Without words, no thing may be; with words, much may be....It will be remembered that language operates within the horizon sketched out or drawn by the human imagination. Thanks to that language, whether it be in the sciences, the arts, or the commonplaces, we set presences of all kinds present. These are the realities with which humankind must deal, but that reality is not what it is independent of the human and human consciousness. Their being what they are emerges from the confluence of human imaginative projections, the human's 
imaginative and informed sayings, and the presences that we have brought about. (p. 83)

Murray (1986) further suggests that the infinite human needs presences, that presences need language and sayings, and that language and sayings need human consciousness with its imaginative horizons. In giving an example of this Murray (1986) writes:

When one says something, lays it out in the open, gathers it up for the speaker and listener, a presence is effected. It might be the presence of a person, a thing, a relationship, a concept. To word the gathered entity as a hill or river is to bring the gathered entity into the forefront of the discussion as a hill or river. (p. 81)

Murray's (1986) discussion on imaginative thinking concludes that personal integration (self-construction) and societal integration (societalconstruction) call for the recognition of the legitimacy and necessity of both logical and imaginative thought at all levels in an ongoing dialectic. In every human one finds both the logical and imaginative dimensions of thought operative. Human thought is engaged in a dialect between both kinds of thinking which appear through the logic of language and the use of metaphor.

"A metaphor is a "trope or figure of speech that includes in it a 'twist' of word meaning. A word or phrase is transferred from something it usually 
designates to something it may designate only by an implicit comparison or analogy" (Smith, 1992, p. 48). Murray (1986) gives examples of imaginative, metaphorical language which affects peoples lives; the metaphor in story, myth, symbols, and religion.

Murray links hope and imagination together in an interconnectedness of envisioning when writing that imaginative thinking bids the person "to look far, to see far, to think far into life. And would urge the person to imagine even in the darkest of moments the light of hope that makes integral living possible" (Murray, 1986, p. 255).

The importance of language in creating meaning and reality through the imagination is highlighted further by Johan Huizinga is his classic work, Homo Ludens (1950). He writes:

Language allows humans to distinguish, to establish, to state things; in short, to name them and by naming them to raise them into the domain of the spirit. In the making of speech and language the spirit is continually "sparking" between matter and mind, as it were, playing with this wondrous nominative faculty. Behind every abstract expression there lie the boldest of metaphors, and every metaphor is a play upon words. Thus, in giving expression to life humans create a second, poetic world alongside the world of nature. (p. 4) 
In addition to imagination being connected to language and metaphors, it is also specified as a mechanism for healing. Imagination as a healing modality is noted in the general theoretical literature on shamanism and various forms of imagery (Achterberg, 1985, 1990; Brown, 1989; Clouser \& Hufford, 1993; Magnuson, 1987; McClenon, 1993; McKellar, 1957; Ornstein \& Sobel, 1989). The characteristic in common to the uses of imagination in healing (shamanism, guided imagery, relaxation training, and others) noted in this literature is the active participation of the person who is the focus of the healing.

The capacity to generate health through creative imagining is supported in Ornstein and Sobel's book, Healthy Pleasures (1989). These authors outline simple, daily routines, such as taking a nap, they believe individuals can do to positively affect health through enjoying pleasure.

Ornstein and Sobel (1989) conclude, "Oscar Wilde wrote that 'simple pleasures are the last refuge of the complex.' They are more than an oasis in life: They may be the best defense against illness and a way to lengthen life" (p. 238). Thus, through such human activity it is suggested that individuals can become their own shaman, sculpturing their own health. This sculpturing of one's own health entails the use of imaginative thinking. In summary, imagination as a mental faculty is viewed as the capacity to spark new ways of being in the world, as a driving spirit of openness moving individuals toward endless possibility, as the ability to form 
authentic, unique, and intimate relationships with others and the community, and as a playful, metaphorical creative force shaping civilized life. Imagination is viewed as essential to the life of the mind itself.

Imagination as a healing modality can be conceptualized as spiritual healing affecting both individuals and communities, involving relationships as well as physical distress. Or, the healing modality may be personal healing accomplished through the use of images loccurring through different mediums) which activate healing resources within the body. The use of imagination in healing surfaces the issues of the mind-body interconnectedness and the need for further study.

Nursing Theoretical Literature-Totality Paradigm

Theoretical literature in nursing pertaining to imagination as a mental faculty focuses on the imaginative mediums of envisioning and the use of myth, metaphor, storytelling, poetry, and imagery in influencing leadership issues, education issues, and caring issues in nursing. This literature describes how imagination can be instrumental in creating change and transformation in nursing service and nursing education; and, how as a healing modality it can be useful in providing nursing care (Birx, 1994; Bunkers, 1993; Bunkers, et al., 1992; Bunkers \& Koerner, 1988, 1990; Gagan, 1984; Gilmore, 1993; Koerner \& Bunkers, 1992; Koerner, Bunkers, \& Nelson, 1991; Kuhn, 1995; Larkin \& Zahourek, 1988; Mast, 1986; Murphy \& DeBack, 1991; Tuyn, 1994; Valiga, 1994; Vines, 1988), but it 
does not add to the understanding of the conceptual essence of imagination and will not be included here in the discussion.

Nursing Theoretical Literature-Simultaneity Paradigm

Imagination, from the simultaneity perspective, is not viewed separately as a mental faculty or healing modality, but is seen as a unitary lived experience. A nursing perspective positing imagination as a unitary lived experience is explicated in nurse theorist Rosemarie Rizzo Parse's theory of human becoming (Parse, 1981, 1992, 1995a). Imagining is central to the three principles of the human becoming theory as well as to the practice methodology, and these principles were discussed in detail in the introduction to this research study.

Living the unitary lived experience of imagining occurs in using the Parse practice methodology in preparing to be in true presence (a reflective loving and focusing with another). The nurse first centers self by imagining the other person as one in the process of unitary becoming. This centering prepares the nurse to be with the other. The nurse lives true presence as the other is illuminating meaning, synchronizing rhythms, and mobilizing transcendence. This mobilizing transcendence "may happen in the presence of the nurse through creative imagining (anticipatory projecting), affirming self (I will and I can), and glimpsing the paradoxical (laughing)" (Parse, 1992, p. 139). An example of this is that the other may discover a new way of 
being with a particular situation as they come to view a situation differently and discover new meaning, which coshapes the reality of the situation. Thus, both Parse's theory of human becoming and Parse's nursing practice methodology explicate the unitary lived experience of imagining.

\section{General Research Studies}

A significant qualitative research study related to imagination was conducted outside of nursing in anthropology (Thalberg \& Pellow, 1979). Imagination as a mental faculty influencing the pattern of one's life was studied by Thalberg and Pellow (1979) who conducted a descriptive field study with thirty-nine women in Accra, Ghana for the purpose of understanding personal independence. The authors defined personal independence as what it would mean to manage one's own life. Findings indicated an inability of the women to take advantage of opportunity (Thalberg \& Pellow, 1979). The researchers labeled this inability as a cognitive shortcoming (Thalberg \& Pellow, 1979).

Further analysis of the culture in which the study took place revealed that the failure of the informants to imagine themselves doing something different was not a case of losing autonomy because of constraint, inability, insufficient means, lack of opportunity, prohibitions, or lack of knowledge. Instead, due to the irresistible pressure of custom, these women had a cognitive conceptual barrier to envisioning options for themselves. "Although the informants were not coerced, had the ability, means, 
opportunity, legal right and knowledge to act differently, they failed to make the negative judgment that they 'need not' follow tradition" (Thalberg \& Pellow, 1979, p. 15).

Thalberg and Pellow's (1979) conception of the need for negative judgment in envisioning alternatives is supported in the writings of noted existential philosopher Jean Paul Sartre (1991), who posits that visualizing options is a form of negative judgment which involves thinking that things can be different. Negative judgment is a detachment from the way things are to how they might be. Thus, autonomous behavior depends upon one's ability to imagine and conceptualize alternatives (Thalberg \& Pellow, 1979).

Casey's classic study entitled, Imagining: A Phenomenological Study (1976) supports the conceptualization of imagining being as a unitary lived experience. This conceptualization is consistent with the simultaneity view. Casey (1976) used the phenomenological method of research as conceived by Husserl to explore the lived experience of imagining. Examples of three first hand experiences of imagining were written down by Casey immediately after the experiences took place. These were used as the basis for the phenomenological analysis of imagining.

Casey (1976) posits that a basic principle to apply in achieving a coherent and complete description of imagining is the principle of intentionality. As an intentional act, imagining has two phases, the "act phase" and the "object phase". Casey points out that these two phases, 
while distinguishable for the sake of analysis, require each other's presence and coexist in the imaginative experience. Thus, the two phases are lived as a unity.

In analysis, the "act phase" of imagining, a content is apprehended. There are three primary ways a person can imagine content: imaging, imagining-that, and imagining-how. To "image" is to form an imaginative presentation whose content occurs in the specific modalities of visualizing, audializing, smelling, feeling, and tasting. "To image, then, is to imagine in a sensory-specific way" (Casey, 1976, p. 41). Imagining-that involves imagining individual objects or events that constitute a situation. "When we imagine things as standing in such relations, we imagine that these relations obtain; we suppose that something is the case, and in this way a given state of affairs forms the specific content of our imaginative experience" (Casey, 1976, p. 42). Imagining-how is similar to imagining-that, but there is an active aspect of imaging-how not found in imagining-that. "To imagine how is to imagine what it would be like to do, think, or feel so-and-so, or to move, behave, and speak in such-and-such ways" (Casey, 1976, p. 45). Casey concludes the discussion on the "act phase" of imagining by stating that imaging, imagining-that, and imagining-how are three alternative ways imagining occurs in human experience. At any given moment a person is either imaging, imagining-that, or imagining-how, but not more than one of these at a time (Casey, 1976). 
The object phase of imagining includes the imagined content, imaginal margin, and the image or mode of givenness (Casey, 1976). Imagined content is that aspect of the total imaginative presentation upon which one's attention focuses. "It is just this that we imagine and not something elsewhere 'just this' means what is thematized in the imaginative presentation" (Casey, 1976, p. 49). The imaginal margin is the fading fringe found at the outer limit of specific imagined content; it cannot be given any location. "We cannot say of the imaginal margin either that it is, or that it is not, spatial or temporal; indeed nothing definite can be said of it at all" (Casey, 1976, p. 55). By image is meant the mode of givenness pertaining to the total imaginative presentation. A presentation may appear in differing degrees of clarity; the texturality (surface quality may be different; and the degree of directness with the imaginative presentation may vary. "The image or mode of givenness is, in briefest terms, the manner of presentation, that is, the specific way in which imagined content and the imaginal margin are together given to the imaginer's consciousness" (Casey, 1976, p. 56).

In concluding his description of the "act phase" and "object phase" of imagining, Casey (1976) stresses the unity of the imagining experience with the following:

One phase presupposes the other. It is only upon analysis that the two phases gain distinctness from each other. But if analysis is to reflect the original experience accurately, it must 
treat both intentional phases as of equal importance, since it is the coordinated activity of the two together that brings about imagination as a single experiential whole. (p. 58)

Casey (1976) identifies the following three pairs of traits that contribute to identifying the structure of the lived experience of imagining: (a) spontaneity and controlledness; (b) self-containedness and self-evidence; and $(c)$ indeterminacy and pure possibility. By spontaneity is meant that imagining may arise in an unsolicited manner. But, controlledness also exists since an imaginative sequence can be terminated merely by wishing to do so.

Self-containedness presents itself as a single, self-enclosed unit of imaginary experience. "To be experienced as self-contained in imagination is to be experienced as not needing clarification of supplementation by subsequent experiences" (Casey, 1976, p. 35). Self-evidence exists in that the object imagined is just what it is supposed to be and not something else. Self-evidence is related to self-containedness. "If I image, say, a five-legged turtledove, I am presented with something that is at once self-contained and unambiguously just the object I set out to imagine. I do not need to seek for further evidence to strengthen my conviction that I am in fact imagining such a creature" (Casey, 1976, p. 94).

Indeterminacy and pure possibility are related to each other in that they are mutually facilitating. By "indeterminacy" is meant a lack of 
specifiable form or content. "Such indefiniteness within given limits exemplifies the openness that the element of indeterminacy introduces into imaginative experience" (Casey, 1976, p. 37). Pure possibility pertains to the fact that whatever one imagines might be, but which, in fact, is not-yet (Casey, 1976). Casey (1974) suggests that "imagining is entertaining oneself with what is purely possible" (p. 18). In imaginative presentations no imaginable options are ruled out-anything and everything becomes possible (Casey, 1974).

Thus, Casey's $(1974,1976)$ description of the structure of imagining identifies important characteristics including: (a) imagining is a unitary lived experience; (b) there is an openness to possibilities in the imaginary experience; (c) imaginative content can be spontaneous or/and controlled; (d) imaginative content needs no proof other than that it exists once it is experienced; and (e) imagining can occur as imaging, imagining-that, and imagining-how. This phenomenological study explicates in detail the structure of the lived experience of imagining.

Nursing Research Studies-Totality Paradigm

Imagination as a mental faculty affecting a person's pattern of living has been a focus of nursing research. Such research has focused on imagery and creative imagination as they relate to changes in patterns of living (Bucher, 1993; Fleury, 1991; Smith, 1988). 
Fleury (1991) used a grounded-theory approach with 29 adults (18 men and 11 women between 25-79 years of age) to identify, describe, and provide an analysis of the social and psychological processes used by individuals to initiate and sustain cardiovascular health. This reported research demonstrates the key role imagining may play in behavior change. Emerging from the data was a construct termed, "empowering potential" which was the basic social process explaining individual motivation to initiate and sustain cardiovascular health. "Transforming change refers to the construction of future goals in creating desired ways of being" (Fleury, 1991, p. 290). The weakness of the study lies in the fact it does not use a nursing theoretical framework, and thus, does not articulate clearly what the nursing care implications are for the model of "empowering potential."

The effects of imagery on learning a specific nursing skill was studied by Bucher (1993). From this research with 108 second-semester sophomore nursing students (ages 19-21) the investigator suggests that mental imagery combined with physical practice may lesson the time needed to master a technical skill. Two further suggestions included: (a) since the evaluation of imagery vividness and imagery control is highly subjective, further exploration of the use of guided imagery in education using qualitative research methods should be considered; and (b) the use of mental imagery plus practice should be considered when developing strategies for skill acquisition (Bucher, 1993). 
Smith (1988) studied the effects of high frequency, low frequency, and ambient sound environments on vividness and creativity of imagery using Rogers' science of unitary human beings as a framework with 108 subjects (90 men and 90 women between $18-25$ years of age). Smith proposed that, according to Rogers' theory, creative imagination is a human field manifestation of higher frequency, shorter wavelengths (Smith, 1988). Four hypotheses regarding this proposition were subjected to analysis of covariance with none of the hypotheses being statistically supported. Smith (1988) suggests that qualitative research methodologies may be more appropriate to develop insight into the experience of creative imagination (Smith, 1988).

Research focusing on the imagination as a healing modality focuses on guided imagery, relaxation and visualization, and imaging (Arathuzik, 1994; Butcher \& Parker, 1988; Mast, 1986; Thompson \& Coppens, 1994; Wynd, 1991). This research does not add to the essence of understanding imagination, but focuses on imagination as a healing modality. Since the research does not focus on the essence of imagination itself, it will not be discussed here. Imagination as a mental faculty and as a healing modality, however, needs further study using nursing theoretical frameworks. Mast (1986) supports this proposition when in evaluating the status of research on imagery she writes, "nursing models based on assumptions of ongoing 
interaction between the mind, the body and the environment provide conceptual frameworks from which imagery research could take place" (p. 120).

Nursing Research Studies-Simultaneity Paradigm

Three nursing studies, where in the findings the unitary lived experience of imagining was explicated, will be reviewed within the simultaneity paradigm in nursing (Parse, 1990b, 1993, 1994a). These three studies have been conducted by Rosemarie Rizzo Parse guided by her theory of human becoming.

Parse $(1990 \mathrm{~b})$ studied the lived experience of hope in ten persons (three women and seven men ages 23 to 75). Using Parse's research analysis methodology, the following structure of the lived experience of hope was formulated: "Hope is anticipating possibilities through envisioning the not-yet in harmoniously living the comfort-discomfort of everydayness while unfolding a different perspective of an expanding view" (Parse, 1990b, p. 15).

At a higher level of abstraction (structural integration), where the structure of the lived experience is connected with the theory of human becoming, hope "is the persistent picturing of possibles while incarnating opportunities-limitations all at once, which unfolds in viewing the familiar in a new light" (Parse, 1990b, p. 16). At both of these levels of abstraction it can be noted that imagining is indicated in "anticipating the possibles" and in 
"persistent picturing of possibles." Conceptual interpretation moves the structure of hope to the level of theory and hope is "imaging the enablinglimiting of transforming" (Parse, 1990b, p. 16). Thus, the lived experience of hope is part of "imaging the will-be" (Parse, 1990b, p. 17).

Parse (1993) studied the experience of laughing in 30 persons over 65 years of age using van Kaam's modification of the phenomenological method. The structural definition of laughing synthesized from the data was the following: "Laughing is a buoyant immersion in the presence of unanticipated glimpsing, prompting harmonious integrity which surfaces anew in contemplative visioning" (Parse, 1993, p. 41). Parse identifies contemplative visioning as linked to the human becoming principle "Structuring meaning multidimensionally is cocreating reality through the languaging of valuing and imaging" (Parse, 1981, p. 69). Thus, laughing is intimately interconnected with the lived experience of imagining. Parse (1993) states, "Picturing an event in which incongruities arose creates laughter bringing new meaning to the situation. The laughing surfaces through the remembered moment; thus, laughing is lived multidimensionally as the languaging of valuing and imaging structure meaning" (p. 42). These findings show that the unitary lived experience of imagining is integral to laughing which is a universally lived experience of health.

Parse (1994a) studied the lived experience of laughing and health using the human becoming theory and research methodology. The following 
structure of laughing and health for 20 participants was formulated: "The lived experience of laughing and health is a potent buoyant vitality sparked through mirthful engagements, prompting an unburdening delight deflecting disheartenments while emerging with blissful contentment" (Parse, 1994a, p. 59).

At an even higher level of abstraction (structural integration), where the structure of the lived experience is connected with the theory of human becoming, laughing and health "is an exuberant exhilaration surfacing as jovial involvements shift perspectives unfolding plenitude" (Parse, 1994a, p. 59). It is at this level of abstraction that the connection of laughing and health with imagining is obvious. Conceptual interpretation moves the structure of laughing and health to the level of theory and laughing and health is "languaging the enabling-limiting of powering as connectingseparating in transforming of imaging evolves through originating the revealing-concealing of valuing" (Parse, 1994a, p. 59).

Imagining becomes central in understanding the shifting of the participants' visions. The core concept of "mirthful engagements prompting an unburdening delight deflecting disheartenments" (Parse, 1994a, p. 61) in the structure of laughing and health is, according to Parse, "connectingseparating in the transforming of imaging" (Parse, 1994a, p. 61). This transforming of imaging involves seeing things differently reflectively and prereflectively; it involves imagining to create anew. Thus, the findings of 
this study again underscore the interconnectedness of imagining with unitary human becoming.

In summary, these three research studies within the simultaneity paradigm in nursing contribute to an understanding of imagining as a unitary lived experience of health. All three studies in some way connect imagining with day-to-day experiences and specify it as inherent to being human. These studies use Parse's theory of human becoming as the nursing perspective and thus, they contribute to the expansion of that nursing theory and the knowledge unique to nursing as well as contributing knowledge about imaging to the general literature.

\section{Conclusion of Literature on Hope and Imagination}

This concludes the literature review on imagining. From the theoretical perspectives reviewed, this author posits the following definition of imagining synthesized from understandings gained from the literature and from Parse's theory of human becoming: Imagining is shifting views of the familiar-unfamiliar while disclosing-not disclosing cherished beliefs in propelling envisioned opportunities and limitations all at once, while cocreating new ways of speaking-being silent, moving-being still while being with and apart from others, objects, ideas, and events.

This definition links imagining to the theoretical structures of Parse's theory of human becoming in the following ways: shifting views of the familiar-unfamiliar while disclosing-not disclosing cherished beliefs is 
transforming the revealing-concealing of valuing; in propelling envisioned opportunities and limitations all at once is powering the imaging of enablinglimiting; and cocreating new ways of speaking-being silent, moving-being still while being with and apart from others, objects, ideas, and events, is originating the languaging of connecting-separating. Thus, at the theoretical level of the human becoming theory imagining is transforming the revealingconcealing of valuing while powering the imaging of enabling-limiting, in originating the languaging of connecting-separating.

A synthesis of the understandings of hope and imagining provides the definition for considering tomorrow. Considering tomorrow is envisioning the not-yet amidst the disclosing-not disclosing of the familiar-unfamiliar, as comfort-discomfort propels cherished opportunities and limitations all at once, cocreating new ways of speaking-being silent, moving-being still while being with and apart from others, objects, ideas, and events.

This definition is linked to the concepts of Parse's theory of human becoming in the following ways: envisioning the not yet amidst the disclosing-not disclosing of the familiar-unfamiliar is imaging the revealingconcealing of transforming; as comfort-discomfort propels cherished opportunities and limitations all at once is powering the valuing of enablinglimiting; and cocreating new ways of speaking-being silent, moving-being still while being with and apart from others, objects, ideas, and events, is originating the languaging of connecting-separating. Thus, at the level of 
theory, considering tomorrow is imaging the revealing-concealing of transforming while powering the valuing of enabling-limiting, in originating the languaging of connecting-separating.

The definition of considering tomorrow is derived from the definitions of hope and imagination and Parse's theory of human becoming. These definitions connect hope, imagining, and considering tomorrow with all nine core concepts of the theory of human becoming. It is important to note that only once in a research study using Parse's theory and research methodology did a health phenomenon connect with all of the core concepts of the human becoming theory. This occurred in Parse's research on the lived experience of laughter and health (Parse, 1994a). In all other previous studies, only one or two concepts from each principle were connected to the structure at the level of theory. In the study on laughter and health, Parse posited that the structure of laughter and health may have connected with all nine core concepts because of the broad nature of the laughing and health experience. 
Theoretical Synthesis Of Concept: Considering Tomorrow

Hope is a pushing-resisting in the comfort-discomfort of the treasured, as persistent visions of possibles are disclosed-not disclosed, cocreating _ - - envisioning the not-yet amidst new ways of moving with the familiarunfamiliar in communion-alopeness. the diąclosing-not disclosing of the familiar-unfamiliar, as

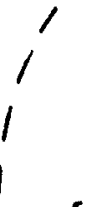
comfort-discomfort propels cherished opportunities and limitations all at once, cocreating nbw ways of Imagining is shifting views of the speaking-being silent, movingfamiliar-unfamiliar while disclosing-not being still while being with and disclosing cherished beliefs in propelling envisioned opportunities apart from others, objects, and limitations all-at-once, while ideas, and events. cocreating new ways of speakingbeing silent, moving-being still while being with and apart from others, objects, ideas, and events.

This conceptualization of considering tomorrow is based purely on a review of literature. Research was necessary to uncover a structure of the lived experience of considering tomorrow. 


\title{
Review of Literature on Women Home-less
}

\author{
"Homeless people carry the roots of human history \\ for you to see. When all of you remember your roots, \\ then homelessness will disappear... \\ Homeless people are here to mirror back human history \\ to you. The inventiveness that turns a packing \\ crate into a house is the very same inventiveness \\ that brought you out of the trees \\ and out into open savannahs... \\ Could you live for even one night on the street? \\ Celebrate the strength of these people... who \\ are finding within themselves the roots of \\ human history" (Ramer, 1995, p. 70).
}

The literature review on women who are home-less was conducted in nursing, sociology, and psychology. Three conceptualizations of being home-less were formulated from the literature review: home-less as involving certain personal characteristics and causes including gender differences; home-less as violation and alienation; and home-less as a unitary life pattern and lived experience. These three conceptualizations will provide the thematic framework for the literature review.

\section{General Theoretical Literature}

Over 600,000 people in the United States are home-less, living and sleeping on streets, in parks, in shelters, or in darkened corners (Federal Task Force on Homelessness and Severe Mental Illness, 1992). Even this number is an estimate because of the differing ways in which homelessness is defined and studied. The faces of the home-less are many and contrary to popular belief the home-less population is not a homogeneous group (Lindsey \& Gottesman, 1992). Of this growing population of home-less individuals, 
home-less families, mostly single mothers with children, represent a growing segment of this population (Hausman \& Hammen, 1993).

Several authors describe women's home-lessness as involving certain characteristics and causes including gender differences (Bassuk, 1993a; 1993b; Belle, 1990, Hagan, 1987; Hausman \& Hammen, 1993). Bassuk (1993a) and Hagan (1987) both emphasize the economic hardship of single parent families and lack of housing as causes of homelessness. Bassuk (1993b) suggests "sexism" in the forms of poor earning power, limited job opportunities, overwhelming child care responsibilities and fragmented social services may cause and contribute to women's home-less situation. Belle (1990) suggests women's coping strategies are constrained by poverty and often poor women experience repeated failures in creating new ways of living because of the lack of a response from social institutions.

Parenting is viewed as a double crises for home-less women by Hausman \& Hammen (1993). These authors suggest that the factors that impede a mother's ability to maintain a stable residence, such as dysfunctional families of origin, dysfunctional or violent relationships with men, lack of supportive social networks, being disadvantaged due to ethnic, educational, or income status, and psychological distress such as depression or substance abuse, are also likely to impair her capacity to care for her children. They also note that stresses endemic to the home-less shelter 
environment may be magnified for these mothers who are less able to mediate risk in the environment (Hausman \& Hammen, 1993).

Home-less as violation and alienation is addressed by Browne (1993) and Goodman, Saxe, \& Harvey (1991) who focus on social disaffiliation, learned helplessness, and victimization as key in describing causes and characteristics of women who are home-less. Browne (1993) suggests that sexual and physical abuse may often be the subtext in stories of women's homelessness. This violation over a life-span may cause women to "become unable to imagine a condition of safety; the idea of choice is thus rendered virtually meaningless because they cannot conceive of any true improvement in their lives" (Browne, 1993, p. 375).

Goodman, Saxe, \& Harvey (1991) view home-lessness itself as psychological trauma which encompasses social disaffiliation and learned helplessness. They suggest this psychological trauma is likely for three reasons: (a) the loss of one's home whether sudden or gradual is a sufficient stressor; (b) conditions of shelter life may be traumatic; and (c) many women become home-less after experiencing physical and sexual abuse and consequent trauma (Goodman, Saxe, \& Harvey, 1991). Thus, these authors view violation and alienation as part of the process of becoming home-less as well as part of the lived experience of being homeless for women. 
Nursing Theoretical Literature-Totality Paradigm

Turner (1993) postulated four concepts describing a theory of

homelessness. They were: (a) marital stress; (b) unemployment; (c) low self-esteem and self-concept; and (d) lack of adequate social support. These characteristics were included in a model to describe attributes of the homeless population including women who are home-less.

Bissonnette \& Hijjazi (1994), Blakeney (1992), Boondas (1985), Ovrebo, Ryan, Jackson, \& Hutchinson (1994), Ugarriza \& Fallon (1994) and Wallsten (1992) depict women's home-less situation as living with violation and victimization. Bissonnette \& Hijjazi (1994) suggest that loss of an address is an assault on personhood and is hardly tolerable to most people. "Once a home is lost, an irrevocable assault on self-esteem and empowerment begins" (p. 413).

Ovrebo, Ryan, Jackson, \& Hutchinson (1994) describe the journey back from home-lessness for women as a long one involving a process of recovery from the physical and psychological effects of homelessness. "In addition, many must recover from substance addiction, and the trauma of sexual violence and a history of battering relationships" (p. 195). Blakeney (1992) describes a home-less woman's experience of having her syringes stolen from her on the street so she could not administer her own insulin. When the health team became aware of this, they placed her in a shelter for 
abused women. Blakeney (1992) writes, "...it is in homelessness that we find all the problems of our society in the extreme" (p. 69).

Wallsten (1992) identified the fact that women are twice as likely as men to live in poverty and many elderly women who are home-less stay away from public shelters because of fears of being mugged or treated insensitively. Ugarriza \& Fallon (1994) address the violation and victimization in home-less women's lives by suggesting that negative attitudes of nurses toward women who are home-less may make them reluctant to seek health care. The authors note that the majority of women who are home-less do not use public health clinics for primary health care and are "reluctant to seek health care because of previous unpleasant experiences with unfriendly, insensitive, and rude health care providers" ( $p$. 27). Thus, the attitudes of some health care providers may contribute to these women's feelings of social alienation.

In depicting women's home-lessness by describing the characteristics of women who are home-less including gender or by the theme of violation and alienation, the above authors note the interrelationship of social structures, ethnic background, impoverished economic situations, dysfunctional family situations, psychosocial functioning and gender in contributing to the causes of being home-less for women. This viewpoint is in accordance with the natural science paradigm of cause and effect, but is not consistent with the human science perspective of mutual evolving 
process upon which this present study is based. From the human science perspective being home-less is viewed as a unitary life pattern and lived experience and will be addressed in the literature related to the simultaneity paradigm in nursing.

Nursing Theoretical Literature-Simultaneity Paradigm

Rasmusson (1995) and Rasmusson, Jonas, \& Mitchell (1991) depict women's experience of being home-less as a unitary life pattern and lived experience. Rasmusson, Jonas, \& Mitchell (1991) described how a woman home-less shared her lived experience with a group at a home-less shelter. The woman stated:

I've been called schizophrenic, personality disorder, and just plain crazy. And maybe those things are true, but I am also a woman who cares about others, who loves children, and who is scared to death of what might happen in the future...I am a heck of a lot more than what they think I am. (p. 143) Rasmusson (1995) goes on to describe the unitary life pattern of persons home-less stating, "When encouraged to express meaning and make choices based on what is important, these people blossom like flowers with petals slowly opening up to the sunshine" (p. 105). Thus, the unitary lived experience of being home-less for women involves looking at the possibilities in their lives while living with the struggles of surviving on the street. 


\section{General Research Studies}

The causes of homelessness and characteristics of women who are home-less has been the focus of several research studies. The research indicates that being home-less has multidimensional characteristics and causes for women including impoverished economic conditions, lack of supportive social networks, heading a single parent family, high risk for health problems including substance abuse and mental illness, overexposure to crime and victimization, and inadequate access to health care and social services (Bassuk, Rubin, \& Lauriat, 1986; Fischer, Shaprio, Breakey, Anthony, \& Kramer, 1986; Ropers \& Boyer, 1987; Roth \& Bean, 1986; Weitzman, Knickman, \& Shinn, 1990; Winkleby, Rockhill, Jatulis, \& Fortmann, 1992). Evidence from research studies suggests that there are subgroups of home-less individuals with different life issues which require a variety of strategies to address their lived situations. Thus no global generalization of causes and characteristics of home-less women is possible.

Home-less as violation and alienation surfaces in several research studies in which home-less women were subjects (Bassuk \& Rosenberg, 1988; Coston \& Finckenauer, 1993; D’Ercole \& Struening, 1990; Goodman, 1991; Grunberg \& Eagle, 1990). Coston \& Finckenauer (1993) found women home-less to have a fear of crime on the streets. Bassuk \& Rosenberg (1988) discovered that mothers who were home-less had more frequently been abused as children. D'Erole \& Struening (1990), Goodman 
(1991), and Grunberg \& Eagle (1990) found themes of violation and victimization permeating the lives of home-less women. Goodman (1991) writes, "homeless women reported that domestic violence was a leading cause of their homelessness" (p. 490).

Several qualitative studies address the personal characteristics of women home-less. These characteristics were discovered through interviews and observations. A personal characteristic theme of adaptability and flexibility in these women is noted by the researchers (Bard, 1990; Kozol, 1988; Lamb \& Lamb, 1990; Liebow 1993; Susnick, 1993). Bard (1990) writes concerning these women, "I respect the obscurity which they nurture; they have designed and developed a way to live with as much dignity as possible" (p. viii).

\section{Nursing Research Studies-Totality Paradigm}

Several nurse researchers have focused on causes, characteristics and gender related issues of women home-less (Adkins \& Fields, 1992; Maurin, Russell, \& Memmott, 1989; Newman, 1993; Wagner \& Menke, 1991). Adkins \& Fields (1992) studied the health values of 10 home-less women and discovered that health care to meet survival needs was a priority for these women. Maurin, Russell \& Memmott (1989) identified needs specified by both women and men who were home-less. The top three needs were: (a) a permanent place to live; (b) a job; and (c) financial assistance. There was no significant statistical difference between women and men in ranking 
these needs. Wagner \& Menke (1991) described home-less mothers as more disadvantaged than other poor and low-income mothers in terms of numbers of children, education, and the ability to seek employment.

Home-less as violation and alienation was identified by Kline \& Saperstein (1992) who in a shelter for 120 women discovered a high frequency of victimization experiences for home-less women along with limited access to economic opportunity. In working with women in homeless shelters Kline \& Saperstein (1992) suggest that a caring relationship appears to provide the most healing for these women.

Newman (1993) in conducting an ethnographic study on the experience of seven battered women in one home-less shelter identified the core concept emerging from the data as that of "giving up" (p. 110). The principal reason for leaving home cited by these women was for the safety and mental welfare of their children. Supporting concepts that described their experience with violation and victimization were helplessness and fear of the unknown (Newman, 1993).

Home-less as a lived pattern of health was addressed by Francis, 1992; Hodnicki, 1992; Hodnicki \& Horner, 1993; and Montgomery, 1994. Francis (1992) described the lived experiences of eight women who were home-less as involving themes describing a pattern of connection/disconnection. They included: (a) violations and disconnections that described how they became home-less; (b) temporary private 
connections described their doubling up in living; (c) temporary public connections involved moving to a public shelter and experiencing long waiting periods and intense feelings; and (d) rebuilding connections portrayed the process of searching for apartments, looking at who and what helped and who and what hindered this process.

Hodnicki (1992) conducted an ethnographic study of women's experiences in a home-less shelter. The 23 women in this study described two major domains of their lived experiences: (a) disconnected--loss of major support; and (b) rebuilding--the regrouping of assets. The author also discovered that the women experienced vulnerability throughout the homeless experience, but it was most intense when the women felt disconnected from support sources. The proactive behavior or rebuilding done by these women had not previously been described in the literature on home-lessness (Hodnicki, 1992).

Hodnicki \& Horner (1993) studied six home-less mothers' caring for children in a shelter. The following lived patterns of caring were identified from stories of: (a) sacrificing for the children; (b) struggling with limitations to health care access and other resources; (c) guarding from harm in an unfamiliar environment; and (d) seeking answers to their problem of homelessness. The researchers suggest these behaviors reflect the pain and hardship home-less mothers experience living the uncertainty of "one step at a time" (Hodnicki \& Horner, 1993, p. 355). 
Montgomery (1994) studied seven women who had survived the lived experience of home-lessness. None of the women were home-less at the time of the interviews. For these seven women a theme emerged that leaving home with no resources had been an act of hope and courage. They needed to find a better way to live. The metaphor synthesized to describe their experience was "swimming upstream" (Montgomery, 1994, p. 34).

\section{Nursing Research Studies-Simultaneity Paradigm}

Three nursing research studies in the simultaneity paradigm were reviewed on the unitary lived experience of women home-less (Baumann, 1993, 1994; Barleben, 1993). A phenomenological study by Baumann (1993) of the meaning of being home-less for 15 women identified seven major themes describing their unitary lived experience. First, there was the theme of struggling to maintain boundaries since the women lacked physical boundaries of a home. Second, a theme of connections emerged. Much energy was demanded of these women to maintain connections to objects, people and institutions. The third theme was the experience of fatigue and despair involving constant movement. The fourth theme was related to selfrespect. Being home-less threatened the participants human dignity. One participant stated, "If you are from social services they treat you like the plague" (Baumann, 1993, p. 66). The fifth theme was lack of selfdetermination. "Without a home you can't do a thing about your life" (Baumann, 1993, p. 66). The sixth theme was one concerning missing 
privacy and the ability to have a place to do what you wanted to do. The seventh theme was mobility. Due to circumstances and, sometimes choice, the subjects moved often. The overall metaphor used to describe the experiences of these women was a whirlpool of poverty and powerlessness (Baumann, 1993).

Baumann (1994) conducted an exploratory study of the meaning of having no place of their own for women and children. Parse's nursing theory of human becoming was the nursing perspective of the study involving 13 women and 25 children. Baumann synthesized the data and in the language of science described the meaning of not having a place of one's own as, "a sense of gratitude for protection, mingling with the discomfort of restriction and exposure, giving rise to fears and reassurances" (Baumann, 1994, p. 166). Baumann (1994) cited living without a place of one's own as a way of becoming involving disruptions and hardships along with possibilities.

Barleben (1993) conducted a phenomenological hermeneutic inquiry on the lived experience of home-lessness for women with children. Universal themes describing 14 women's lived experiences included: (a) feeling disconnected or connected; (b) searching; (c) being done to; (d) not being able to do; (e) waiting and wanting; ( $f$ ) being devoured or empowered; (g) losing and re-collecting; (h) up-rooting and re-rooting; (i) being worn down or learning; and (j) having or not having. The message of "challenge 
to care" was identified by the researcher as the challenge of these women to care for their children as well as a challenge to society to care for these home-less persons (Barleben, 1993). Baumann's studies (1993, 1994) and Barleben's (1993) explicated the issues present in the day-to-day lived experience for women home-less. Their attempts at providing a tomorrow for themselves and their children denote a struggle for survival amidst hardship and hope.

\section{Conclusion}

This concludes the literature review on women who are home-less. From this literature review it can be seen that home-lessness cannot be merely interpreted as caused by personal limitations of individuals. Being home-less for women involves the mutual evolving process of an assortment of lived experiences in the human-universe interconnectedness. Based on the literature review and on the theory of human becoming this researcher posits the following conceptualization of being home-less for women: The lived experience of being home-less involves the paradoxical processes of being connected and disconnected with persons and places, while experiencing the comfort-discomfort of making life choices involving struggling for survival amidst limited access to resources, yet moving with hopes and dreams beyond the now to the not-yet. With this conceptualization of being home-less, what considering tomorrow means for home-less women is intertwined and closely related to their health which is 
human becoming and quality of life. The study presented here provides a contribution to the body of nursing knowledge concerning the un iversal lived experience of considering tomorrow for women who are home-less. 


\section{CHAPTER III \\ METHODOLOGY}

The mode of inquiry used for this study was Parse's (1987, 1990b, $1995 b)$ research method. This is a phenomenological-hermeneutic method in congruence with the philosophy and principles of the nursing theory of human becoming. In this chapter, the background of the method and a description of the processes of the method are presented. Also, issues related to rigor, credibility, and ethical considerations are addressed.

\section{Background of the Method}

The Parse research methodology is "generically phenomenological in that the entities for study are experiences as described by people who have lived them" (Parse, 1995b, p. 153). It is a hermeneutic method in that nursing inquiry from the human becoming perspective focuses on uncovering the meanings of lived experiences of health. "Hermeneutics is an ancient, yet modern and postmodern mode of inquiry. Its traditional focus is meaning, and its central processes are interpretation and understanding" (Parse, 1995b, p. 154).

Parse's research methodology is designed to be congruent with the philosophy of the human becoming theory of nursing (Parse, 1981, 1992, 1995a). The assumptions of the human becoming theory were synthesized from Rogers' science of unitary human beings and concepts of existential- 
phenomenological thought, particularly from Heidegger, Sartre, and MerleauPonty.

Heidegger's phenomenology is based on the belief that bracketing is not possible or desirable for coming to know the world. Heidegger (1962) suggests that one's Being-in-the-world makes understanding of the world possible. It is impossible to set aside all of one's beliefs, to bracket, when seeking to understand a phenomenon. Heidegger (1962) writes:

When we are talking ontically we sometimes use the expression "understanding something" with the signification of "being able to manage something", "being a match for it", "being competent to do something." In understanding, as an existentiale, that which we have such competence over is not a "what", but Being as existing. The kind of Being which Dasein has, as potentiality-for-Being, lies existentially in understanding. Dasein is not something present-at-hand which possesses its competence for something by way of an extra; it is primarily Being-possible. Dasein is in every case what it can be, and in the way in which it is its possibility. (p. 183)

Thus, Heidegger's phenomenology posits that the ontological nature of Dasein (being human) is understanding. This understanding is central to Being and cannot be separated or bracketed off from Being. Heidegger posits the world and the person as a unity (Heidegger, 1962). 
A differing view on bracketing was presented by Husserl, an earlier phenomenologist, who believed bracketing was possible and desirable when investigating a specific phenomenon. His thoughts on this issue are not consistent with Heidegger or with Parse's human becoming theory of nursing and research methodology (Mitchell \& Cody, 1993).

The research method used in this study, Parse's research methodology, is specific to nursing and was developed as a distinct way to investigate human becoming. Prior to the development of Parse's research method, nursing borrowed methods of research from other sciences. Research using the human becoming theory was conducted using borrowed research methods such as ethnography, descriptive exploratory methods, and phenomenology (Parse, Coyne, and Smith, 1985). However, a characteristic of a mature discipline is the development of distinct methods of inquiry congruent with the ontological bases of that discipline (Parse, 1987, 1992). Parse's research methodology flows from the principles of the human becoming theory and that theoretical perspective permeates the research process. The interpretation of participants' descriptions also reflects this theoretical orientation (Mitchell \& Cody, 1993).

Research to refine and expand distinct nursing methods of inquiry should be a priority in nursing. A goal of this research is to make a contribution to nursing science using Parse's nursing research methodology. 


\section{Description of the Method}

The Parse research methodology was constructed in congruence with the ontological base of the human becoming theory. The principles of methodology construction as outlined by Parse $(1987,1995 \mathrm{~b})$ include the following:

* The methodology is constructed to be in harmony with and evolve from the ontological beliefs of the research tradition.

* The methodology is an overall design of precise processes that adhere to scientific rigor.

* The methodology specifies the order within the processes appropriate for inquiry within the research tradition.

* The methodology is an aesthetic composition with balance in form. ( p. 173, p. 152)

The basic assumptions underlying Parse's research method are:

1. Humans are open beings in mutual process with the universe. The construct human becoming refers to the human-universe-health process.

2. Human becoming is uniquely lived by individuals. People make reflective and prereflective choices in 
connection with others and the universe which incarnate their health.

3. Descriptions of lived experiences enhance knowledge of human becoming. Individuals and families can describe their own experiences in ways that shed light on the meaning of health.

4. Researcher-participant dialogical engagement uncovers the meaning of phenomena as humanly lived. The researcher in true presence with the participant can elicit authentic information about lived experiences.

5. The researcher, through inventing, abiding with logic, and adhering to semantic consistency during the extraction-synthesis and heuristic interpretation processes, creates structures of lived experiences and weaves the structure with the theory in ways that enhance the knowledge of nursing. (Parse 1992, p. 41, 1995b, p. 152)

The purpose of the research method is to enhance understanding of lived experiences of health, and to integrate this understanding with Parse's theory of human becoming (Parse, 1987, 1992, 1995b). The overall purpose of the research "is to uncover the structure of lived experiences 
with persons or groups who can articulate the meaning of an experience" (Parse, 1992, p. 41). Entities for study are universal lived experiences of health such as suffering, hope, grieving, and feeling restricted-feeling free (Parse, 1992, 1995b).

\section{Processes of the Method}

The processes of the method are: (a) participant selection; (b) dialogical engagement; (c) extraction-synthesis; and (d) heuristic interpretation. These processes occur simultaneously as the study emerges (Parse, 1987, 1992, 1995b). Each process will be described separately to facilitate the understanding of the research.

\section{Participant Selection}

"Participants are persons who can describe through words, symbols, metaphor, poetry, or drawings the meaning of the experience under study" (Parse, 1995b, p. 153). Participants who are living the research phenomenon are invited to volunteer, and it is assumed that persons agreeing to participate will give a genuine account of their experience in dialogue with the researcher (Parse, 1987, 1992, 1995b). An adequate sample for this research method is usually two to ten participants (Parse, 1987).

Ten women who are home-less, 18 years of age and over with the knowledge and desire to participate, were invited to take part in this study on considering tomorrow. Participants were free to discuss any life situation 
where they experienced considering tomorrow. Participants were able to understand, read, and speak English and were willing to talk with the researcher, and, were able to focus on and describe the lived experience of considering tomorrow. The discussions were tape recorded, and varied in length from about 30 to 60 minutes, depending on how long the participant wanted to discuss her experience of considering tomorrow.

Participants were recruited through a large metropolitan health outreach center for the home-less. Community outreach workers assisted the researcher in informing and recruiting women who were home-less and interested in volunteering to participate in the study. The final explanation of the study and obtaining of informed consent was conducted by this researcher. Potential participants were informed that refusal to participate in the study would not affect the services they received from the outreach program.

\section{Protection of Human Subjects}

Approval was obtained from the Loyola University Chicago Institutional Review Board (see Appendix A). Permission to recruit volunteers from Chicago Health Outreach was requested (see Appendix B) and formal approval was received (see Appendix C). All participants were given a general explanation of the project, both verbal and written (see Appendix D). Participants signed a consent form (see Appendix E) and a copy of the consent was given to each participant. 
All consent forms and audio tapes have been kept in a locked cabinet in the researcher's home. All audio tapes will be erased upon completion of the study. Participants' names, or personal identifying information, were not used on transcriptions, reports, or publications resulting from this research.

\section{Dialogical Engagement}

Dialogical engagement is a discussion between the researcher and participant. This discussion is not an interview, but a true presence in which the researcher focuses on the phenomenon under study as described by the participant (Parse, 1992, 1995b). The researcher comes to the dialogue having centered self to be open to the becoming of the other, and the process originates as the researcher-participant discussion proceeds (Parse, 1987, 1992). The process of centering by this researcher was initiated through calming and imaging in a quiet place. The dialogical engagement for this research began with the researcher making the following statement: "Can you tell me what it is like for you to consider tomorrow." Only statements like "go on" or "how does that relate to your thinking about tomorrow?" were used by the researcher to gain clarity from the participant.

\section{Extraction-Synthesis}

"Extraction-synthesis is culling the essences from the dialogue in the language of the participant and conceptualizing these essences in the language of science to form a structure of the experience" (Parse, 1995b, 
p. 153). The extraction-synthesis process occurred as the researcher "dwelled with" the dialogical engagement, both the audio tape and the typed dialogue. This "dwelling with" means the researcher centers on the meaning of the lived experience through immersion with the descriptions (Parse, 1987). There are five processes in extraction-synthesis which occur simultaneously. First, the researcher extracted and synthesized essences through intuiting from the entire dialogical engagement. These essences are written in the participants' language. Secondly, the researcher extracted and synthesized essences at a more abstract level forming a conceptualization in the language of science. The researcher then formulated a proposition from the essences of each participant. This proposition captures the participant's experience in "a nondirectional statement conceptualized by the researcher" (Parse, 1987, p. 177). Core concepts were then drawn from all propositions and these concepts describe the central meaning of the lived experience under study. A core concept is one which represents a recurring theme in all of the descriptions. A structure of the lived experience was synthesized from these extracted core concepts. "The structure arising from this process is the answer to the research question" (Parse, 1995b, p. 153).

Heuristic Interpretation

Heuristic interpretation is the final process of the research method. It is the interpreting of the structure of the lived experience in the language of 
the human becoming theory. "Heuristic interpretation weaves the structure into the theory and beyond (Parse, 1987, 1992). Structural integration and conceptual interpretation are processes that move the discourse of the structure to the discourse of theory" (Parse, 1995b, p. 153). Structural integration is an expression of the meaning of the phenomenon at a higher level of abstraction than the structure. Conceptual interpretation specifies the structure of the lived experience with the principles of the human becoming theory. The phenomenon under study is illuminated through the lens of the theory, and new ideas for further research and practice are also generated.

\section{Rigor and Credibility}

Burns (1989) described five standards for qualitative research to ensure scientific rigor: (a) descriptive vividness; (b) methodological congruence; (c) analytic preciseness; (d) theoretical connectedness; and (e) heuristic relevance.

Descriptive vividness: this is a description that is presented so clearly that the reader has the sense of personally experiencing the event (Burns, 1989). Descriptive vividness was accomplished by staying close to the words of the participant in the dialogical engagement as the process of extraction-synthesis emerged. 
Methodological congruence: this is congruence between the metatheory and methodology of the research. The research reviewer must have knowledge of the metatheory and the methodological approach (Burns, 1989). This researcher addressed methodological congruence by forming a dissertation committee that reviewed all dialogical engagements, extractionsyntheses, and heuristic interpretations. The committee consisted of the nurse theorist who is the author of the human becoming theory and the Parse research methodology, one expert in women's health who is engaged in working with women who are home-less, and an expert in qualitative research, manuscript writing, and editing. Parse's theory of human becoming and research methodology is uniquely appropriate for investigating the meaning of the lived experience of considering tomorrow. No other method attends so closely to the meaning of lived experience (Cody, 1994).

Burns (1989) identifies four dimensions within methodological congruence: (a) rigor in documentation; (b) procedural rigor; (c) ethical rigor; and (d) auditability. Rigor in documentation requires the researcher to present all the elements of the study: "phenomenon; purpose; research question; justification of the significance of the phenomenon; identification of assumptions; identification of metatheories; researcher credentials; the context; role of the researcher; ethical implications; sampling and subjects; data-gathering strategies; data analysis strategies; theoretical development; 
conclusions; implications and suggestions for further study and practice; and a literature review" (p. 48). These elements are addressed in the written reports of this study.

Procedural rigor requires that the researcher be clear about the steps taken to ensure that data were accurately recorded. This was accomplished by audio taping all dialogical engagements and retaining all tapes until the research was completed. Audio tapes were also compared to the transcribed texts for accuracy.

Ethical rigor was addressed by requesting review and approval from the Loyola University Institutional Review Board prior to the initiation of this research. Participants signed a consent form prior to their participation. The consent form included: (a) the procedures to be followed; (b) the participant's right to have all questions or concerns about the procedures answered; and (c) the participant's freedom to withdraw from the study at any time. Participants were assured of confidentiality and that their names and other personal identifying information would not appear on any written or published material generated from this research. Robley (1995) writes, "Ethics is woven into the fabric of qualitative research and must be given serious thought throughout the process" (p. 48).

Auditability involves the clear development of a decision trail (Burns, 1989). The researcher must outline all the decisions involved in 
transformation of data to the theoretical level. The reporting of decisions should be detailed enough so that a second researcher, using the same data, would arrive at similar conclusions (Burns, 1989). This researcher kept detailed methodological notes to support auditability.

Analytical preciseness: is a detailed recording of the decision making processes through which data are transformed across levels of abstraction. In this study, the researcher kept a detailed, analytic documentation regarding all phases of extraction-synthesis. Thoughts, speculations, insights, and intuitions were documented. The three member dissertation committee's review of all extraction-synthesis ensured analytical preciseness.

Theoretical connectedness: "requires that the theoretical schema developed from the study be clearly expressed, logically consistent, reflective of the data, and compatible with the knowledge base of nursing" (Burns, 1989, p. 50). This standard was ensured by the review of the three member dissertation committee.

Heuristic relevance: this requires "the reader's capacity to recognize the phenomenon described in the study, its theoretical significance, its applicability to nursing practice situations, and its influence in future research activities" (Burns, 1989, p. 51). The three dimensions of heuristic 
relevance are intuitive recognition, relationship to existing body of knowledge, and applicability.

Intuitive recognition occurs when readers are confronted with the theoretical schema and it has meaning in their personal knowledge base. This researcher clearly described the phenomenon under study and its relationship to the human becoming theory of nursing. The findings are discussed in view of the existing body of knowledge on the phenomenon.

Applicability occurs when findings can be integrated into the knowledge base of the nurse and contribute to theory development within nursing. The findings should also guide the development of future nursing research (Burns, 1989). This researcher believes studying considering tomorrow through the lens of Parse's theory of human becoming has contributed to nursing theory development and to an understanding of this lived human health experience. Such understanding can influence how nurses are "truly present" as they participate in healing and the quality of life with persons during times of considering tomorrow.

\section{Summary}

This dissertation focused on considering tomorrow, thus an understanding of the structure of this human health phenomenon has been realized. This understanding contributes to the knowledge of the human becoming theory of nursing, thus to nursing science. This study also 
contributes to information concerning the use of Parse's phenomenologicalhermeneutic method of nursing research. 


\section{CHAPTER IV}

\section{PRESENTATION OF FINDINGS}

Considering tomorrow as lived and described by women who are home-less was the phenomenon of interest in this research study. Parse's theory of human becoming and research methodology, which is a phenomenological-hermeneutic method, was utilized to generate the structure of the considering tomorrow experience as described by home-less women.

This chapter presents the findings from the research. First are the extracted-synthesized essences from ten women participants. The essences are the central ideas found in each participant's description that relate to the lived experience of considering tomorrow. These ideas are first presented in the language of the participant and then presented in the language of the researcher. The language of the researcher denotes a synthesis of meaning and is at a higher level of abstraction. Following the extraction-synthesis process is a proposition for each participant that combines the central ideas concerning considering tomrrow in the language of science.

The core concepts are named following the extraction-synthesis process. The core concepts are the universal ideas of the considering tomorrow experiences as described by the 10 participants. They are written in the language of science at the same level of abstraction as the 
synthesized-extracted essences in the language of the researcher and the propositions. When linked together, the core concepts are the structure of the lived experience of considering tomorrow, which is the central finding of the research. The last section presents the heuristic interpretation of findings linking the structure of considering tomorrow with the concepts of Parse's theory of human becoming. 
Essences

(Participant's Language)

1. Feeling that it is real scary for her to think about tomorrow while staying sober and not knowing how to begin to accomplish all the things she wants to accomplish, the participant still identifies goals for going back to school, becoming a chef, starting her own business, establishing stable housing, becoming employed and making clear choices concerning her future.

2. Feeling that she wasn't the mother in the past that she could have been with addiction to drugs, nervousness, and a low tolerance level for caring for her children, the participant states she is looking forward to going forth to be the mother she feels she can be. She says she is alone with her baby and wants her three other children back so she can care for them.

3. Experiencing frustration with wanting things to happen right now and knowing such frustration and feelings of nervousness are part of her thinking of using drugs again, the participant talks about needing to take one day at a time and doing a little each day to work toward what she wants for herself and her children.

\section{Essences}

(Researcher's Language)

1. Frightening unsureness amidst intentional holding surfaces with contemplation of desired undertakings.

2. Disillusioning disengagement arises with ardent anticipation of initiating intimate alliances anew.

3. Disturbing impatience emerges with deliberate resolve in longing for the cherished.

\section{Proposition}

The lived experience of considering tomorrow is ardent anticipation of initiating intimate alliances anew, while disillusioning disengagement arises amidst intentional holding, as the presence of disturbing impatience emerges with deliberate resolve in longing for the cherished, when frightening unsureness surfaces with contemplation of desired undertakings. 


\section{Essences}

(Participant's Language)

1. Viewing life as very hard and rough and getting worse the participant states she feels very down and worries about what is going to happen day to day and if she and her children will survive to see tomorrow. She says she believes in taking one day at a time and with the help of hope and faith in God, tomorrow will be better.

2. Feeling that life has been very disappointing, painful and difficult and feeling a loss of trust in fellow human beings, the participant states she still hopes for a job, a nice place to live, a chance to go back to school, and the opportunity to bring her and all her children together again so she can care for them. She says that talking with friends also helps her to keep trying.

Essences

(Researcher's Language)

1. The tormenting despair of disturbing unsureness surfaces with solemn anticipation in the persevering steadfastness of the immediate.

2. Disillusioning anguish amidst isolating estrangement and a longing for the cherished emerges with the contemplation of launching desired undertakings with intimate alliances.

\section{Proposition}

The lived experience of considering tomorrow is contemplation of launching desired undertakings with intimate alliances emerging with disillusioning anguish amidst isolating estrangement and longing for the cherished, while the tormenting despair of disturbing unsureness surfaces with solemn anticipation in the persevering steadfastness of the immediate. 
Essences

(Participant's Language)

1. Feeling good when she has goals, the participant looks forward to the ones she sets for each day. She states, she tries to do the best she can and gets less depressed when she is active in spite of lack of money and back pain from slipped disks.

2. Expressing concern for people who don't have anyone to care about them, and noting that she too has been through that type of experience, the participant states she feels good about planning to care for and play with her grandchildren, talk with persons who seek encouragement and support, and travel back to the country she misses with her daughter to see her oldest son.

3. Stating she feels a lack of safety since she could walk out on the street and get hit by a car or a stray bullet, the participant states that one never knows if one will die today or tomorrow, but she prays to the Lord to keep her safe and asks Him to give her strength and keep her alive so that she can do something with her life.

Essences

(Researcher's Language)

1. Contentment arises with deliberate anticipation of undertakings amidst striving with multiple encumbrances.

2. Reflections on isolating estrangement arise with a pleasurable longing for nurturing cherished intimate affiliations.

3. Threatening unsureness surfaces with faithfully envisioning endurance.

\section{Proposition}

The lived experience of considering tomorrow is contented deliberate anticipation of undertakings amidst striving with multiple encumbrances, while reflections of isolating estrangement arise with a pleasurable longing for nurturing cherished intimate affiliations, as threatening unsureness surfaces with faithfully envisioning endurance. 
Essences

(Participant's Language)

1. Trying to decide whether to plan only for today since today is all a person can count on, or to make long term plans for the future (which may not come), the participant states she does not put off until tomorrow what she can do today. She says she finds it helpful to develop a pattern of activity for day to day accomplishments.

2. Wanting to get her life back to the way things were before she used drugs, the participant says she would like to be reunited with her husband and children and prays to God for strength and thanks Him for the chance to see tomorrow. She states it is scary for her to think about tomorrow and she wonders if she will live to see another day or whether she will be put out of the place where she is staying.

3. Feeling good about herself right now because she has been off drugs for four months, the participant states that she feels positive about getting back into life. She says she is concerned over whether she will use drugs again and wonders how she will handle something bad that may happen to her alone on the streets.

Essences

(Researcher's Language)

1. Puzzling deliberations of desired endeavors shift with the ease of routinizing the immediate.

2. A longing for the remembered cherished surfaces with grateful solemn alliances amidst the frightening unsureness of estrangement.

3. Enthused vigor for moving on arises with the disquieting forebodings of deliberate contemplation.

\section{Proposition}

The lived experience of considering tomorrow is the puzzling deliberations of desired endeavors which shift with the ease of routinizing the immediate, while a longing for the remembered cherished surfaces with grateful solemn alliances amidst a frightening unsureness of estrangement, as enthused vigor for moving on arises with the disquieting forebodings of deliberate contemplation. 
Essences

(Participant's Language)

1. Expressing that it is scary for her to think about tomorrow and whether she will start using drugs again, the participant states she takes one day at a time. She says that having a plan and writing it down assists her in living a more manageable life.

2. Recalling a time in her life when she had dropped out of college, was using drugs and alcohol and was not caring about anything, the participant states she was stuck and was not growing as a person. However, now she says she cares about making something of her life and sees growth in herself.

3. Wanting to be rejoined with her children soon, the participant states her children are part of her future and she wants to bring them up to go to school, have good jobs, and have a good life. However, she says first God is in her life, and she prays to Him that she will be OK tomorrow.

Essences

(Researcher's Language)

1. Frightening unsureness in contemplation eases with routinizing undertakings.

2. Troubling reflections of alienation arise amidst anticipating new likelihoods.

3. Longing for nurturing the cherished surfaces meditating on solemn alliances.

\section{Proposition}

The lived experience of considering tomorrow is anticipating new likelihoods amidst troubling reflections of alienation, while longing for nurturing the cherished surfaces meditating on solemn alliances as frightening unsureness in contemplation eases with routinizing undertakings. 


\section{Essences}

(Participant's Language)

1. Feeling that it is not wise to plan for tomorrow because you never know where you will be or what is going to happen to you, the participant states she still hopes for a better life. She says she is working on preparing a way to get an apartment, start her own typing business, and make some money.

2. Feeling a lack of trust in others because she believes her home, belongings, and children were taken from her and that she has been used by others, the participant states she still wants to be reunited with her children and be around and talk to people at the airport. She says she does not want to get involved with many people, but believes meeting others may help her and she refuses to be defeated.

3. Expressing the idea that she thinks people look down on her like a piece of dirt and wanting to hide her homelessness, the participant states that she is disappointed in herself in areas of her life. However, at the same time she says she wants to maintain what dignity she has, is not ashamed of herself, is not a bad person, and is a person with a conscience.

\section{Essences}

(Researcher's Language)

1. Disturbing unsureness emerges with deliberations on desired endeavors.

2. Longing for the cherished amidst disillusioning estrangement surfaces a renewed vigor for launching new alliances.

3. Resilient integrity arises with the simultaneous presence of pride and disgrace.

\section{Proposition}

The lived experience of considering tomorrow is longing for the cherished amidst a disillusioning estrangement that surfaces with renewed vigor for launching new alliances, while deliberations on desired endeavors emerge with disturbing unsureness, as resilient integrity arises with the simultaneous presence of pride and disgrace. 
1. Feeling scared about change, the participant states there is a lot for her to work on in one day. However, at the same time she says she looks forward to trying hard for a better way to live by starting a new maintenance job, making money, taking a computer class, and being a good mother to her children.

2. Expressing that it is hard for her to be with others because she does not have a lot of trust in people and that she needs to stay away from a mother she states is toxic to her, the participant says she still looks to other people to learn more about how she can live with love, happiness and peace of mind.

\section{$\checkmark$}

3. Stating she fought hard to stay with the insane life she was in, the participant says at times she still feels like walking out of the place where she now is. However, she says she has let go of many things she once thought important and depends on God's help in choosing what to do each day. She states God and her children are her future.

Essences

(Researcher's Language)

1. Threatening doubts of unsureness surface amidst contemplating significant strivings.

2. The solitary aloofness of disillusionment emerges with the desired calmness of harmonious alliances.

3. Resisting nurturing yields to gradual acceptance surfacing solemn confidence in forging ahead with the cherished.

\section{Proposition}

The lived experience of considering tomorrow is contemplating significant strivings amidst threatening doubts of unsureness while forging ahead with the cherished in solemn confidence, surfacing the solitary aloofness of disillusionment with the desired calmness of harmonious alliances, as resisting nurturing yields to gradual acceptance. 
Essences

(Participant's Language)

1. Stating that at one time all her tomorrows were dark and feeling like she didn't have a tomorrow, the participant says she had given up on life. However, now in a treatment house, she states she sees tomorrow as a blessing and as a time for her to learn about herself and build her self-esteem. She says she looks to ward having her children living with her.

2. Indicating that she feels like everyone else has turned their back on her and that she is getting the dirt back that she has done to others, the participant states that she sees Jesus as the only one who has not forsaken her. However, she says she is thankful to her mother for being there to care for her children so they are not taken from her.

3. Feeling ashamed and scared of saying things in a group, the participant states she is now building herself up, depending on her own self-esteem, and learning to talk to and share herself with others.

\section{Essences}

(Researcher's Language)

1. Disillusioning unsureness shifts while contemplating the gift of launching ahead with what is cherished.

2. Alienating isolation emerges amidst gratefulness for nurturing solemn alliances.

3. Innovative engagements arise with the dread of potential humiliation in intimacy.

\section{Proposition}

The lived experience of considering tomorrow is contemplating the gift of launching ahead with what is cherished while disillusioning unsureness shifts, and alienating isolation emerges amidst gratefulness for nurturing solemn alliances, as innovative engagements arise with the dread of potential humiliation in intimacy. 
1. Feeling that there are so many things happening and so much going on that one never knows if there will be a tomorrow, the participant says she worries about her two children being taken care of if something would happen to her. She states she lives for today and wants to get everything she can out of today so that she can raise her children and be happy with them.

2. Stating that she put her children through so much the past year and has put off working on her goals, the participant now wants to make things right. She says she wants to put more effort into her life. She states she hopes and prays to wake up tomorrow so as to be able to work toward something of her own.

3. Feeling like she was going to cry if she kept talking and that it takes so much energy and is so draining to be in an upsetting situation, the participants states she wants to be happy. She says she wants to love everyone and be on good terms with all people so her life will go smoother.

\section{Essences}

(Researcher's Language)

1. Disturbing unsureness emerges with aspiring for a stability with what is cherished in the immediate.

2. Remorse for the remembered surfaces with contemplating desired endeavors.

3. Turbulent distancing arises amidst longing for attentive joyous alliances.

\section{Proposition}

The lived experience of considering tomorrow is contemplating desired endeavors amidst remorse for the remembered, while disturbing unsureness emerges with aspiring for a stability with what is cherished in the immediate, as turbulent distancing arises amidst longing for attentive joyous alliances. 
1. Feeling that she cannot plan on tomorrow since when she used to plan things it was difficult when those things didn't happen, the participant says she now takes one day at a time. She states she wants to focus on her sobriety and on getting her life back together with her three children. She says she prays that she will live to see tomorrow since it is not promised.

2. Indicating that she used to feel very low about the things she did while on drugs and that life was once full of hate and evil, the participant states that this is a bad world full of trickeries. However, she says now she feels good about her life and that she has a beautiful life, is gaining respect for herself, and is learning to be patient and to have determination.

3. Stating that she used to be hard-headed and did not listen to others, the participant says that she has now learned to listen and have a lot of faith, for God has stuck with her and brought her to where she needs to be.

\section{Essences}

(Researcher's Language)

1. Disillusioning unsureness surfaces with concentrating on the immediate strivings of longing for the cherished.

2. Rueful adversity emerges with the contented prosperity of a tolerant resolute integrity.

3. Stubborn distancing yields to sustaining solemn alliances.

\section{Proposition}

The lived experience of considering tomorrow is concentrating on the immediate strivings of longing for the cherished amidst disillusioning unsureness, while rueful adversity emerges with the contented prosperity of a tolerant resolute integrity, as stubborn distancing yields to sustaining solemn alliances. 


\section{Propositional Statements Of Participants}

1. The lived experience of considering tomorrow is ardent anticipation of initiating intimate alliances anew, while disillusioning disengagement arises amidst intentional holding, as the presence of disturbing impatience emerges with deliberate resolve in longing for the cherished, when frightening unsureness surfaces with contemplation of desired undertakings.

2. The lived experience of considering tomorrow is contemplation of launching desired undertakings with intimate alliances emerging with disillusioning anguish amidst isolating estrangement and longing for the cherished, while the tormenting despair of disturbing unsureness surfaces with solemn anticipation in the persevering steadfastness of the immediate.

3. The lived experience of considering tomorrow is contented deliberate anticipation of undertakings amidst striving with multiple encumbrances, while reflections of isolating estrangement arise with a pleasurable longing for nurturing cherished intimate affiliations, as threatening unsureness surfaces with faithfully envisioning endurance.

4. The lived experience of considering tomorrow is the puzzling deliberations of desired endeavors which shift with the ease of routinizing the immediate, while a longing for the remembered cherished surfaces with grateful solemn alliances amidst a frightening unsureness of estrangement, as enthused vigor for moving on arises with the disquieting forebodings of deliberate contemplation.

5. The lived experience of considering tomorrow is anticipating new likelihoods amidst troubling reflections of alienation, while longing for nurturing the cherished surfaces meditating on solemn alliances as frightening unsureness in contemplation eases with routinizing undertakings.

6. The lived experience of considering tomorrow is longing for the cherished amidst a disillusioning estrangement that surfaces with renewed vigor for launching new alliances, while deliberations on desired endeavors emerge with disturbing unsureness, as resilient integrity arises with the simultaneous presence of pride and disgrace.

7. The lived experience of considering tomorrow is contemplating significant strivings amidst threatening doubts of unsureness while forging ahead with the cherished in solemn confidence, surfacing the 
solitary aloofness of disillusionment with the desired calmness of harmonious alliances, as resisting nurturing yields to gradual acceptance.

8. The lived experience of considering tomorrow is contemplating the gift of launching ahead with what is cherished while disillusioning unsureness shifts, and alienating isolation emerges amidst gratefulness for nurturing solemn alliances, as innovative engagements arise with the dread of potential humiliation in intimacy.

9. The lived experience of considering tomorrow is contemplating desired endeavors amidst remorse for the remembered, while disturbing unsureness emerges with aspiring for a stability with what is cherished in the immediate, as turbulent distancing arises amidst longing for attentive joyous alliances.

10. The lived experience of considering tomorrow is concentrating on the immediate strivings of longing for the cherished amidst disillusioning unsureness, while rueful adversity emerges with the contented prosperity of a tolerant resolute integrity, as stubborn distancing yields to sustaining solemn alliances. 


\section{The Lived Experience of Considering Tomorrow}

\section{Core Concepts}

- Contemplating Desired Endeavors

- Longing For What Is Cherished

- Intimate Alliances With Isolating Distance

- Resilient Endurance Amidst Disturbing Unsureness

Structure of the Lived Experience

The lived experience of considering tomorrow is contemplating desired endeavors in longing for what is cherished, while intimate alliances emerge with isolating distance as resilient endurance surfaces amidst disturbing unsureness.

\section{Heuristic Interpretation}

Heuristic interpretation is a process of weaving the findings of the study with the theory of human becoming (Parse, 1987, 1995b). Structural integration connects the structure of the lived experience of considering tomorrow to the theory and conceptual interpretation "further specifies the structure with the concepts of the human becoming theory, leading to a specific theoretical structure from the principles" (Parse, 1987, p. 177). (See Tables 1-5)

Structural Integration. The lived experience of considering tomorrow is the pondering of possibles while yearning for the treasured, as communion-aloneness emerges with certainty-uncertainty.

Conceptual Interpretation. The lived experience of considering tomorrow is imaging the valuing in the connecting-separating of originating. 
Table 1.--Concept Evident In Propositions Of Participants: Contemplating Desired Endeavors

Structure: Contemplating Desired Endeavors

Structural Integration: Pondering The Possibles

Theoretical Concept: Imaging

Participant

1. ardent anticipation of initiating anew...contemplation of desired undertakings...

2. contemplating launching desired undertakings...

3. deliberate anticipation of endeavors...

4. the puzzling deliberations of desired endeavors...deliberate contemplation...

5. anticipating new likelihoods...in contemplation...

6. deliberations on desired endeavors...

7. contemplating significant strivings...

8. contemplating the gift of launching ahead...

9. contemplating desired endeavors...

10. concentrating on immediate strivings... 
Table 2.--Concept Evident In Propositions Of Participants: Longing For What Is Cherished

\begin{tabular}{ll}
\hline \hline Structure: & Longing For The Cherished \\
Structural Integration: & Yearning For The Treasured \\
Theoretical Concept: & Valuing \\
Participant &
\end{tabular}

1. longing for the cherished...

2. longing for the cherished...

3. longing for nurturing the cherished...

4. longing for the remembered cherished...

5. longing for nurturing the cherished...

6. longing for the cherished...

7. forging ahead with the cherished...

8. launching ahead with what is cherished...

9. with what is cherished...

10. longing for the cherished... 
Table 3.--Concept Evident In Propositions Of Participants: Intimate Alliances With Isolating Distance

Structure:

Intimate Alliances With Isolating Distance

Structural Integration: Communion-Aloneness

Theoretical Concept: Connecting-Separating

Participant

1. intimate alliances...disillusioning disengagement...

2. intimate alliances...isolating estrangement...

3. nurturing intimate affiliations...isolating estrangement...

4. solemn alliances...estrangement...

5. solemn alliances...troubling reflections of alienation...

6. launching new alliances...disillusioning estrangement...

7. desired calmness of harmonious alliances...solitary aloofness of disillusionment...

8. nurturing solemn alliances...alienating isolation...

9. longing for attentive joyous alliances...turbulent distancing...

10. solemn alliances...stubborn distancing... 
Table 4.--Concept Evident In Propositions Of Participants: Resilient Endurance Amidst Disturbing Unsureness

$\begin{array}{ll}\text { Structure: } & \text { Resilient Endurance Amidst Disturbing } \\ \text { Unsureness }\end{array}$

Structural Integration: Certainty-Uncertainty

Theoretical Concept: Originating

Participant

1. deliberate resolve...intentional holding... frightening unsureness...

2. persevering steadfastness...disturbing unsureness...

3. faithfully envisioning endurance...threatening unsureness...

4. the ease of routinizing the immediate...enthused vigor for moving on...frightening unsureness...

5. routinizing undertakings...frightening unsureness...

6. resilient integrity....renewed vigor...disturbing unsureness...

7. solemn confidence....resisting nurturing yields acceptance...threatening doubts of unsureness...

8. gift of launching...innovative engagements... disillusioning unsureness...

9. stability...remorse...disturbing unsureness...

10. contented prosperity of a tolerant resolute integrity....disillusioning unsureness...rueful adversity... 
Table 5.--Progressive Abstraction Of Core Concepts Of Considering Tomorrow With Heuristic Interpretation

\begin{tabular}{|c|c|c|}
\hline CORE CONCEPT & $\begin{array}{l}\text { STRUCTURAL } \\
\text { INTEGRATION }\end{array}$ & $\begin{array}{l}\text { CONCEPTUA } \\
\text { INTERPRETA }\end{array}$ \\
\hline $\begin{array}{l}\text { Contemplating -----> } \\
\text { Desired Endeavors }\end{array}$ & $\begin{array}{l}\text { Pondering The } . . . .>> \\
\text { Possibles }\end{array}$ & Imaging \\
\hline $\begin{array}{l}\text { Longing For What -----> } \\
\text { Is Cherished }\end{array}$ & $\begin{array}{l}\text { Yearning For -----> } \\
\text { The Treasured }\end{array}$ & Valuing \\
\hline $\begin{array}{l}\text { Intimate Alliances } \\
\text { With Isolating --.--> } \\
\text { Distance }\end{array}$ & $\begin{array}{l}\text { Communion- -----> } \\
\text { Aloneness }\end{array}$ & $\begin{array}{l}\text { Connecting- } \\
\text { Separating }\end{array}$ \\
\hline $\begin{array}{l}\text { Resilient Endurance } \\
\text { Amidst Disturbing --.--> } \\
\text { Unsureness }\end{array}$ & $\begin{array}{l}\text { Certainty- -----> } \\
\text { Uncertainty }\end{array}$ & Originating \\
\hline
\end{tabular}

Structural Integration. Considering tomorrow is the pondering of possibles while yearning for the treasured, as communion-aloneness emerges with certainty-uncertainty.

Conceptual Interpretation. Considering tomorrow is imaging the valuing in the connecting-separating of originating. 


\section{CHAPTER V}

\section{DISCUSSION OF FINDINGS}

Considering tomorrow as lived and described by women who are home-less was the phenomenon of interest in this research study. The researcher, guided by Parse's (1981, 1987, 1992, 1995a) theory of human becoming, explored the lived experience with 10 women ranging in age from 25 to 51 years who were home-less in a large metropolitan city. A meaning structure of the considering tomorrow phenomenon was generated by following the processes of Parse's $(1987,1995 \mathrm{~b})$ research methodology. The structure, considering tomorrow is, contemplating desired endeavors in longing for what is cherished, while intimate alliances with isolating distance emerge as resilient endurance surfaces amidst disturbing unsureness. This structure answers the research question and lays the foundation for discussion of findings.

Contemplating desired endeavors, longing for what is cherished, intimate alliances with isolating distance, and resilient endurance amidst disturbing unsureness were the four core concepts described by all participants during dialogues about considering tomorrow. These core concepts emerged from the descriptions given by the participants and provide the scientific data for describing the meaning of considering tomorrow in the language of science. This description expands nursing 
knowledge by providing understanding of the research generated structure of considering tomorrow as a universal lived phenomenon of human becoming.

\section{Contemplating Desired Endeavors}

The first concept, contemplating desired endeavors, was described by participants as an envisioning of goals and aspirations for creating new ways of living. This core concept describes the hopes and dreams that all participants held for moving beyond what was by thinking about acquiring education, a job or some type of income, and a place to call home.

One woman who had been home-less for many years stated, "All I want is a little room for me and a little kitten and my own little typing business. I don't need a lot of luxury and fancy stuff...Now I've got to find a way to restructure my existence, my being, so that even if I don't get everything back that I lost, at least I can have some comfort and peace of mind." Another woman said, "I just want to go to school, I want to get a shop, I want somethin' of my own. I want somethin' of my own that I can show to my children and say, 'This is ours'."

Contemplating desired endeavors involves creative tension between the now and the not-yet. As one participant noted, "I like waking up thinking about tomorrow and things I can help with because I do volunteer work at the Salvation Army...It gives me something to think about and look forward to." Concerning one's dreams a participant stated, "I've had this dream about being a beautician all my life. I like hair...If I accomplish that 
gettin' into school, then I can rent out a shop front or just work in one until I can better myself." Another participant said, "I just hope and hold on to the hope...I keep hoping things will get better...But, I don't know. I don't know if it is going to get any better...I want to keep going forward."

The conceptualization of contemplating desired endeavors emerged as the participants expressed their concerns and described their experiences in living moment-to-moment in anticipation of tomorrow. One participant stated, "I want better for my kids than I got right now...। want to go back to school." This woman's imaginings illuminated the meaning of her reality at this time. Another woman stated, "I think thinking about tomorrow is scary...I have a lot of things in life that I want to do, you know. But, I'm not sure how to begin to do them...It is my decision to go forth or not to go forth. And today I choose to go forth."

The core concept of contemplating desired endeavors was structurally integrated with the theory of human becoming at a higher level of abstraction as pondering the possibles. Pondering the possibles is described by Parse who writes, "hope is the persistent picturing of possibles" (Parse, 1990b, p. 16). This persistent picturing of possibles moves a person beyond the moment and changes one's lived experience of health (Parse, 1990b), thus diversifying one's way of becoming.

At the conceptual interpretation level of theory contemplating desired endeavors and pondering the possibles is imaging. Imaging is a way of 
structuring meaning and cocreating reality as the first principle in Parse's theory states $(1981,1995 a)$ : "Structuring meaning multidimensionally is cocreating reality through the languaging of valuing and imaging" (p. 42; p. 6).

Reality is constructed through one's simultaneous reflectiveprereflective imaging and is the shaping of personal knowledge. As the participants in this study contemplated desired endeavors they each created their own personal reality of "doing better," "going back to school" or "going into business." The creating of reality occurs explicitly and tacitly all at once (Parse, 1981). "Explicit knowing is articulated logically and reflected upon critically. It has form and substance. Tacit knowing is prearticulate and acritical, and involves the unreasoned conclusions of our senses" (Parse, 1981, p. 43). Imaging involves knowing at both an explicit and tacit level. As the philosopher Fischer (1985) suggests, imagining is a fundamental way of knowing and is central to human becoming.

Related literature that is consistent with the notion of contemplating desired endeavors found in this study, as an envisioning and a choosing to go forth, includes Marcel (1962) who depicts this choosing to go forth during a time of trial. He notes that out of various types of captivity and illness arises a pushing forward to overcome what seems like a closing off of life. The pushing forward involves envisioning a future. Philosopher Eric Fromm (1968) addresses the envisioning of a future as a component of hope 
when he writes, "Hope is paradoxical. It is neither passive waiting nor is it unrealistic forcing of circumstances that cannot occur. It is like a crouched tiger, which will jump only when the moment for jumping has come" (p. 9).

Contemplating desired endeavors is anticipating beginning anew and Stanley (1978) in a research study describes this anticipation as a hopeful "confident expectation of a significant future outcome" (p. 165). Stotland (1969) suggests that the active expectation of attaining a goal involves an element of hope. Contemplating desired endeavors is addressed also by Kirkegaard (1980) as the hopeful process of transcending oneself.

All participants in the study described the imaging process involved in contemplating desired endeavors by statements like, "My days was dark from the drugs and alcohol, ya know. I just gave up on life...now I say tomorrow is a blessing. I'm finished with drugs and alcohol...I can live tomorrow better. I can smell the grass. I can hear birds whistle." The descriptions of imaging in this study are similar to what Parse (1993) described in a laughing and health study as "contemplative envisioning" (p. 41) and in a hope study as "anticipating possibilities through envisioning the not-yet" (Parse, 1990b, p. 15). It is also consistent with Knowles (1985) when he describes the imaginative process as a form of perceiving which includes an openness, willingness and a movement toward action. Murray (1986) writes that it is this possibility of a "person to imagine even in the darkest moments the light of hope that makes integral living possible" 
(p. 255). Murray's notion of hope being present in the darkest of moments stands in direct contrast with those authors viewing hope as an attribute which can be measured and one that can be acquired or lost (Dufault \& Martocchio, 1985; Farran \& McCann, 1989; Herth 1991, 1992; Miller \& Powers, 1988; Nowotony, 1989; Raleigh 1980, 1992).

Frankl's (1984) work is consistent with the process involved in considering tomorrow when he suggests it is humanity's salvation that in the most difficult moments of our existence we live by looking to the future. As one participant stated, "I just hope tomorrow comes. And, I'll be blessed for that."

Literature on women who are home-less suggests that being homeless for women involves focusing on survival and moving toward a future. Even if a woman chooses to leave home and live on the streets or in a shelter, it is a time of intense, purposeful pushing toward tomorrow (Bard, 1990; Hagan, 1987; Heise, 1993; Francis, 1992; Maurin, Russell, \& Memmott, 1989; Rasmussen, 1995). Rasmussen (1995) notes how homeless people focus on moving beyond the now moment. "The moving beyond is witnessed in the dreams of what might be, in the struggles to go on one more day..." (p., 107). Statements by participants in this study that were consistent with struggling to go on one more day included such declarations like, "It's rough right now. I just go with what day it is and how that day progresses. If I can. I just take it one day at a time cause that is all I can do 
right now... figure I got this to do, but tomorrow I can do something else..." Statements like this concerning hoping for a better future is consistent with how Lynch (1965) describes such hoping as a sense of the possible. He states, "Hope therefore involves three basic ideas that could not be simpler: what I hope for I do not yet have or see; it may be difficult; but I can have it-it is possible" (p. 32).

Envisioning the not-yet by the participants in contemplating desired endeavors depicts the notion Kiros (1994) writes about concerning humans' imaginative capacities. Kiros (1994) posits the notion that human beings are value-creating possibilities. "As possibilities, humans can create values that reflect their authentic desires, desires that power the self to tenaciously and courageously seek freedom as self-realization" (p. 100). Contemplating desired endeavors involves seeking the freedom of self-realization and creating anew through imaging. Translating visions into realities is supported in the work of Adair (1984) who writes, "If you imagine something, you can create it" (p. 3). As Parse (1990a) writes concerning creative imagining:

Creative imagining, when seriously approached as a way of moving through the moment, immerses the person in the structured situation. This whole self-immersion is a way of experiencing a change and learning about self and environment while unfolding with imaged possibles. (p. 138) 
Fischer (1985) describes this unfolding and creating anew when writing, "The imagination takes images from the past and shapes them into new constellations. It calls out the possibilities embedded within the actual" (p. 36).

Contemplating desired endeavors is creating actuality out of possibility in living the now with hopes and dreams of the not-yet. The women in this study described envisioning new ways of living and in envisioning these new ways created new meanings in the lived experience of considering tomorrow.

\section{Longing For What Is Cherished}

All study participants described longing for what is cherished by describing wanting to be rejoined with loved ones and wanting life to be different from now or the way it was before. One woman's description of longing for what is cherished was the following: "Ya know, you see these people on TV where they are reunited with their families. Maybe one day somethin' like that might happen. It may not be as glamorous. Somethin' like that might come up where I'm reunited with my children." Another woman stated, "That's all I think about right now. A beautiful home, my children, and where they are goin' to be going to school." One woman spoke about praying for survival so she could do something with her life. She stated, "Lord, please let me live to see tomorrow... because I have three beautiful, lovely children that I always will love and I want to be back in their 
world with them." Another said, "I want to get back into the way things used to be...and, hopefully, things will remain as they once was." Another woman stated, "I want my children back because I need to be the mother that I know that I can be." One participant indicated a desire for mending broken relationships. She stated, "It's goin' to take a lot of work, a lot of hard work, a lot of time, a lot of patience to mend the relationship that I broke with my kids. But, I'm goin' to. And, I'm goin' to be there for them." Longing for what is cherished is denoted in another woman's comments when she said, "But, basically that's what tomorrow mean to me. Wake'n up healthy every morning to take care of my children and try to enjoy life with my children."

The core concept of longing for what is cherished was structurally integrated with the theory of human becoming through the concept of yearning for the treasured. Yearning for the treasured involves what Parse (1990a) describes as living patterns of preference in affirming self. That which is treasured is highly valued. "To persist in living these patterns of preference confirms specific values" (Parse, 1990a, p. 138). Thus, at the conceptual interpretation level of theory, vearning for the treasured is valuing and is connected to the first principle of the the ory of human becoming (1981, 1995a): "Structuring meaning multidimensionally is cocreating reality through the languaging of valuing and imaging" (p. 42, p. 6). 
Valuing, according to the human becoming theory, is living the cherished in structuring meaning. Valuing is the choosing, prizing and acting on the choices (Parse, 1981). As one chooses and acts on values, meaning is created. Parse (1990) states, "The 'I will' and 'I can' attitude toward a given desire for change creates it and affirms self in a different way, thus changing health" (p. 138). Such meaning-making and shaping of reality through the valuing process is clear in all participants' descriptions in this study and is portrayed in the following statement of one of the participants: "I hope God walks with me in tomorrow the same as He does today. I know with His power and my determination, I'm sure my tomorrow will be OK...I got to have something to show for my life."

In the related literature the conceptualization of longing for what is cherished as valuing, choosing new experiences while at the same time longing for what was, is congruent with the writings on hope of existential philosopher Gabriel Marcel (1962) concerning a returning-to and a goingbeyond. Longing for the cherished can be viewed as a rhythmical pattern of desiring what-was while desiring what-can-be. Marcel (1962) writes, "Might we not say that hope always implies the superlogical connection between a return (nostos) and something completely new (kainon)...as before, but differently and better than before" (p. 67).

All participants' descriptions indicated statements like, "I know tomorrow I will work a little harder because I don't like the way yesterday 
was... I can plan things for us to do for tomorrow, ya' know. So we will be a happy and a functional family." Such longing for the cherished amidst the struggles in the here-and-now is described by Wu (1972) when he writes, "Whether the dreams become productive hope or defeatist opiates depends on what we do with those visions when we are confronted with the disastrous here and now" (p. 146).

The valuing that the participants in this study depicted is congruent with the findings of Baumann's (1993) study of the lived experience of being home-less for women. Seven themes were identified concerning what the women in his particular study longed for in their lives: These themes consisted of: (a) struggling to maintain physical and personal boundaries associated with a desire for safety; (b) wanting to maintain connections with objects, people and institutions; (c) desiring a place to rest from the fatigue and despair of constant movement; (d) wanting to maintain self-respect since being home-less threatened their human dignity; (e) longing for selfdetermination; (f) wanting privacy and a place to do what one wanted to do; and (g) wanting permanency, but needing to keep moving because of lack of income or needing to flee an abusive relationship.

Participants in the study on considering tomorrow indicated the effort to maintain dignity and a sense of self. They indicated a desire to be certain of themselves and to feel good about what they were doing by such statements as, "I want to be proud." Frankl (1984) focuses on the human 
desire and capacity to creatively turn life's negative aspects into something positive when he identifies what he sees as the central theme of human existence: "To live is to suffer, to survive is to find meaning in the suffering" (p. 9). The participants in this study created meaning in their lived situations in longing for what is cherished and focusing on deriving from life's transitoriness an incentive to be connected with that which they yearned for and treasured.

Oliver (1974) depicts this longing for what is cherished, this creating meaning in valuing when he writes:

The experience of hope is not just a collection of ideas about the future, though its form will include futuristic symbols. It is a way of being in the world by which the meaning of life is affirmed in the face of the apparent meaninglessness of death. (p. 85)

Frankl (1984) discusses creating possibilities in one's life as the essence of creating meaning. The perception of meaning in one's life, according to Frankl (1984), "boils down to becoming aware of possibility against the background of reality, or, to express it in plain words, to becoming aware of what can be done about a given situation" (p. 145).

Meaning making in valuing is depicted in all of the participants' descriptions through statements like, "After I get myself together and settle down maybe I can start looking for my kids. At least I want them to know that I'm not a bad person and that I didn't give them away, they were 
actually stolen from me...I would like to make it up to my kids... And, I would like them to have respect for me and understanding."

Participants' statements describing longing for the cherished are similar to what Thornburg (1993) describes in her study concerning the structure of the lived experience of hope for parents whose children had died from sudden infant death syndrome. She found hope to be "moving on despite barriers in the comfort-discomfort of being with and apart from others while anticipating the possibilities amidst treasured moments" (p. 57). Rasmusson, Jonas \& Mitchell (1991) highlight this valuing in a woman who is home-less when they describe her statements made in a group. The woman elaborates on how she has been labeled by others as deranged and incapable, but describes herself as a woman who cares for and loves others.

Longing for what is cherished for women home-less involves the yearning to be with cherished others and cherished moments while continuing moving on to create anew. The creating anew moves one toward that which is yearned for and prized.

\section{Intimate Alliances With | solating Distance}

The women in this study depicted intimate alliances with isolating

distance in describing their day-to-day struggles in relationships (past, present, and future) with identifying a sense of alienation from others as well as identifying feelings of connectedness to those loved. Many of the women also described connectedness to a higher power most often identified as God 
or Jesus. The dialogues surfaced intense feelings concerning how the participants viewed belonging in community with others. One woman's description of this paradoxical relational pattern of intimate alliances with isolating distance involved focusing on people who were wanting to help the home-less. She stated, "They say they want to help people, but they don't really want to. They just shuffle you from one place to another. You are just a number, just a statistic, they don't care." She then went on to say, "It's not that I dislike people, it's that I see what they have done to me. They don't know what honesty is...it's just like let me dig my claws in you 'til you bleed and hey, then I'm satisfied. And then when there is no more blood throw you away." At the same time, however, this women indicated she looked forward to being associated with others by saying, "I like to go out to the O'Hare Airport. You meet a lot of positive people out there. You know, I leave there at night and I say, well, I'll be back here tomorrow...I try to keep myself in a state of mind where I can meet people with some kind of intelligence who are about something...maybe tomorrow we might meet each other and talk or come to some kind of agreement and help each other out." The paradoxical rhythm of engaging and distancing is present in this woman's message. Another participant stated, "So, it's not going to be easy for me. No, not at all. I have had to distance myself from family members. I have had to let go a lot of things that I thought meant a lot to me. But, the value of what I have today, you can't put a price on it and no 
money can buy it...I've got peace of mind and that is only through God's grace."

One woman said, "I just thank my Higher Power 'cause He is the only one that never turned His back on me. If it weren't for Jesus I'd be gone." One participant described her isolating estrangement by stating, "You know, say you're getting your life back together and they don't want you to have these good things. They'll push you away." However, this same participant looked to the Lord to be with her and protect her. She stated, "I know the Lord ain't gonna give ya nothin' to hurt ya'. He gonnar give you something to fulfill you and help you and the Lord has given me a blessing." Her statement concerning her intimate alliance with her Lord is congruent with the related Christian biblical literature Jeremiah 29:11 where it is written, "For I know the plans I have for you, declares the Lord, plans to prosper you and not harm you, plans to give you a future and a hope" (Holy Bible, 1985, p. 1171).

The core concept of intimate alliances with isolating distance was structurally integrated with the theory of human becoming as communionaloneness. The core concept of communion-aloneness portrays the participants moving toward and away from alliances. As the participants conveyed their distancing from certain persons and situations and their moving toward other persons and situations in their struggle of moving from the now to the not-yet, the paradoxical pattern of engaging-disengaging 
became apparent and is consistent with related literature of Marcel (1962) and his notion that hope for liberation and salvation--is experienced in communion with the situation and those in the situation. Marcel's (1962) major thesis concerning hope for liberation and salvation is: "I hope in thee for us" (p. 60).

Communion-aloneness at the conceptual interpretation level of theory is connecting-separating. Connecting-separating is a coming together with others and various phenomena while simultaneously separating from other possibilities (Parse, 1981). This connecting-separating is related to the second principle of the theory of human becoming which is: "Cocreating rhythmical patterns of relating is living the paradoxical unity of revealingconcealing and enabling-limiting while connecting-separating" (Parse, 1981, p. $50 ; 1995 a$, p. 7$)$.

The conceptualization of intimate alliances with isolating distance involves envisioning new ways of connecting and separating from persons and situations. In living the core concept of intimate alliances with isolating distance the participants in this study were moving from the now to the notyet being open to the new and indicating a willingness to risk in relationships. Parse $(1995 a)$ writes:

Through languaging, humans disclose and hide all-at-once the who that they are, while living the opportunities and limitations of being close to and apart from others. Humans change 
moment to moment as they actualize dreams and hopes through inventing new ways to propel beyond what is to what is notyet. (p. 8)

The women in this study propelled beyond what is to what is not-yet as intimate alliances with isolating distance unfolded new opportunities and limitations all-at-once.

Connecting-separating in new ways to "propel bevond what is to what is not-yet" (Parse, 1995a) is congruent with the findings of the study conducted by Francis (1992) who used the conceptualization of connectiondisconnections in describing the lived experiences of eight women who became home-less. Themes involving connection-disconnection emerged in the study. They included: (a) violations and disconnections that described how they became homeless; (b) temporary private connections described their doubling up in living; (c) temporary public connections involved moving to a public shelter and experiencing long waiting periods and intense feelings; and (d) rebuilding connections portrayed the process of searching for apartments, looking at who and what helped and who and what hindered this process. Thus, the process of becoming home-less for the women in the Francis (1992) study had involved suffering some type of violation leading to a disruption of family relationships and subsequent disconnections from home, family, and community. The process of trying to re-establish a home involved making new connections in the community (Francis, 1992). 
The connection-disconnection described by Francis (1992) is similar to the connecting-separating described in the communion-aloneness of the women in this study. The core concept of intimate alliances with isolating distance sheds light on the languaging of the rhythmical, paradoxical nature of being with and apart from others when moving from the now to the not-yet all-atonce.

Intimate alliances with isolating distance is a paradoxical lived pattern of moving toward and away from persons, ideas, places, and events as one considers tomorrow. It involves the languaging of closeness and distancing all-at-once.

\section{Resilient Endurance Amidst Disturbing Unsureness}

The fourth core concept, resilient endurance amidst disturbing

unsureness, was characterized by the participants as a knowing of unique ways of moving into the not-yet with particular patterms of relating to others, planning activities, and diverse ways of structuring their treasured possibles. Coexisting with the resilient endurance was a pervasive feeling of not knowing what tomorrow would bring or whether or not one would live to see tomorrow. This paradoxical pattern of being sure and unsure, of knowing and not knowing was noted in the participants' stories. One woman said, "I just keep hoping that the future will be better than it is...As long as I keep faith and keep on hoping and praying things will improve and life will go on." However, she also stated, "You don't know what to expect anymore. You 
go out to the store and somebody can mug you. It's rough. Life is getting worse." Resilient endurance was accompanied by disturbing unsureness for all participants. The tension of resilient endurance with disturbing unsureness present in the descriptions of the women in this study involved actively imaging that things would get better. These women's unique way of moving in their world included believing in the power of hope and faith which supported resilient endurance. Knowles (1985) suggests that this type of believing, which is related to imagining, is "a particular way of moving in the world" (p. 61). Consistent with this Bloch (1986) posits that the work of pushing forward "requires people to throw themselves actively into what is becoming to which they themselves belong" (p. 3).

Another participant described her resilient endurance amidst disturbing unsureness in the following comments: "You already know these people can't do nothin' for you except hold you down. It's rough being homeless, true enough, but its not a disgrace. And there's got to be a way out of it... I don't care to much for shelters. I know that negativeness, it's dangerous... Get on the bus, just go. You have to take the initiative yourself. I know the library isn't open on Sunday, maybe you can't do it on Sunday, but you could sure be there on Monday." Her resilient endurance with disturbing unsureness manifested itself in her constantly moving on to new locations. 
Another woman stated, "I live for today. Don't set aside something I can do tomorrow when I can do it today... I set everything up in a pattern for me." This sureness, however, was countered by the woman saying, "And tomorrow scares me because right now I feel good about myself. But, for today. But the thought of tomorrow--l never know if you goin' to get put out of this place and what will happen." This woman demonstrated her dealing with the resilient endurance amidst disturbing unsureness through the routinizing of immediate tasks and focusing on today.

One participant said, "Well, you try to plan, but that's not wise either 'cause you never know where you're going to be or what's going to be goin' on. I keep saying I'm going to get a job, but everywhere I go as soon as they find out you're homeless that's the end of it." Later in the dialogue the woman remarked, "You see, I got to hold on to the little bit of sanity I have, the little bit of dignity that I have... at least tomorrow I can push myself a little closer to getting to that goal...search for ways to put yourself in the best position to meet people who can help you get to that position." This woman depicts in her statements the search for possibilities emerging as part of her response to the lived paradox of resilient endurance amidst disturbing unsureness. Searching for possibilities as part of resilient endurance amidst disturbing unsureness involves imagining the possibles and is described by Lynch (1965) who writes that the imagination will always suppose that there is a fact and a possibility that is not yet known. 
The core concept of resilient endurance amidst disturbing unsureness was structurally integrated with the theory of human becoming as certaintyuncertainty. Certainty-uncertainty is lived "in human encounters as individuals make concrete or clear their choices in situation yet, simultaneously, live the ambiguity of the unknown outcomes" (Parse, 1981, p. 60).

At the conceptual interpretation level of theory certainty-uncertainty is originating. Originating is a process of mutual unfolding, of choosing unique individual ways of living (Parse, 1981) and is connected to the third principle of the human becoming theory: "Cotranscending with the possibles is powering unique ways of originating in the process of transforming" (Parse, 1981, p. 55; 1995a, p. 7).

The conceptualization of resilient endurance amidst disturbing unsureness enhances the understanding of considering tomorrow for women who are home-less by shedding light on the explicit and tacit knowing that occurs in their lived experience. Originating unique ways of moving with the not-yet surfaces new meanings in lived experiences. All participants stated that "they were at a new place" for themselves. The originating depicted by the participants is consistent with related literature. Brunsman (1987) describes the process of structuring new meaning when she writes, "hope is the process of creating anew" (p. 115). Wu (1972) notes that "misery is created by a person's conscious practice against and within an existing 
situation. It is this life-protest that makes misery a stigmata, and it is this stigmata that gives rise to hope" (p. 132).

This notion of resilient endurance with disturbing unsureness is described in the related writings of Marcel (1962) when he writes that when little is a stake, hope is at its lowest tension; when much is at stake, hope is at its greatest tension. In living the resilient endurance amidst disturbing unsureness of originating these participants were living with the ambiguities of the situation while forging different ways of thinking about their circumstances. The paradoxical nature of knowing and not-knowing, being sure and not-sure all-at-once, gives rise to challenges in imagining innovative ways of struggling with survival. Parse (1994a) identified in a study on laughter and health that imagining was central in understanding the shifting of people's visions and consistent with this, Casey (1976) states that at any given moment a person is either imaging, imagining-that, or imagining-how.

Resilient endurance amidst disturbing unsureness involves novel ways of struggling with what-is to what-is-not-yet. In the related literature on being home-less Bard (1990) highlights innovative methods of living this struggle from the now to the not-yet for home-less women in the urban and suburban milieu. She cites such innovative, imaginative strategies as "strolling a mall with assumed purchases; sitting quietly, reading in a library; walking market aisles nibbling on finger goods and sipping a soda; waiting patiently for transportation; utilizing free cosmetics while browsing in a 
store" (Bard, 1990, p. viii). Bard (1990) writes: "I respect the obscurity which they nurture; they have designed and developed a way to live with as much dignity as possible" (p. viii). Bard (1990) suggests that the unique ways women who are home-less struggle to survive helps bridge the gap between "mere life and meaningful existence" ( $p$. xiii). The participants in this study depicted a hopeful readiness for the future.

Hopeful readiness for the future is congruent with the writings of Fromm (1968) who connects such inner readiness with hope and faith. Fromm's major thesis concerning hope is: it is "a state of being--an inner readiness,--that of intense but not-yet activeness" (Fromm, 1968, p. 12). He links this inner readiness of hope closely to faith. He writes, "faith is a vision of the present in a state of pregnancy; it is certainty about the reality of a possibility. The paradox of faith is: It is certainty of the uncertain" (Fromm, 1968, p. 13). The lived experience of considering tomorrow for the women in this study uncovered the lived experience of the certaintyuncertainty of originating.

Resilient endurance with disturbing unsureness stands in direct contrast to the findings of the studies conducted by Newman (1993) who found the core concept emerging from data in a study of abused home-less women was "giving up" and Baumann (1993) who used the metaphor of "a whirlpool of poverty and powerlessness" to describe the experiences of home-less women. However, consistent with resilient endurance amidst 
disturbing unsureness is Hodnicki \& Horner's (1993) findings of the core theme of "one step at a time" for home-less mothers' caring for children in a shelter and Montgomery's (1994) synthesis of the metaphor of "swimming upstream" to describe home-less women's experience of courage and strength.

Resilient endurance amidst disturbing unsureness is struggling with the paradoxical nature of being sure and not-sure while moving beyond the now with resoluteness to the not-yet. It involves knowing and not-knowing one's possibilities and moving toward the not-yet with confidence while pausing with the realization of unpredictability.

\section{Considering Tomorrow, Health, and Quality of Life}

It was identified in chapter one that nurses connect with individuals and groups during some of the most difficult moments in life, as well as during some of the most joyous moments in life, and that both understanding and openness by nurses are needed to be truly present with others during these moments. Thus, explicating the lived experience of considering tomorrow, which is a lived experience of health, is important. Considering tomorrow as contemplating desired endeavors in longing for what is cherished, while intimate alliances with isolating distance emerge as resilient endurance surfaces amidst disturbing unsureness provides the basis for understanding the ways persons choose changing health patterns as they move from moment to moment. 
Nurse theorist Rosemarie Rizzo Parse's nursing theory of human becoming $(1981,1992,1995 a)$ was used as the theoretical framework for this study. Parse $(1981,1987,1990 \mathrm{~b}, 1992,1995 \mathrm{a})$ posits that health is a process of unfolding, a personal commitment to a lived value system. Women who were home-less in this study shared their unique ways of emerging lived patterns of health as they moved to the not-yet. These patterns were described by them and interpreted in the language of science as the four core concepts of contemplating desired endeavors, longing for the cherished, intimate alliances with isolating distance, and resilient endurance with disturbing unsureness.

Parse further defines health as "a personal commitment that is lived through abiding with the struggles and joys of everydayness in a way that incarnates one's quality of life" (Parse, 1990b, 138). Quality of life is further defined as, "what the person there living the life says it is" (Parse, 1994b, p. 17). The women in this study described and defined their own quality of life as they related the meanings of considering tomorrow through describing the struggles and joys of their day to day patterns of moving from the now to the not-yet.

The first core concept, contemplating desired endeavors, was described by participants as an envisioning of what tomorrow's activities might be while focusing intensely on today. Contemplating desired endeavors relates to Parse's $(1981,1995$ a) concept imaging. Imaging is a 
concept in Parse's first principle, "Structuring meaning multidimensionally is cocreating reality through the languaging of valuing and imaging" (Parse, 1981 , p. $69 ; 1995 a$, p. 6$)$. "Imaging is the picturing or making real of events, ideas, and people" (Parse, 1987, p. 164). In pondering the possibles through imaging the women in this study depicted unique stances toward creating anew. The cocreation of the new arose in thinking about what could be. These considerations shaped the emerging health patterns of these women.

Studies conducted by Brunsman, 1987; Parse, 1990b Smith, 1990b; Stanley, 1978; and Thornburg, 1993 also uncovered the notion of an envisioning of and orientation toward the future. For example, Stanley (1978) in studying young healthy adults' experiences of hope, found that the lived experience of hope contained, "a confident expectation of a significant future outcome..." (p. 165). Brunsman (1987) studied hope in two families with a chronically ill child and defined hope as "the process of creating anew" (p. 115) and linked hope to imaging within Parse's theory of human becoming. Parse (1990b) studied hope with 10 persons and found hope to include "anticipating possibilities through envisioning the not-yet..." and linked it to "imaging the will-be" (Parse, 1990b, p. 17).

Smith (1990b) found in fifteen families of critically ill persons that hope included a "confident view of the not-yet" (audiotape). Imaging was also identified as an important core concept in Mitchell's (1995) study on the 
lived experience of restriction-freedom in later life. The concept surfaced in older persons as anticipating limitations and envisioning the will-be. The common features in these research findings consistent with the findings concerning contemplating desired endeavors are (a) imaging is a way of envisioning the future, and (b) anticipation of what will be is embedded in the now and the was, as the will be is heralded in humans changing health patterns. Considering tomorrow is intrinsic to health and quality of life for persons living the challenge of moving toward a new way of becoming. Envisioning and choosing unique and different ways of becoming is health. Casey's (1976) study on imagining also relates to these findings. He suggests that pure possibility pertains to the fact that whatever one imagines might be, but which, in fact, is not-yet. He further suggests that "imagining is entertaining oneself with what is purely possible" (Casey, 1974, p. 18). In imaginative presentations no imaginable options are ruled out-anything and everything becomes possible (Casey, 1974). This is consistent with Parse's (1990a) view that in relation to health one pictures unique possibles that only the person as coauthor of personal health can cocreate.

All participants described a longing for the cherished related to the considering tomorrow experience. This second core concept was described in relation to wanting to be reconnected with loved ones and places while moving into the desired not-yet. Longing for the cherished relates to Parse's 
theory of human becoming concept of valuing. Valuing also is a concept in Parse's first principle of the human becoming theory (Parse, 1981, 1995a). "Valuing is the confirming-not confirming of what is cherished in the prereflective-reflective knowing of imaging" (Parse, 1995a, p. 7). Parse (1995a) states that people live their treasured beliefs and meanings in the process of cocreating their becoming which is health. The participants in considering tomorrow yearned for persons, places, and events that were absent from them or not within their reach in the moment.

Valuing as a yearning for the treasured is shown in Pilkington's (1993) study of the lived experience of grieving the loss of an important other. Pilkington (1993) in her study with five mothers who had lost a baby at birth interpreted valuing to be, "pronounced agony with intense yearning for the cherished other" (p. 136). Cody (1991) also identifies valuing as integral to grieving a personal loss which is prized. In both of these studies the participants struggled in cocreating their health with shifting views concerning being with the cherished losses. Smith (1990a) similarly describes "grieving the loss of what was cherished" (p. 23) as a valuing for those struggling with unemployment.

The findings from these other Parse studies raises the question concerning whether or not the participants in yearning for the treasured are not also grieving a loss. Further research could explore such a possibility. However, other Parse studies (Kelley, 1991; Costello-Nickitas, 1994) 
describe the core concept of valuing as affirming cherished beliefs. Thus, the similarity concerning valuing found in all studies cited is the cherishing component of the lived experience and is consistent with Parse's (1995a) statement that "valuing is the confirming-not confirming of what is cherished..." (p. 7). Confirming-not confirming the cherished is integral to the human health experience (Parse, 1981, 1992, 1995a).

The third core concept, intimate alliances with isolating distance was manifest in all participants descriptions of relationships. The communionaloneness described by participants is linked to Parse's concept of connecting-separating. Connecting-separating is part of the theory of human becoming's second principle, "Cocreating rhythmical patterns of relating is living the paradoxical unity of revealing-concealing and enabling-limiting while connecting-separating" (Parse, 1981, p. 69; 1995a, p. 7). "In moving together and apart all-at-once, one connects and separates with the universe in the rhythmical flow of cocreation" (Parse, 1995a, p. 7).

The paradoxical nature of the connecting-separating experience described by the participants as intimate alliances with isolating distance is shown in findings of other Parse studies (Cody, 1991, 1995; Pilkington, 1993). Cody (1991) describes those grieving a personal loss as having an ongoing experience with the presence of the one who was lost. This finding uncovers the paradoxical nature of being both present to and absent from another. He describes this essence as living communion-aloneness. For 
those living with AIDS Cody (1995) identifies a communion-solitude of "bearing witness to aloneness with togetherness" (p. 220) and links this to Parse's concept of connecting-separating. Pilkington (1993) describes connecting-separating as engaging and disengaging with the absent presence and others. The participants in these studies lived connectingseparating in unique ways of living health through communion-aloneness.

The fourth core concept, resilient endurance amidst disturbing unsureness, is an expression of the life pattern of certainty-uncertainty. The paradox of certainty-uncertainty is linked to Parse's concept of originating in the third principle of the theory of human becoming, "Cotranscending with the possibles is powering unique ways of originating in the process of transforming" (Parse, 1981, p. 69; 1995a, p. 7). Originating is "living conformity-non-conformity and certainty-uncertainty in moving the unfamiliar to the familiar" (Parse, 1995a, p. 7). It is creating anew.

Although originating has been identified as a core concept in other Parse studies (Brunsman, 1987, Mitchell \& Heidt, 1994; Mitchell, 1994, 1995; Parse, 1994a), this is the first study to identify resilient endurance with disturbing unsureness as a changing health process of living the rhythm of certainty-uncertainty. However, Fromm (1968), Frankl (1984), and Marcel $(1962,1965)$ in their writings on hope also relate the human phenomenon of moving on with fortitude in times of trial and uncertainty. 
The lived experience of considering tomorrow is contemplating desired endeavors in longing for what is cherished, while intimate alliances with isolating distance emerge as resilient endurance surfaces amidst disturbing unsureness. The paradoxes inherent in the process of considering tomorrow are part of living health which is one's quality of life. In light of considering tomorrow, health is the process of envisioning what will be while living cherished personal commitments. The cherished possibles of personal commitment surface in the connecting-separating with what was, what is and what will be while inventing new patterns of becoming. The meaning given to the process of imaging and valuing a personal commitment in the connecting-separating of originating new patterns of becoming emerges as one's quality of life. Considering tomorrow is the way persons create themselves in the now.

This research has provided scientific data to describe the structure of the lived experience of considering tomorrow within the framework of Parse's theory of human becoming, thus expanding nursing science. Considering tomorrow is a new formulation of a health phenomenon providing new information for nursing and for the literature on home-less women. The final chapter will discuss conclusions, recommendations, and reflections. 


\section{CHAPTER VI}

\section{CONCLUSIONS, RECOMMENDATIONS, REFLECTIONS}

The purpose of this research study was to explore the lived experience of considering tomorrow in order to generate a research-based meaning structure of the phenomenon. No prior research has been conducted on this newly conceptualized human health phenomenon. This researcher was guided by nurse theorist Rosemarie Rizzo Parse's theory of human becoming which provided a nursing framework and nursing research methodology to explore the considering tomorrow experience for women who are home-less.

Ten home-less women between the ages of 25 to 51 years from a large metropolitan area described their experiences of considering tomorrow. Four core concepts of shared meaning were linked to form the structure: The lived experience of considering tomorrow is contemplating desired endeavors in longing for what is cherished, while intimate alliances with isolating distance emerge as resilient endurance surfaces amidst disturbing unsureness. This structure was the central finding of the study and was discussed in relation to participants' descriptions, the theoretical concepts and principles of the human becoming theory, and theoretical and researchrelated literature. Findings expand nursing's scientific base and contribute to the growing body of nursing science. Parse's theory of human becoming provided the lens through which to understand considering tomorrow as a 
paradoxical process of health as lived by human beings. Findings have been presented and discussed, now conclusions, recommendations, and reflections will be offered.

\section{Conclusions}

Bard (1990), Liebow (1993), Kozol (1988) and Parse (1987, 1995b) are among the qualitative researchers who suggest that the lived experience of people encountering ambiguity and paradox in day to day living needs to be described in their own words. Parse's process-orientated theory and phenomenological-hermeneutic research methodology provided the vehicle to make such research possible.

The Parse research methodology related to the human becoming theory is value-based research. Science as value-based means fully acknowledging the critical role of theory in all interpretation of data, including that of findings (Mitchell, 1992, Mitchell \& Cody, 1993). Such value-based research arises in the tradition of the human sciences. Wilhelm Dilthy (1833-1911) originated the term human science and proposed that human beings were the preeminent source of knowledge and that the subject matter of the human sciences should be lived experiences with a focus on meaning, values, and relationships (Dilthy, 1976).

The purpose of this research has been fulfilled. The structure of considering tomorrow was specified within the framework of the human becoming theory. The findings were linked to health and quality of life, and 
the human becoming theory was expanded. This was the first nursing research study as well as the first Parse study to explore the health phenomenon of considering tomorrow, thus the building of knowledge related to this phenomenon has just begun.

Considering tomorrow is concerned with moving from the now to the not-yet with envisioned plans, hopes, and dreams. It is a new notion in relation to health and quality of life since it looks at a person's way of cocreating tomorrow. Thus this research provides new knowledge for nursing and new information to add to the home-less literature about the lived experience of living into the not-yet when resources and relationships seem limited. There was no literature that addressed this human health phenomenon.

\section{Recommendations}

Future studies of considering tomorrow conducted with different persons may surface knowledge through uncovering different relationships that further enhance understanding of considering tomorrow and health. No generalizations of findings or inferences for how women who are home-less should experience considering tomorrow is attempted here. What the research reported here offers is an understanding of a paradoxical lived experience involving these women's hopes, dreams, and envisioning of the not-yet, as well as their participation in the day-to-day struggle of living with the now and the not-yet all-at-once. 
One recommendation for researchers interested in participating in research with the home-less is to be affiliated with an agency and community outreach workers working with the home-less population. Community outreach workers connected to the population of home-less women afforded a direct linkage to the women and provided this researcher with valuable insights as to how to proceed with inviting participation in the study.

Conducting human science research on considering tomorrow for women who are home-less using Parse' theory and research methodology breaks down the stereotypes of labeling and categorizing often seen in the empirical research on being home-less. Being truly present with these participants in dialogical engagement shed light on the hopes, dreams, goals, and aspirations of people often labeled as hopeless and disenfranchised. It surfaced the intense desire of these women to "live in their own chosen, preferable way."

The considering tomorrow structure was woven back into the human becoming theory so as to illuminate new relationships concerning health as a process of becoming. Considering tomorrow for women home-less highlights the concept of situated freedom in the human becoming theory. These women, within the context of their home-less situation, through imaging the valuing in the connecting-separating of originating, chose unique ways of moving into the not-yet. 
The considering tomorrow experience should be explored with other groups, especially with home-less individuals (other adult women, children, and men) who are living in different settings, such as small towns and rural communities as well as in different cultures. The phenomenon of considering tomorrow could also be investigated with persons who are struggling with difficult moments as well as with moments of joy in other circumstances. Such persons could include the very poor who are housed, persons imprisoned, those with HIV/AIDS, those with chronic disabilities, and persons grieving a loss of a loved one. Exploring considering tomorrow with different age groups across the life span and with persons at different socioeconomic levels in society may also be informing. Since this is the first nursing study conducted on considering tomorrow, more inquiry is needed on this health phenomenon to uncover the range of variations and similarities posed for different groups of persons.

In addition to these possibilities, the core concepts of the structure could be further explored as related lived experiences. There are four core concepts linked together from the structure: contemplating desired endeavors in longing for what is cherished, as intimate alliances with isolating distance emerge as resilient endurance surfaces amid st disturbing unsureness. The phenomenon for study with Parse's human becoming theory must be a universal lived experience. These core concepts appear to be of such a universal nature. 
The concept of contemplating desired endeavors might be studied as the lived experience of setting a goal for oneself or the lived experience of imagining a preferred outcome in one's life. Contemplating desired endeavors was linked to the human becoming's theory of imaging which could be used to develop a study using art or storytelling as a vehicle to seek depth of meaning of considering tomorrow with women who are homeless. Women who are home-less could be invited to draw a picture or write a story depicting what it would be like to accomplish a longed for goal in life.

There could be further query into longing for what is cherished by studying the lived experiences of loving another or feeling loved. Longing for what is cherished was linked to valuing in the human becoming theory and is related to prizing and choosing. Thus, the lived experience of choosing a certain way to live might be explored. Also, study of the lived experience of feeling valued would illuminate understanding of valuing.

Isolating distance with intimate alliances is a complex concept linked to connecting-separating, and suggests the possibility of many lived experiences for study. For example, separating from a person one cares for, or the lived experience of feeling rejected. Another focus for study could be the lived experience of being a friend.

The fourth core concept, resilient endurance with disturbing unsureness, is another complex concept and provides many prospects for future study. For instance, the lived experience of moving forward with 
assurance while doubting at the same time. Other possibilities include studying the lived experience of doubting, the lived experience of being sure, or studying the experience of feeling strong. This core concept was linked to originating in the theory of human becoming and, thus, gives rise to studying the whole area of creating anew. For example, a study could be conducted on the lived experience of creating something for oneself. The significance of these core concepts in generating future research is immense.

\section{$\underline{\text { Reflections }}$}

Understanding the meaning of the lived experience of another is the essence of coming to know another and valuing the other as a unique human being. Research on considering tomorrow with women who are home-less using Parse's theory-guided research, has provided this researcher with a new appreciation of the importance of understanding in participating in health with others.

Dialoguing with these women in true presence, as they shared their struggles and joys in considering tomorrow while surviving on the streets, illuminated the fact that women who are home-less are not faceless or nameless as so often depicted in the literature. These women have names and are unique individuals who are imaging life goals and are cocreating the not-yet with their hoping, envisioning and choosing. In telling their stories these women shed light on the difficulty, the pain and suffering, and the 
promise of the meaning of considering tomorrow when access to resources such as money, property, and significant others poses a challenge.

In dialogue, this researcher cocreated opportunities with these women to lift their voices and uncover personal truths for others to hear and understand. Kearney (1987) suggests that a critical-poetic-hermeneutical imagination "bids us to tell and retell the story of ourselves...out of fidelity to the other. It is above all the other who demands that I remain responsible to myself. For if there is no longer a self to abide by its promises or covenants, there is no ethical relation to the other possible" (p. 55). Heidegger (1962) writes, "The most primordial phenomenon of truth is first shown by the existential-ontological foundations of uncovering... This uncoveredness is preserved in what is expressed" (p. 263, p. 266). This uncovering and uncoveredness referred to by Heidegger represents an uncovering of one's Being in the processes of coming to know and understand.

A coming to know and understand the meaning of another's lived experience is the focus of Parse's theory-guided human science research. Such understanding surfaces for nurses new ways of being with persons in situations and shifts nurses' perspectives concerning lived experiences of health. Understanding sheds light on the importance of respect for human diversity and emerges different nurse-person patterns of cocreating quality of life. 
Parse's theory of human becoming and research methodology provided this researcher with the opportunity to participate in the expansion of nursing science by connecting the structure of considering tomorrow with the three principles of the human becoming theory. And, although all core concepts of the theory of human becoming are present in human experiences, at the conceptual interpretation level of theory considering tomorrow for women home-less brings to the foreground the imaging of valuing in the connecting-separating of originating.

The use of nursing theory guided research in exploring the humanuniverse-health process provides possibilities for advancing nursing as an informed and independent discipline. For "the knowledge base that guides the nurse-person process and research is the very ingredient that separates nursing from all other health-related disciplines" (Parse, 1995c.

p. 1). In the theoretical base of the science of nursing is housed the promises and covenants of the profession.

The evolution of nursing science, with an emphasis on quality of life from the person's perspective, surfaces nursing's fidelity to itself as an emerging discipline and accents nursing's fidelity to the personal reality of the other in matters of health. As Kearney (1987) writes, "...it is above all the other who demands that I remain responsible to myself. For if there is no longer a self to abide by its promises or covenants, there is no ethical relation to the other possible" (p. 55). 
APPENDIX A

LOYOLA UNIVERSITY INSTITUTIONAL REVIEW BOARD APPROVAL 
APPENDIX A

\title{
LOYOLA UNIVERSITY INSTITUTIONAL REVIEW BOARD APPROVAL
}

\author{
INSTITUTIOHAL REVIEW BOARU \\ RESEARCH GERUICES OFFICE \\ LOYOLA UHIVERSTTY OF CHICAGO \\ 6525 HORTII BHER IONT ROAD \\ CHICAGO Ih 60626 \\ Te1, (312) 508-2471 Mattlew creighton, SJ, Chair \\ Marcl: 31, 1995
}

Investigator: Sandra Schmidt Bunkers

Home Addrege: 1.19 Plum Creek Road

Stoux Falle, South Dakota

57105

Home Ielephone: 335-0828 [Area Code: 605]

please check the above information for accuracy and call in any corrections to 50 3-2471.

Dear Colleague.

Thank you for submitting the following reaearch project for review by the Ingtitutional Review Board Eor the Protection of lluman subjecta:

project ritle: Congidering Tomorrow

nfter careful examination of the materlals you aubutted, we have approved thie project as degcribed for a period of one year from the date of this letter.

Approximately eleven montha from today, you will receive from the IRB a lettex which wLll a ak whether you wiah to apply for renewal of IRB approwal of youx project. You will be asked whether the re have been any clianges in the nature of the involvement of human anbject in your project aince it was first approved, and whether you foregee any such changes in the near future. IE your responges to thege questions are timel $Y$ and oufficientiy explicit, the IRB will at that time renew pour approval for a further twelve-month period. If you do not return that form by March 30, 1996, however, Your approval will automat ically lapse.

This review procedure adminlatex ad by the IRB Itoele. In no way abgolyos you pereona ly Erom your obilgation to Inform the IRB in writing lmmediateiv If you propose to make any changeg In aspecta of your work that involve the participation of human aubjects. The sole exception to this requirement is in the case of decistan not to puraue the project--that is, not to use the researcis instrumente, procedures or populations origilalily approved. Reaearchera are regpect $f$ ull $Y$ reminded that the Univeraity'g willingnesg to aupport ox to defend ita employees in legal. cases that may arise from their use of human subjecta ig dependent upon those emplovees'

conformity with Univeraity polldeg regarding 1 RB approval for their work.

Should you have any queat tong regardirig thia letter or the procedures of the IRB in general, I invite you to contact me at the addregg or the te leplone number fhown on the letterhead. If your question liag diectly to do with the project we have just approved for you. plespe quote Elle number 1356 .

with best wishes for your work,

Sincerely,

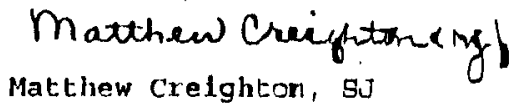


APPENDIX B

CHICAGO HEALTH OUTREACH REQUEST 


\section{CHICAGO HEALTH OUTREACH REQUEST}

Sarah Jackson MS, RN

Director, Chicago Health Outreach

1015 West Lawrence Avenue

Chicago, Illinois 60640

Dear Sarah:

I am writing to obtain permission to use Chicago Health Outreach as an agency through which to recruit participants for my dissertation research. This research project focuses on considering tomorrow and the participants 1 would like to invite to join in the study are women who are home-less in Chicago.

I am seeking review and approval for this research from the Loyola University Institutional Review Board For the Protection of Human Subjects. Included with this letter, for your information, is a copy of the participant explanation for the study and a sample consent form.

What I will need from you, Sarah, is a letter with the following: (a) an invitation for me to conduct my research through your agency; (b) a statement that clearly denotes that approval of my research by the Loyola IRB will meet your agency guidelines for the protection of human subjects; and (c) an offer that your staff will act as a referral source for contacting possible participants who are women 18 years of age or older, able to read and speak English, and are at the present time, home-less.

You can send that letter to the address below. I am anxious to work with you and your staff as I undertake this research. Please call me if you have any questions.

Sincerely,

Sandra J. Bunkers, PhDc, RN

Loyola Doctoral Candidate 
APPENDIX C

CHICAGO HEALTH OUTREACH LETTER OF APPROVAL 
CHICAGO HEALTH OUTREACH LETTER OF APPROVAL

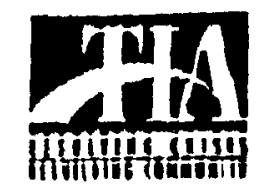

March 15, 1995

Sandra J. Bunkers, PhiDc, RN

1119 Plum Creek Road

Sioux Falls, South Dakote S7ios

\section{Dear Sandra.}

I an very pleased w Invite you to conduct your resesench at Chicago tiealut Outreach. As you know, our organization has over a ten year history of providing prinary care to homeless persons at shelcer sices throughout the city and at our clinic. We believe your research, Considering Townoriow, will provide data that will enhance our understanding of tie homeless women we serve.

Though the population served by our agency is often transient, our mulli-discipilnary team has develuped ongoing relationships with rany homeless individiaals. We are lappy to act as a referral source for contacting potential participantes that meet the criteriz of your study: women age 18 of age or older, able to read and speak English, and cutrendy homeless.

Documentation of approval of your research by the Loy ola Uni ver sity Ingtitutional Review Board will meel all dio requirements for conducting your research in our agericy. We look forward to working with you on this projoct.

Sincerely,

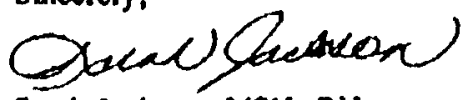

Sarah Jackson, MSN, RN

Director of Primary Care

\section{CC: Ileidt Romans \\ Chief Operating Officer}




\section{APPENDIX D}

\section{PARTICIPANT EXPLANATION}

CONSIDERING TOMORROW 


\section{APPENDIX D}

\section{PARTICIPANT EXPLANATION CONSIDERING TOMORROW}

You are being asked to participate in a study conducted by Sandra Bunkers, a graduate doctoral student, Niehoff School of Nursing, Loyola University Chicago.

This study focuses on considering tomorrow.

The study will consist of one tape recorded discussion between you and Sandra Bunkers. The focus of this discussion will be what it is like for you to consider tomorrow. This discussion will be scheduled at your convenience at a mutually agreed upon location and will last for approximately 30 to 60 minutes, depending on what you want to share.

The information you share will remain confidential and the tape will be erased after the study is completed. Your name will not appear in the transcription of the tape or on any other written report of this study.

You may stop the discussion and may withdraw from participation in this study at any time, for any reason, without penalty.

You may find it helpful to discuss your experience of considering tomorrow and you will be contributing to nursing knowledge. There are no known risks related to this study. If you become uncomfortable about some aspect of the discussion, you may talk with Sandra Bunkers at 708-934-8648, or seek referral from Ms. Bunkers for support services.

You are free to talk with Sandra Bunkers, at any time, about any concerns or questions you may have regarding this study.

Thank you for considering participating in this study. Findings from this study will be shared with those interested. 
APPENDIX E

CONSENT FORM

CONSIDERING TOMORROW 


\section{APPENDIX E \\ CONSENT FORM \\ CONSIDERING TOMORROW}

I, , am 18 vears of age or older and wish to participate in this study on considering tomorrow being conducted by Sandra Bunkers, doctoral graduate student, Niehoff School of Nursing, Loyola University Chicago.

I acknowledge that the purpose and design of the study have been fully explained to me and I may withdraw at any time without penalty.

I understand I will be talking with Sandra Bunkers one time at an agreed upon convenient location for approximately 30 to 60 minutes, depending on what I want to share. This discussion will be tape recorded and this tape recording will be erased once the study is completed. I also understand my name will not appear on written transcripts, reports, or published papers. I have been informed that all tapes and written materials will be kept in a locked file.

I understand there are no known risks to this study and that my descriptions may aid the development of nursing knowledge.

I understand I am free not to answer any question(s). If during the discussion I become uncomfortable I have the options to stop and withdraw from the study, stop and reschedule, or stop and rest, and then continue the discussion. I may also ask for referral to support services.

I understand I may call Sandra Bunkers at (708) 934-8648 at any time prior to or after our discussion to talk about any concerns or questions regarding my participation. I freely and voluntarily consent to my participation in this study and will be given a copy of this consent form.

Signature of Participant

Signature of Investigator

\section{Date}

Date 


\section{REFERENCES}

Achterberg, J. (1985). Imagery in healing: Shamanism and modern medicine. Boston: Shambhala.

Achterberg, J. (1990). Woman as healer. Boston: Shambhala.

Adair, M. (1984). Working inside out: Tools for change. Berkeley,

CA: Wingbow Press.

Adkins, C., \& Fields, J. (1992). Health care values of homeless women and their children. Family \& Community Health, 15(3), 20-29.

Arathuzik, D. (1994). Effects of cognitive-behavioral strategies on pain in cancer patients. Cancer Nursing, 17(3), 207-214.

Bard, M. (1990). Shadow women: Homeless women's survival stories. Kansas City: Sheed \& Ward.

Bassuk, E., \& Rosenberg, L. (1988). Why does family homelessness occur? A case-control study. American Jourmal of Public Health, $\underline{78}(7)$, 783-788.

Bassuk, E., Rubin, L., \& Lauriat, A. (1986). Characteristics of sheltered homeless families. American Journal of Public Health, 76(9), 1097 1101.

Bassuk, E. (1993a). Homeless women-economic and social issues: Introduction. American Journal of Orthopsvchiatry, 63(3), 337-339. 
Bassuk, E. (1993b). Social and economic hardships of homeless and other poor women. American Journal of Orthopsychiatry, $\underline{63}$ (3), 340-347.

Barleben, S. (1993). Women over the edge: A challenge to care. A phenomenological/hermeneutic inquiry on the experience of homelessness for women with children. [CD-ROM]. Abstract from: Dialog File: Dissertation Abstracts Item: AAD93-24732

Baumann, S. (1993). The meaning of being homeless. Scholarly Inquiry for Nursing Practice: An International Journal, $\underline{I}(1), 59-70$.

Baumann, S. (1994). No place of their own: An exploratory study. Nursing Science Quarterly, ㄱ, 162-169.

Belle, D. (1990). Poverty and women's mental health. American Psychologist, $\underline{45}(3), 385-389$.

Birx, E. (1994). The poetry of nursing. Clinical Nurse Specialist, $\underline{8}(6)$, 293-295.

Bissonnette, A., \& Hijjazi, H. (1994). Elder homelessness: A community perspective. Nursing Clinics Of North America, 29(3), 409-416.

Blakeney, B. (1992). Nursing the homeless: Problems and solutions. Imprint, 67-69.

Bloch, E. (1986). The principle of hope. Cambridge: The MIT Press. Boondas, J. (1985). The despair of the homeless aged. Journal of Gerontological Nursing, $11(4), 9-14$. 
Brackney, B., \& Westman, A. (1992). Relationships among hope, psychosocial development, and locus of control. Psychological Reports, 70, 864-866.

Brown, M. (1989). Dark side of the shaman. Natural History,11, 8-10.

Browne, A. (1993). Family violence and homelessness: The relevance of trauma histories in the lives of homeless women. American Journal of Orthopsychiatry, $\underline{63}(3), 370-384$.

Brunsman, C. (1987). A phenomenological study of the lived experience of hope in families with a chronically ill child. An unpublished masters thesis, Michigan State University, Ann Arbor, MI.

Bucher, L. (1993). The effects of imagery abilities and mental rehearsal on learning a nursing skill. Journal of Nursing Education, 32 (7), 318-324.

Bunkers, S.S. (1993). This was not an ordinary day. Nursing Forum, $\underline{28}(3), 33-36$.

Bunkers, S. S. (1995). Considering tomorrow in a time of difficulty. Unpublished paper, Loyola University Chicago.

Bunkers, S.S., Brendtro, M., Holmes, P.K., Howell, J., Johnson, S., Koerner, J., Larson, J., Nelson, J., Weaver, R. (1992). The healing web: A transformative model for nursing. Nursing \& Health Care, 13(2), 68-73. 
Bunkers, S.S., \& Koerner, J.G. (1988). Making the glue stick: A group experience in communication and creativity. Journal Of Nursing Administration, $18(6), 41$.

Bunkers, S.S.,\& Koerner, J.G. (1990). The M-I-D-D-L-E-G-R-O-U-N-D:

A model for interinstitutional integration of nursing. Nursing Connections, $\underline{3}(1), 17-22$.

Burns, N. (1989). Standards for qualitative research. Nursing Science Quarterly, 2, 44-52.

Bushkin, E. (1993). Signposts of survivorship. Oncology Nursing Forum, 20(6), 869-875.

Butcher, H., \& Parker, N. (1988). Guided imagery with Rogers' science of unitary human beings. Nursing Science Quarterly, 1, 103-109. Carson, V., Soeken, K., \& Grimm, P. (1988). Hope and its relationship to spiritual well-being. Journal of Psychology and Theology, $16(2), 159-167$.

Carson, V., Soeken, K., Shanty, J., \& Terry, L. (1990). Hope and spiritual well-being: Essentials for living with AIDS. Perspectives in Psychiatric Care, 26(2), 28-34.

Casey, E. (1974). Toward a phenomenology of imagination. Journal of the British Society for Phenomenology, $5(1), 3-19$. 
Casey, E. (1976). Imagining: A phenomenological study.

Bloomington: Indiana University Press.

Clouser, K., \& Hufford, D. (1993). Nonorthodox healing systems and their knowledge claims. The Journal of Medicine and Philosophy, 18(2), 101-106.

Cody, W. (1991). Grieving a personal loss. Nursing Science Quarterly, 4, 61-68.

Cody, W. (1994). Meaning and mystery in nursing science. Nursing Science Quarterly, $\underline{7}, 48-50$.

Cody, W. (1995). Chpt. 14: The lived experience of grieving, for families living with AIDS. In R. R. Parse (Ed.), Illuminations: The human becoming theory in practice and research (pp. 197-237).

Costello-Nickitas, D. (1994). Choosing life goals: A phenomenological study. Nursing Science Quarterly, 7. 87-92.

Coston, C., \& Finckenauer, J. (1993). Fear of crime among vulnerable populations of homeless women. Journal of Social Distress and the Homeless, $\underline{2}(1), 1-21$.

D'Ercole, A., \& Struening, E. (1990). Victimization among homeless women: Implications for service delivery. Journal of Community Psychology, 18, 141-151. 
Dilthey, W. (1976). Selected writings (H.P. Rickman,

Trans.) Cambridge: Cambridge University Press.

Dufault, K., \& Martocchio, B. (1985). Hope: Its spheres and dimensions. Nursing Clinics of North America, 20(2), 379-391.

Erikson, E. (1964). Childhood and society, (2nd. ed.). New York: W. W. Norton.

Ersek, M. (1992). The process of maintaining hope in adults undergoing bone marrow transplantation for leukemia. Oncology Nursing Forum, 19 $(6), 883-889$.

Farran, C., Herth, K., \& Popovich, J. (1995). Hope and hopelessness: Critical clinical constructs. Thousand Oaks, CA: Sage Publications.

Farran, C., \& McCann, J. (1989). Longitudinal analysis of hope in community-based older adults. Archives of Psychiatric Nursing, III(5), 272 276.

Federal Task Force on Homelessness and Severe Mental Illness. (1992). Outcasts on mainstreet. Washington, DC: Department of Health and Human Services.

Fischer, K. (1985). The imagination, justice, peace. Studies In Formative Spirituality, VI (1), 29-37. 
Fischer, P., Shapiro, S., Breakey, W., Anthony, J., \& Kramer, M. (1986). Mental health and social characteristics of the homeless: A survey of mission users. American Journal of Public Health, $\underline{76(5)}, 519-524$.

Fleury, J. (1991). Empowering potential: A theory of wellness motivation. Nursing Research, 40(5), 286-291.

Francis, M. (1992). Eight homeless mother's tales. Image: The Journal of Professional Nursing, 24(2), $111-114$.

Frankl, V. (1984). Man's search for meaning. New York: Simon \& Schuster.

Fromm, E. (1968). The revolution of hope. New York: Harper \& Row.

Fryback, P. (1993). Health for people with a terminal diagnosis. Nursing Science Quarterly, 10(3), 79-88.

Gagan, J. (1984). The therapeutics of guided imagerv. Perspectives In Psychiatric Care, XII(1), 20-25.

Gewe, A. (1994). Hope: Moving from theory to practice. Journal of Christian Nursing, 11(4), 18-21.

Gilmore, V. (1993). Insight, initiative, and imagination in nursing administration. Holistic Nursing Practice, $\underline{Z}(3), 15-20$.

Godfrey, J. (1987). A philosophy of human hope. Boston: Martinue Nijhoff Publishers. 
Goodman, L. (1991). The prevalence of abuse among homeless and housed poor mothers: A comparison study. American Journal of Orthopsychiatry, 61(4), 489-500.

Goodman, L., Saxe, L., \& Harvey, M. (1991). Homelessness as psychological trauma. American Psychologist, $\underline{46}(11), 1219-1225$.

Grunberg, J., \& Eagle, P. (1990). Shelterization: How the homeless adapt to shelter living. Hospital and Community Psychiatry, 41(5), $521-525$.

Hagen, B. (1987). Gender and homelessness. Social Work, 32, 312 316.

Hall, B. (1990). The struggle of the diagnosed terminally ill person to maintain hope. Nursing Science Quarterly, $\underline{3}, 177-184$.

Hausman, B., \& Hammen, C. (1993). Parenting in homeless families: The double crisis. American Journal of Orthopsychiatry, $\underline{63}(3), 358-369$.

Heidegger, M. (1962). Being and time. New York: Harper \& Row. Heise, L. (1993). Violence against women. World Health, (1), 22.

Herth, K. (1989). The relationship between level of hope and level of coping response and other variable in patients with cancer. Oncology Nursing Forum, 16(1), 67-72.

Herth, K. (1990). Fostering hope in terminally-ill people. Journal of Advanced Nursing, 15, 1250-1259. 
Herth, K. (1991). Development and refinement of an instrument to measure hope. Scholarly Inquiry for Nursing Practice: An International Journal, $\underline{5}(1), 39-49$.

Herth, K. (1992). Abbreviated instrument to measure hope:

Development and psychometric evaluation. Journal of Advanced Nursing, $\underline{17}, 1251-1259$.

Herth, K. (1993). Hope in the family caregiver of terminally ill people. Journal of Advanced Nursing, 18, 538-548.

Hinds, P. (1988). Adolescent hopefulness in illness and health. Advances in Nursing Science, 10(3), 79-88.

Hockley, J. (1993). The concept of hope and the will to live. Palliative Medicine, $\underline{7}, 181-186$.

Hodnicki, D. (1992). Being homeless: An ethnographic study of women's experiences in a shelter. [CD-ROM]. Abstract from: Dialogu File: Dissertation Abstracts Item: AAD92-25149

Hodnicki, D., \& Horner, S. (1993). Homeless mothers caring for children in a shelter. Issues in Mental Health Nursing, 14, 349-356.

Hodnicki, D., Horner, S., \& Simmons, S. (1993). The sea of life: A metaphorical vehicle for theory explication. Nursing Science Quarterly, $\underline{6}$, 25-27. 
Holy Bible (The New International Version Study Bible). (1985). Grand Rapids: Zondervan Bible Publishers.

Huizinga, J. (1950). Homo ludens: A study of the play element in culture. Boston: The Beacon Press.

Jones, A. (1985). Soulmaking: The desert way of spirituality. New York: Harper \& Row.

Kant, I. (1951). Critique of judgment. New York: Hafner.

Kant, I. (1982). Critique of pure reason. Germany: Scientia Verlag Aalen.

Kearney, R. (1987). Ethics and the postmodern imagination. Thought, $\underline{62}(244), 39-58$.

Kelley, L. (1991). Struggling with going along when you do not believe. Nursing Science Quarterly, 4, 123-129.

Kierkegaard, S. (1980). This sickness unto death. Princeton: Princeton University Press.

Kierkegaard, S. (1992). Actual subjectivity, ethical subjectivity; the subjective thinker. In $\mathrm{H}$. Hong \& E. Hong (Eds.), Concluding unscientific postscript to philosophical fragments (pp. 301-360).

Kierkegaard, S. (1993). Point of view: That individual. In M. Friedman (Ed.), The worlds of existentialism. (pp. 111-114). New Jersey: Humanities Press International. 
Kiros, T. (1994). Self-construction and the formation of values that empower. Journal of Social Philosophy, 25(1), 97-109.

Klenow, D. (1991). Emotion and life threatening illness: A topology of hope sources. Omega, 24(1), 49-60.

Kline, E., \& Saperstein, A. (1992). Homeless women: The context of an urban shelter. Nursing Clinics of North America, 27(4), 885-899.

Knowles, R. (1985). Fantasy and imagination. Studies In Formative Spirituality, VI(1), 53-63.

Koerner, J.G., Bunkers, S.S., \& Nelson, J. (1991). Change: A professional challenge. Nursing Administration Quarterly. 16(1), 15-21.

Koerner, J.G., \& Bunkers, S.S. (1992). Transformational leadership: The power of symbol. Nursing Administration Quarterly. 1Z(1), 1-9.

Kozol, J. (1988). Rachel and her children: Homeless families in America. New York: Fawcett Columbine.

Kuhn, M. (1995). Gaming: A technique that adds spice to learning. The Journal of Continuing Education in Nursing, 26 (1), 35-39.

Lamb, H.R, \& Lamb, D.M. (1990). Factors contributing to homelessness among the chronically and severely mentally ill. Hospital and Community Psychiatry, 41(3), 301-305.

Larkin, D., \& Zahourek, R. (1988). Therapeutic storytelling and metaphors. Holistic Nursing Practice, 2(3), 45-53. 
Liebow, E. (1993). Tell them who / am: The lives of homeless

women. New York: The Free Press.

Lindsey, A., \& Gottesman, M. (1992). Overview: Homelessness in America. Imprint, 60-63.

Lynch, W. (1965). Images of hope: Imagination as healer of the hopeless. London: University Of Notre Dame Press.

Lynch, W. (1985). Imagining past, present, future in one piece. Studies In Formative Spirituality, VI(1), 65-72.

Mackenzie, P. (1983). Personal identity and the imagination. Philosophy, 58, 161-176.

Magnuson, J. (1987). Echoes of a shaman's song: Artifacts and ethics in the northwest. Christian Century, 104, 406-408.

Marcel, G. (1962). Homo viator: A metaphysics of hope. New York: Harper \& Row.

Marcel, G. (1965). Being and having. New York: Harper \& Row. Mast, D. (1986). Effects of imagery. Image: Journal of Nursing Scholarship, 18(3), 118-120.

Maurin, J., Russell, L., \& Memmott, R. (1989). An exploration of gender differences among the homeless. Research in Nursing and Health, 12, 315-321. 
McClenon, J. (1993). The experiential foundations of shamanic healing. The Journal of Medicine and Philosophy, 18(2), 107-127.

McGee, R. (1984). Hope: A factor influencing crisis resolution. Advances In Nursing Science, $\underline{6}(4), 34-43$.

McKellar, P. (1957). Imagination and thinking. London: Cohen \& West.

Mehl, P. (1992). Despair's demand: An appraisal of Kierkegaard's argument for God. Philosophy of Religion, 32, 167-182.

Metz, J.B. (1966). Responsibility of hope. Philosophy Today, $\underline{X}(4 / 4)$, 280-287.

Mickley, J., \& Soeken, K. (1993). Religiousness and hope in Hispanic-and Anglo-American women with breast cancer. Oncology Nursing Forum, 20(8), 1171-1177.

Miller, J. (1989). Hope-inspiring strategies of the critically ill. Applied Nursing Research, 2 $(1), 23-29$.

Miller, J., \& Powers, M. (1988). Development of an instrument to measure hope. Nursing Research, 37(1), 6-10.

Mitchell, G. (1992). Exploring the paradoxical experience of restriction-freedom in later life: Parse's theory-guided research. Unpublished doctoral dissertation, University of South Carolina, Columbia. 
Mitchell, G. (1993). Living paradox in Parse's theory. Nursing Science Quarterly, $\underline{6}, 44-51$.

Mitchell, G. (1994). Discipline-specific inquiry: The hermeneutics of theory-guided nursing research. Nursing Outlook, 42(5), 224-228.

Mitchell, G. (1995). Chpt. 13: The lived experience of restrictionfreedom in later life. In R. R. Parse (Ed.), Illuminations: The human becoming theory in practice and research (pp. 159-195).

Mitchell, G., \& Cody, W. (1992). Nursing knowledge and human science: Ontological and epistemological considerations. Nursing Science Quarterly, $\underline{6}, 44-51$.

Mitchell, G., \& Cody, W. (1993). The role of theory in qualitative research. Nursing Science Quarterly, 6, 170-178.

Mitchell, G., \& Heidt, P. (1994). The lived experience of wanting to help another: Research with Parse's method. Nursing Science Quarterly, Z, 119-127.

Moltman, J. (1967). Theology of hope. New York: Harper \& Row. Montgomery, C. (1994). Swimming upstream: The strengths of women who survive homelessness. Advances In Nursing Science, 16(3), 34-45.

Moore, T. (1992). Care of the soul. New York: HarperCollins. Moore, T. (1994). Soulmates. New York: HarperCollins. 
Morris, T. (1992). Making sense of it all: Pascal and the meaning of

life. Grand Rapids: Wm. V. Eerdmans.

Murphy, M., \& DeBack, V. (1991). Today's nursing leaders: Creating the vision. Nursing Administration Quarterly, 16 (1), 71-80.

Murray, E. (1986). Imaginative thinking and human existence.

Pittsburgh: Duquesne University Press.

Newman, K. (1993). Giving up: Shelter experiences of battered women. Public Health Nursing, $10(2), 108-113$.

Nowotny, M. (1989). Assessment of hope in patients with cancer: Development of an instrument. Oncologv Nursing Forum, 16(1), 57-61.

Oliver, H. (1974). Hope and knowledge: The epistemic status of religious language. Cultural Hermeneutics, $\underline{2}, 75-88$.

O'Malley, P., \& Menke, E. (1988). Relationship of hope and stress after myocardial infarction. Heart \& Lung $\underline{17}(2), 184-190$.

Ornstein, R., \& Sobel, D. (1989). Healthy pleasures. New York: Addison-Wesley.

Ovrebo, B., Ryan, M., Jackson, K., \& Hutchinson, K. (1994). The homeless prenatal program: A model for empowering homeless pregnant women. Health Education Quarterly, 21 (2), 187-198. 
Owen, D. (1989). Nurse's perspectives on the meaning of hope in patients with cancer: A qualitative study. Oncology Nursing Forum, 16(1), 75-79.

Parse, R. R. (1981). Man-living-health: A theory of nursing. New York: Delmar Publishers.

Parse, R. R. (1987). Nursing science: Major paradigms, theories, and critiques. Philadelphia: W.B. Saunders.

Parse, R. R. (1990a). Health: A personal commitment. Nursing Science Quarterly, 3 , 136-140.

Parse, R. R. (1990b). Parse's research methodology with an illustration of the lived experience of hope. Nursing Science Quarterly, $\underline{3}$, 9-17.

Parse, R. R. (1992). Human becoming: Parse's theory of nursing. Nursing Science Quarterly, $\underline{5}, 35-41$.

Parse, R. R. (1993). The experience of laughter: A phenomenological study. Nursing Science Quarterly, $\underline{6}, 39-43$.

Parse, R. R. (1994a). Laughing and health. A study using Parse's research method. Nursing Science Quarterly, Z , 55-64.

Parse, R. R. (1994b). Quality of life: Sciencing and living the art of human becoming. Nursing Science Quarterly. $I_{r}$ 16-20. 
Parse, R. R. (1995a). Chpt. 1: The human becoming theory. In R. R. Parse (Ed.), llluminations: The human becoming theory in practice and research (pp. 5-8). New York: National League for Nursing.

Parse, R. R. (1995b). Chpt. 12: Research with the human becoming theory. In R. R. Parse (Ed.), Illuminations: The human becoming theory in practice and research (pp. 151-157). New York: National League for Nursing.

Parse, R. R. (1995c). Nursing theories and frameworks: The essence of advanced practice nursing. Nursing Science Quarterly, $\underline{\mathbf{8}}, 1$.

Parse, R. R., Coyne, B., \& Smith, M.J. (1985). Nursing research: Qualitative methods. Maryland: Brady Communications.

Pascal, B. (1966). Pensees. New York: Penguin Books.

Paulus, T. (1972). Hope for the flowers. New York: Paulist Press.

Pilkington, F. B. (1993). The lived experience of grieving the loss of an important other. Nursing Science Quarterly, $\underline{6}, 130-138$.

Plato. (1991). The republic. New York: Vintage Books.

Raleigh, E. (1980). An investigation of hope as manifested in the physically ill adult. Unpublished doctoral dissertation, Wayne State University, Detroit, Michigan.

Raleigh, E. (1992). Sources of hope in chronic illness. Oncology Nursing Forum, 19(3), 443-448. 
Ramer, A. (1995). Angel answers. New York: Pocket Books.

Rasmusson, D. (1995). Chpt. 9: True presence with homeless persons. In R. R. Parse (Ed.), Illuminations: The human becoming theory in practice and research (pp. 105-113). New York: National League for Nursing.

Rasmusson, D., Jonas, C., \& Mitchell, G. (1991). The eye of the beholder: Parse's theory with homeless individuals. Clinical Nurse Specialist, $\underline{5}, 139-143$.

Robley, L. (1995). The ethics of qualitative nursing research. Journal of Professional Nursing, $11(1), 45-48$.

Ropers, R., \& Boyer, R. (1987). Perceived health status among the new urban homeless. Social Science and Medicine, 24(8), 669-678.

Roth, D., \& Bean, G. (1986). New perspectives on homelessness: Findings from a statewide epidemiological study. Hospital and Community Psychiatry, 37(7), 712-719.

Saint-Exupery, A. (1971). The little prince. New York: Harcourt Brace Jovanovich.

Sartre, J.P. (1991). The psychology of imagination. New York: Carol Publishing Group.

Scanlon, C. (1989). Creating a vision of hope: The challenge of palliative care. Oncology Nursing Forum, 16(4), 491-496. 
Schalow, F. (1992). Time as an afterthought. Philosophy Today, $\underline{36}(1), 71-82$.

Smith, M. C. (1988). Testing propositions from Rogers' conceptual system. Nursing Science Quarterly, 1, 60-67.

Smith, M. C. (1990a). Struggling through a difficult time for unemployed persons. Nursing Science Quarterly. 1, 18-27.

Smith, M. C. (Speaker). 1990b. The lived experience of hope in families with critically ill persons. Los Angeles: UCLA National Nursing Theory Conference.

Smith, M. C. (1992). Metaphor in nursing theory. Nursing Science Quarterly, $\underline{5}, 48-49$.

Stanley, A. T. (1978). The lived experience of hope: The isolation of discreet descriptive elements common to the experience of hope in healthy adults. Unpublished doctoral dissertation, Catholic University of America, Washington, D.C.

Steindl-Rast, D. (1984). Gratefulness, the heart of prayer. New York: Paulist Press.

Stephenson, C. (1991). The concept of hope revisited for nursing. Journal of Advanced Nursing, 16, 1456-1461. 
Stoner, M., \& Keampfer, S. (1985). Recalled life expectancy information, phase of illness and hope in cancer patients. Research in Nursing \& Health, $\underline{8}, 269-274$.

Stotland, E. (1969). The psychology of hope. San Francisco: Jossey-Bass, Inc.

Susnick, L. (1993). Service providers to the homeless mentally ill: Their thoughts, perceptions, and recommendations for the homeless. Journal of Social Distress and the Homeless, 2(4), 315-323.

Thalberg, I., \& Pellow, D. (1979). Imagining alternatives. The Philosophical Forum, $\underline{X I}(1), 1-17$.

The Random House Dictionary Of The English Language (2nd ed.). (1987). New York: Random House, Inc.

Thompson, M. (1994). Nurturing hope: A vital ingredient in nursing. Journal of Christian Nursing, 11(4), 10-17.

Thompson, M., \& Coppens, N. (1994). The effects of guided imagery on anxiety levels and movement of clients undergoing magnetic resonance imaging. Holistic Nursing Practice, $\underline{8}(2), 59-69$.

Thornburg, P. D. (1993). The meaning of hope in parents whose infants died from sudden infant death syndrome, Unpublished doctoral dissertation, University of Cincinnati, Cincinnati, Ohio.

Tillich, P. (1963). The eternal now. New York: Charles. 
Tillich, P. (1980). The courage to be. New Haven: Yale University Press.

Turner, G. (1993). American Black Nursing Forum Journal, 4(2), 35-39.

Tuyn, L. (1994). Using guided imagery exercises in the classroom. Journal of Nursing Education, 33(4), 157-158.

Ugarriza, D., \& Fallon, T. (1994). Nurses' attitudes toward homeless women: A barrier to change. Nursing Outlook, 42(1), 26-29.

Valiga, T. (1994). Leadership for the future. Holistic Nursing Practice, $\underline{9}(1), 83-90$.

Vines, S. (1988). The therapeutics of guided imaging. Holistic Nursing Practice, 2 (3), 34-44.

Wagner, J., \& Menke, M. (1991). Stressors and coping behaviors of homeless, poor, and low-income mothers. Journal Of Community Health Nursing, $\underline{8}(2), 75-84$.

Wallsten, S. (1992). Geriatric mental health: A portrait of homelessness. Journal of Psychosocial Nursing, 30(9), 20-24.

Webster's ninth new collegiate dictionary. (1990). Springfield: Merriam-Webster. 
Weitzman, B., Knickman, J., \& Shinn, M. (1990). Pathways to homelessness among New York City families. Journal of Social Issues, $\underline{46}(4), 125-140)$.

Winkleby, M., Rockhill, B., Jatulis, D., \& Fortmann, S. (1992). The medical origins of homelessness. American Journal of Public Health, $\underline{82}(10)$, 1394-1397.

Wu, Kuang-Ming. (1972). Hope and world survival. Philosophy Forum, 12, 131-148.

Wurzbach, M. (1992). Assessment and intervention for certainty and uncertainty. Nursing Forum, 27(2), 29-35.

Wynd, C. (1991). Relaxation imagery used for stress reduction in the prevention of smoking relapse. Journal of Advanced Nursing, 17(3), 294-302.

Yancey, D., Greger, H., \& Coburn, P. (1994). Effects of an adult cancer camp on hope, perceived social support, coping, and mood states. Oncology Nursing Forum, 21(4), 727-733. 


\section{VITA}

The author, Sandra Schmidt Bunkers, was born in Madison, South Dakota. In 1967 Ms. Bunkers graduated from Presentation School of Nursing, Sioux Falls, South Dakota with a diploma in nursing. She received the State Nursing Student Of The Year Award in 1967.

In 1978 she graduated cum laude from Augustana College, Sioux Falls, South Dakota with a Bachelor of Arts in nursing. At this time she was inducted into the Zeta Zeta Chapter of Sigma Theta Tau International Honor Society for Nursing. Ms. Bunkers attended South Dakota State University and graduated in 1983 with a Master of Science in nursing. In 1983 she was inducted into Phi Kappa Phi National Honor Society. In 1988 Ms. Bunkers completed a two year post-graduate program in Gestalt Therapy at The Gestalt Institute of The Twin Cities.

In September, 1992, Ms. Bunkers was awarded a fellowship and research assistantship at Loyola University Chicago. She completed her PhD in nursing in January, 1996, Loyola University Chicago. 


\section{APPROVAL SHEET}

The dissertation submitted by Sandra Schmidt Bunkers has been read and approved by the following committee:

Dr. Rosemarie Rizzo Parse, Director

Professor and Niehoff Chair, Nursing

Loyola University Chicago

Dr. Diane Boyer

Associate Professor, Nursing

Loyola University Chicago

Dr. Esther Matassarin-Jacobs

Associate Professor, Nursing

Loyola University Chicago

The final copies have been examined by the director of the dissertation and the signature which appears below verifies the fact that any necessary changes have been incorporated and that the dissertation is now given final approval by the Committee with reference to content and form.

The dissertation is therefore accepted in partial fulfillment of the requirements for the degree of Doctor of Philosophy.
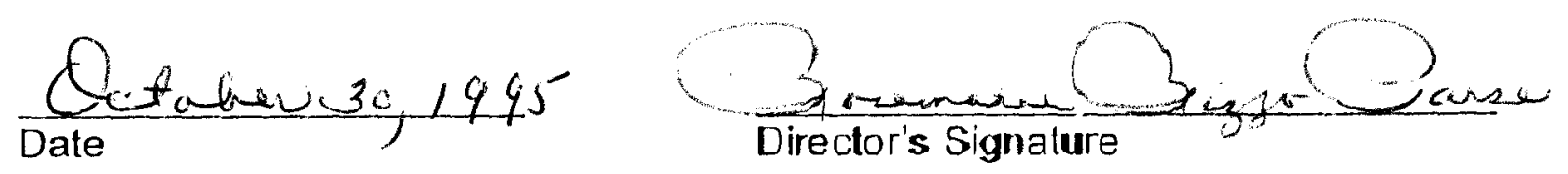